\title{
WestVirginiaUniversity
}

THE RESEARCH REPOSITORY @ WVU

Graduate Theses, Dissertations, and Problem Reports

2014

\section{Reducing Tobacco Related Health Disparities}

Andrew Alexander Anesetti-Rothermel

Follow this and additional works at: https://researchrepository.wvu.edu/etd

\section{Recommended Citation}

Anesetti-Rothermel, Andrew Alexander, "Reducing Tobacco Related Health Disparities" (2014). Graduate Theses, Dissertations, and Problem Reports. 5109.

https://researchrepository.wvu.edu/etd/5109

This Dissertation is protected by copyright and/or related rights. It has been brought to you by the The Research Repository @ WVU with permission from the rights-holder(s). You are free to use this Dissertation in any way that is permitted by the copyright and related rights legislation that applies to your use. For other uses you must obtain permission from the rights-holder(s) directly, unless additional rights are indicated by a Creative Commons license in the record and/ or on the work itself. This Dissertation has been accepted for inclusion in WVU Graduate Theses, Dissertations, and Problem Reports collection by an authorized administrator of The Research Repository @ WVU.

For more information, please contact researchrepository@mail.wvu.edu. 


\title{
Reducing Tobacco Related Health Disparities
}

\author{
Andrew Alexander Anesetti-Rothermel
}

\author{
Dissertation submitted \\ to the School of Public Health \\ at West Virginia University \\ in partial fulfillment of the requirements for the degree of \\ Doctor of Philosophy in \\ Epidemiology
}
Kimberly Horn, Ed.D., Chair
Motao Zhu, M.D., Ph.D.
Lan Guo, Ph.D.
Jamison Conley, Ph.D.
Michael Hendryx, Ph.D.
Juhua Luo, Ph.D.
Steven Branstetter, Ph.D.

Department of Epidemiology
Morgantown, West Virginia
2014

Keywords: Tobacco Use, Rural, Disparities, Adults, Youth, Retail Environment, Density, Proximity, Schools, Spatial Statistics, Geographical Information Systems

Copyright 2014 Andrew Anesetti-Rothermel 


\section{ABSRTACT \\ Reducing Tobacco Related Health Disparities}

\section{Andrew Alexander Anesetti-Rothermel}

Despite the historic declines in the prevalence of cigarette smoking in the United States, tobacco use remains a major public health burden. The persistent use and susceptibility of tobacco arises from tobacco-related health disparities, which historically occur among vulnerable and underserved populations. Since rural/nonmetropolitan populations suffer disproportionately more tobacco-related health disparities than urban/metropolitan populations, the main goal of this project and its three component studies was to address rural tobacco-related health disparities. Study 1 utilizes an exploratory spatial data analysis approach to identify those rural areas disproportionately affected by tobacco. This study assessed the overall spatial association between county-level rurality and county-level adults smoking rates in the contiguous United States. Furthermore, local indicators of spatial association identified localized county clusters with either positive or negative spatial association. Results found an overall significant positive spatial association (Moran's I $=0.0438$, pseudo $p$-value $<0.0001$ ) between county-level rurality and county-level adult cigarette smoking prevalence. Among the significant ( $\mathrm{p}$-value $<0.05$ ) rural county clusters identified, rural areas of Appalachia were a primary area of concern, while other rural clusters (e.g., spatial outliers), like those found in the Pacific Northwest had much lower rates of smoking than expected based upon their rural nature. While Study 1 identified the rural areas disproportionately affect by tobacco use, Study 2 and Study 3 examine the relationships between the retail tobacco environment $(\mathrm{N}=276)$ and public middle/high schools $(\mathrm{N}=33)$ within metropolitan $(\mathrm{N}=3)$ and nonmetropolitan $(\mathrm{N}=3)$ counties of West Virginia. Study 2 visualizes the location of each county's public middle/high school relative to the underlying density of tobacco retailers in each county. Additionally, Study 2 examines the spatial relationship between the locations of tobacco retailers and public middle/high schools in each of the metropolitan and nonmetropolitan counties in West Virginia. Results found that $77 \%$ of the public middle/high schools with an above average tobacco retailer density value were located within a metro county. While each county's density surface of tobacco retailers took on either a monocentric or polycentric urban pattern, which was dependent on the structure of each county's underlying built environment, but was independent of their metropolitan/nonmetropolitan status. Additionally, the spatial relationship between the locations of tobacco retailers and public middle/high schools in each county exhibited a significant spatial interaction. Study 3 examines the relationship between tobacco retailer density and tobacco retailer's proximity to a public middle/high school in each of the metropolitan and nonmetropolitan counties in West Virginia. Additionally, Study 3 assesses the effects of tobacco retailer proximity - density groups, metropolitan/nonmetropolitan status, and store types on tobacco retailer characteristics (e.g., tobacco marketing and cigarette pack price). A significant positive relationship (Chi-square $=$ 116.54, p-value $<0.001$ ) existed between levels of tobacco retailer density and tobacco retailer proximity to school levels. The amount of exterior tobacco marketing displayed in each tobacco retailer displayed a significant $(\mathrm{F}(6,254)=3.528$, p-value $<0.01)$ between proximity -density groups and store types. While a significant $(\mathrm{F}(4,254)=5.593$, $\mathrm{p}$-value $<0.001)$ three-way 
interaction between proximity - density groups, metropolitan/nonmetropolitan status, and store types existed for the average pack price of non-menthol cigarettes. Together, these three studies identify the need in reducing tobacco-related health disparities among those most vulnerable rural populations. However, because tobacco-related health disparities result from the complex interactions between numerous factors future research must identify how these factors affect the burden of tobacco use in these rural populations. Only then, can tobacco control specialist begin to implement tailored comprehensive, systemic tobacco control programs in these rural areas. 


\section{DEDICATION}

To my Grandfather - My hero and inspiration. 


\section{ACKNOWLEDGEMENTS}

First, I would like to thank my family who supported me throughout the whole dissertation process. To my wife, Elizabeth, who has had to listen to me constantly rant about my dissertation for the past three years, I thank you for your unconditional love and support. To my mother, Angela, without your love and support I would not be here today, thank you for motivating me each day to complete my degree and for keeping me sane throughout the whole process.

I would also like to thank my mentor, Dr. Kimberly Horn, who over the course of my education has provided me guidance and wisdom beyond expectation. Dr. Horn's support and encouragement has pushed me to challenge myself both inside and outside of the classroom. She has provided me with numerous opportunities to grow as a researcher and has always been there for me in my time of need. She has not only been my mentor, but has been my colleague and friend throughout my graduate education. Thank you.

The work presented here would also not be possible without the additional expertise and guidance provided to me by my committee members- Dr. Motao Zhu, Dr. Lan Guo, Dr. Michael Hendryx, Dr. Juhua Luo, Dr. Jamison Conley, and Dr. Steven Branstetter. I know my dissertation was atypical, but I thank you all for your willingness and support throughout the whole process. The guidance you all provided me over the course of my studies and dissertation was insurmountable.

I would also like to thank Dr. Keith Zullig, who over the course of my doctoral studies has been vital in assisting me with the various administrative aspects needed to complete my doctoral degree. Along with Dr. Keith Zullig, I would also like to thank Dr. Fred Minnear for providing me the necessary University oversight for my Pre-doctoral Research Fellowship at the Steven A. Schroeder Institute for Tobacco Research and Policy Studies.

At last, I would like to thank my Pre-doctoral Research Fellowship mentor, Dr. Thomas R. Kirchner, who over the past two years has provided me guidance on various analytical aspects of my dissertation research. He has challenged me to grow as an independent researcher. His insights addressing the "when" and "where" of health behaviors form the foundation of my future research endeavors. Thank you.

Finally, this work would not have been possible without the generous financial support of the American Legacy Foundation. 


\section{TABLE OF CONTENTS}

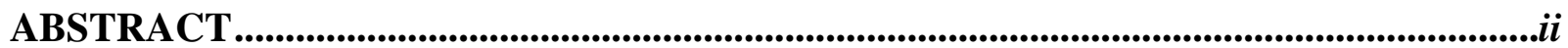

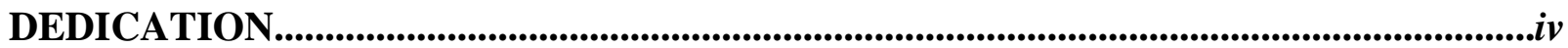

ACKNOWLEDGEMENTS ..........................................................................................................

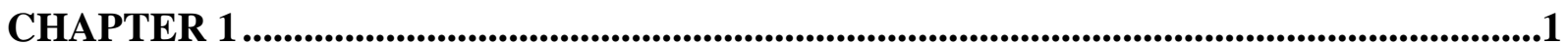

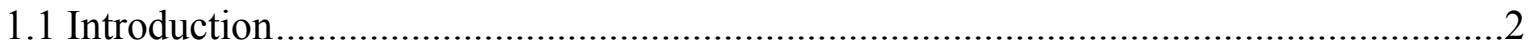

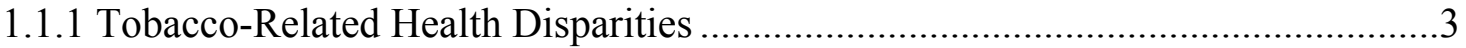

1.1.2 Rural Tobacco-Related Health Disparities ............................................................

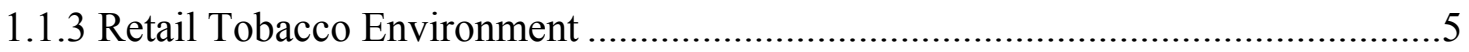

1.1.4 Summary of Significance .............................................................................

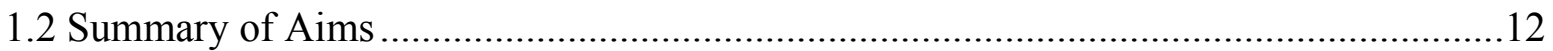

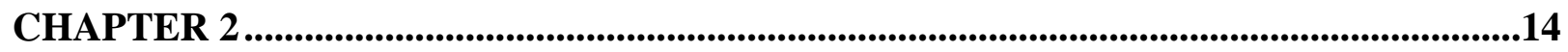

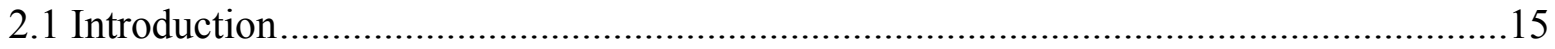

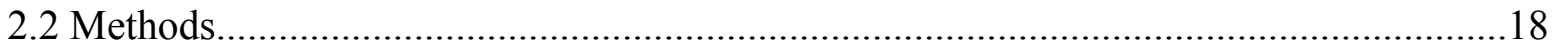

2.2.1 County-Level Current Adult Cigarette Smoking ....................................................18

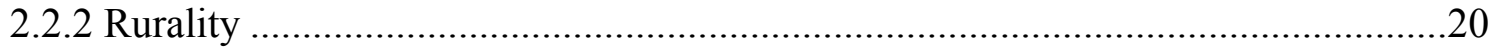

2.2.3 Exploratory Spatial Data Analysis (ESDA)......................................................21

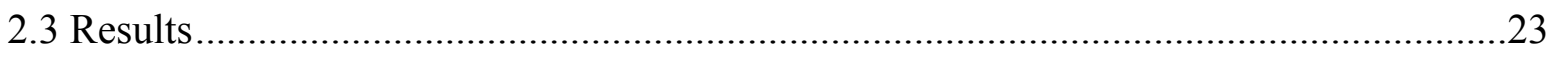

2.3.1 County-Level Current Adult Cigarette Smoking .....................................................23

2.3.2 Spatial Association between Rurality and Current Adult Cigarette Smoking........28

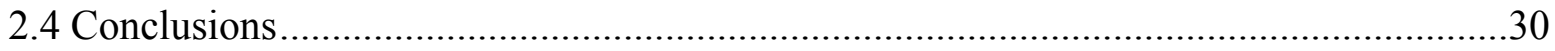

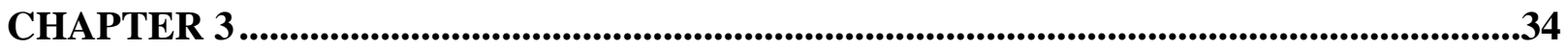

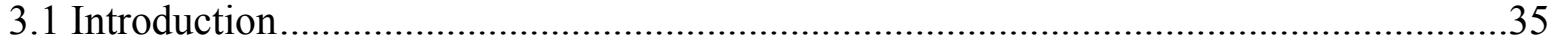

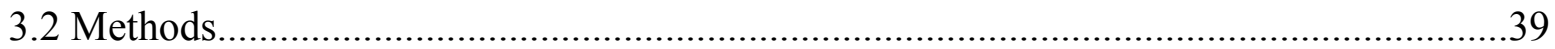

3.2.1 Metro and Nonmetro West Virginia Counties ...........................................................39

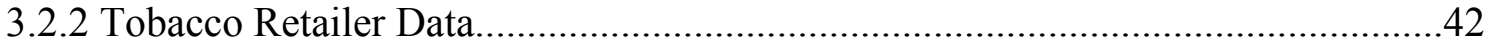

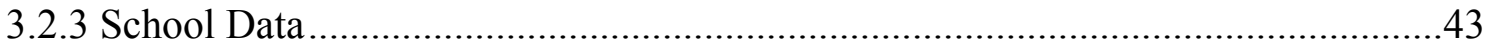

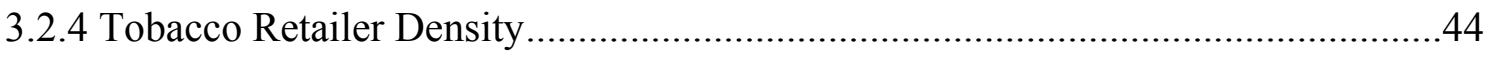

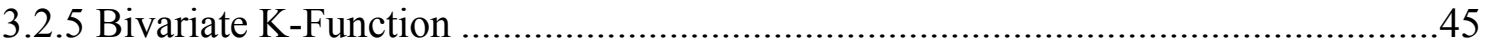




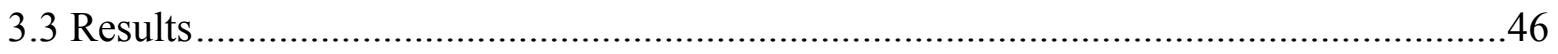

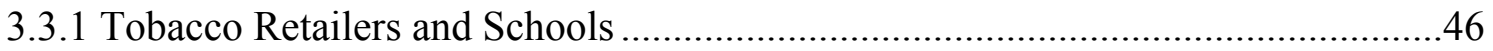

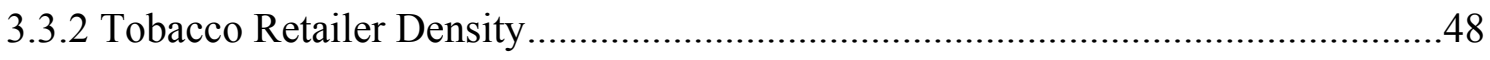

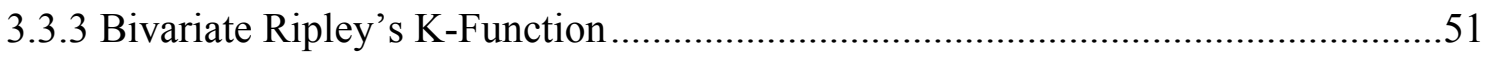

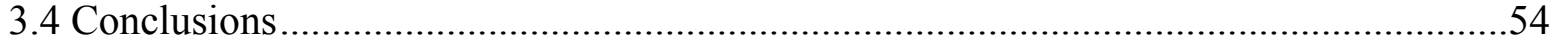

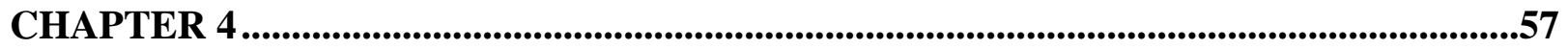

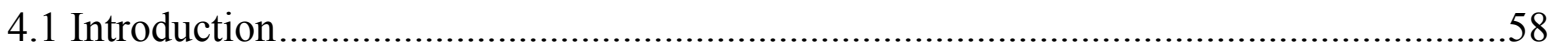

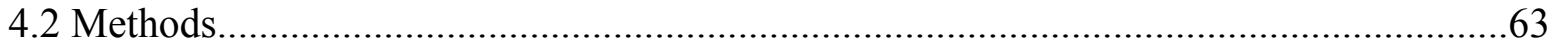

4.2.1 Metro and Nonmetro West Virginia Counties ....................................................63

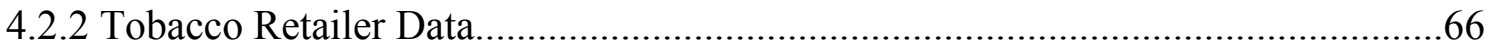

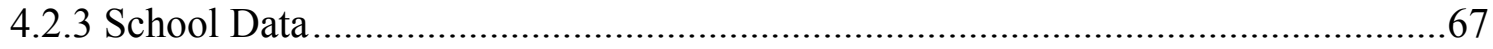

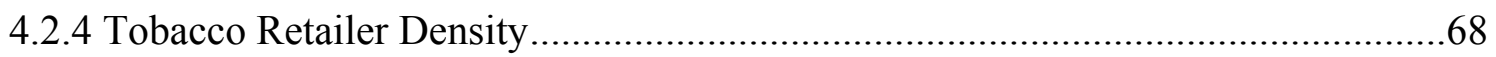

4.2.5 Tobacco Retailer Proximity to Public Middle/High Schools ..................................69

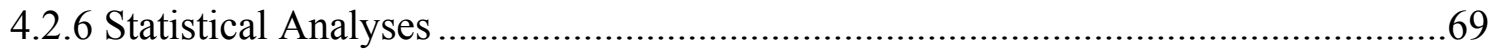

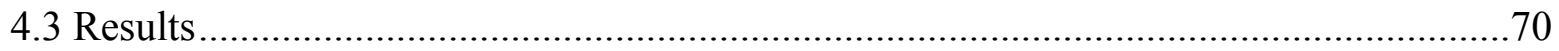

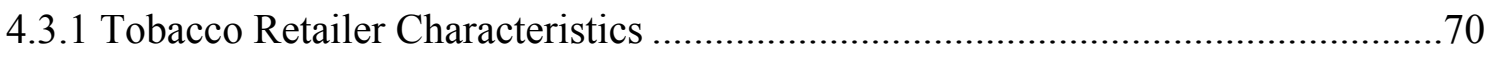

4.3.2 Tobacco Retailer Density and Proximity ...............................................................73

4.3.3 Tobacco Retailer Proximity - Density Groups and Store Characteristics ...............77

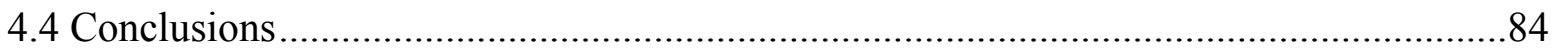

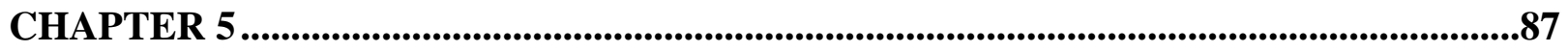

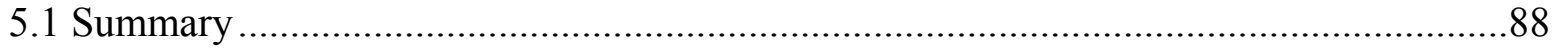

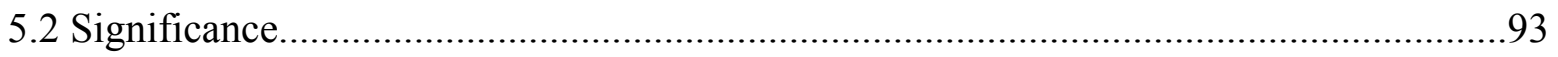

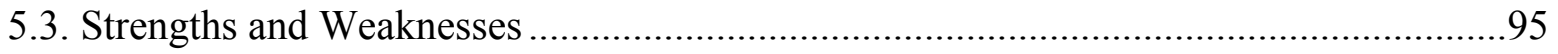

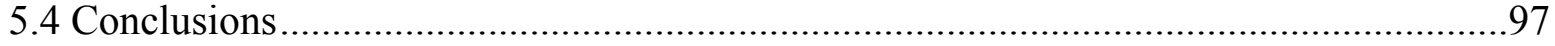

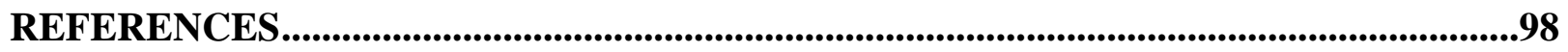


Chapter 1 


\section{Chapter 1}

\subsection{Introduction}

Since the landmark 1964 Surgeon General's Report on the health effects of cigarette smoking, the historic decline in adult cigarette smoking is characterized as one of the 10 greatest achievements in public health in the $20^{\text {th }}$ century. ${ }^{1,2}$ Despite this progress, tobacco use remains the leading cause of premature and preventable death in the United States (U.S.). ${ }^{3}$ In the U.S., cigarette smoking and the exposure to secondhand smoke kills an estimated 480,000 people each year. ${ }^{3}$ Additionally, more than 16 million people in the U.S. currently suffer from a smokingrelated illness. ${ }^{3}$ Cigarette smoking is a casual factor for numerous diseases, including bladder, esophageal, laryngeal, lung, oral, and throat cancers; chronic lung diseases; coronary heart and cardiovascular diseases; reproductive effects; and sudden infant death syndrome. ${ }^{4}$ However, since the 2004 Surgeon General's Report on The Health Consequences of Smoking, this list of diseases has expanded to include cataract, aortic aneurysm, pneumonia, periodontal diseases, diabetes, congenital defects, rheumatoid arthritis, cervical cancer, kidney cancer, pancreatic cancer, stomach cancer, liver cancer, and colorectal cancer. ${ }^{2,3}$ Smoking-related illnesses cost the U.S. over $\$ 280$ billion in health care costs and lost productivity each year. ${ }^{3}$ The current prevalence of adult cigarette smoking in the U.S. is $18.1 \%$ (e.g., approximately 42.1 million adults currently smoke cigarettes). ${ }^{5}$ Furthermore, $20.5 \%$ of men and $15.8 \%$ of women currently smoke cigarettes in the U.S. ${ }^{5}$ While cigarette smoking among U.S. adults is down significantly from a decade ago, this decline has no stalled, with virtually no change in the adult cigarettesmoking rate since $2004 .^{6}$ 
Youth cigarette smoking is the driving force behind the U.S. tobacco problem, because most adult cigarette smokers try their first cigarette before the age of $18 .{ }^{7}$ Each day, more than 3,000 youth try their first cigarette and approximately 700 youth become daily smokers. ${ }^{7}$ Currently, $15.7 \%$ (e.g., approximately 2.7 million) of all U.S. high school students currently smoke cigarettes. ${ }^{8}$ While the 2013 prevalence of cigarette smoking among male and female high school students was $16.4 \%$ and $15.0 \%$ respectively. ${ }^{8}$ From $2000-2009$, the prevalence of current cigarette use declined for both middle school students (11\% to 5.2\%) and high school students ( $28 \%$ to $17.2 \%$ ); however, since 2006 these prevalence estimates have not decreased substantially. ${ }^{9}$ Even though the prevalence of youth cigarette smoking has decreased over the past decade, youths' susceptibility to initiate cigarette smoking had not. ${ }^{9}$ Adolescent susceptibility, never smokers, who reported being open to trying cigarettes smoking (e.g., a youth who thinks they would smoke a cigarette during the next year and who would smoke a cigarette if it was offered by their best friends), ${ }^{9,10}$ might explain the slowing in decline of youth smoking rates. ${ }^{9,11}$ Currently, $21.2 \%$ of middle school and $24 \%$ of high school aged students are susceptible to initiate cigarette smoking within the next year. ${ }^{9}$ Unless youth smoking rates decline, 5.6 million youth under the age of 18 alive today will ultimately die from a smokingrelated illness. ${ }^{3}$

\subsubsection{Tobacco-Related Health Disparities}

Persistently high rates of cigarette smoking and susceptibility still exist among specific population groups in the U.S. Traditionally, tobacco-related health disparities occur among historically underserved populations and are defined by socioeconomic status (e.g., education, occupation, income, poverty) race and ethnicity. ${ }^{12}$ While other factors such as: geographic 
location/isolation, sexual orientation, gender, marital status, and age also contribute to tobaccorelated health disparities. ${ }^{13}$ More specifically, tobacco-related health disparities are: "differences in patterns, prevention, and treatment of tobacco use; differences in the risk, incidence, morbidity, mortality, and burden of tobacco-related illness that exist among specific population groups in the United States; and related differences in capacity and infrastructure, access to resources, and environmental tobacco smoke exposure."14, p. 211

However, the Surgeon General has noted that no single factor determines the patterns of cigarette smoking and other tobacco use among vulnerable populations; rather, it stems from complex interactions between multiple factors (e.g., socioeconomic status, cultural characteristics, acculturation, stress, biologic elements, targeted advertising, price of tobacco products, and varying capacities of communities to mount effective tobacco-control initiatives). ${ }^{15}$

\subsubsection{Rural Tobacco-Related Health Disparities}

Compared to urban/metropolitan areas, rural/nonmetropolitan areas suffer disproportionately more tobacco-related health disparities, including higher rates of cigarette smoking initiation, current use, intensity of use, exposure to second hand smoke, and cessation failure. ${ }^{16,17}$ While cigarette smoking prevalence has declined slightly in U.S. urban areas, rural residents are showing increasing rates. ${ }^{17,18}$ Rural communities vary in terms of their social, economic, cultural, and geographic characteristics. ${ }^{19}$ According to the Institute of Medicine, "Rural communities are heterogeneous in other ways as well, differing in population density, remoteness from urban areas, and economic and social characteristics." ${ }^{20, \text { p. }}{ }^{1}$ Additionally, each

rural community has a specific combination of factors that lead to increased tobacco use. ${ }^{19}$ Two 
major factors that greatly influence rural tobacco use are lower socioeconomic status and educational attainment, ${ }^{16,21}$ while other factors associated with rural tobacco use include low levels of medical coverage, reduced access to medical services due to geographic isolation, reduced availability of cessation resources, cultural attitudes that foster tobacco use, and a regional economy that relies on tobacco production..$^{22,23}$

Relevant to the current work, a rural area of primary concern is the Appalachian region. Forty-two percent of Appalachia's population lives in a rural community, compared to $20 \%$ of the national population. ${ }^{24}$ The Appalachian region, includes all of West Virginia and part of 12 other states: Alabama, Georgia, Kentucky, Maryland, Mississippi, New York, North Carolina, Ohio, Pennsylvania, South Carolina, Tennessee, and Virginia, ${ }^{24}$ and suffers disparately poorer health than the rest of the nation. This region has suffered from a long history of economic underdevelopment, which has led to high rates of poverty, disability, unemployment, as well as low rates of educational attainment. ${ }^{25,26}$ Moreover, the Appalachian culture is vastly distinct compared to mainstream U.S. society. Appalachian people are more independent and self-reliant, due to their strong sense of individualism and strong family ties, ${ }^{27}$ which can be attributed to both their geographic isolation and their tendency to function within their own kin group. ${ }^{28}$ All these factors increase the risk of cigarette smoking among Appalachian residents.

\subsubsection{Retail Tobacco Environment}

Emerging evidence suggest that research must address the environmental factors that favorably influence tobacco use. The 1998 Master Settlement Agreement aimed to prevent youth smoking by restricting tobacco sponsorships and promotional activities, banning tobacco billboards, and the use of cartoons in all advertising, while advertising provisions included 
limiting the size of exterior sings to no more than 14 square feet. ${ }^{29}$ Since these restrictions, tobacco companies have become more dependent on the retail environment to market their products. ${ }^{30,31}$ For example, the prevalence of interior and exterior tobacco advertising has increased significantly in tobacco retailers since the Master Settlement Agreement. ${ }^{32,33}$ The prevalence of cigarette promotions (e.g., multipack promotions, gift-with-purchase promotions, and cents-off promotions) and functional objects has also increased significantly in tobacco retailers. ${ }^{33}$

In 2001, Feighery and colleagues found that the average number of tobacco advertisements varies among different types of tobacco retailers. ${ }^{34}$ They found that liquor stores tend to have the greatest number of tobacco advertisements followed by small stores (e.g., small drug stores and markets) and convenience stores (e.g., including those that sold gasoline). ${ }^{34}$ Other studies have found that retail outlets popular among youth, display three times the amount of exterior and interior tobacco marketing and reserve twice as much shelf space for Marlboro, Camel and Newport brand cigarettes, which are the brand that account for more than $80 \%$ of the cigarettes bought by youth. ${ }^{35,36}$ Taken together with estimates that $75 \%$ of youth shop at a convenience store at least once a week and on average shop twice as long as adults, ${ }^{37,38}$ available data make it clear that youth and young adults experience disproportionate exposures to tobacco products and marketing.

In 2011, the tobacco industry spent $\$ 8.37$ billion on tobacco marketing nationwide. ${ }^{39}$ These expenditures pay for traditional retail tobacco advertising (e.g., exterior/interior signage/advertisements and branded/non-braded function items), price discount for consumers (e.g., "Buy two, get one free"), and retail promotional allowances (e.g., shelving and incentive payments to retailers for displaying cigarettes in prime locations, especially around the 
counter). ${ }^{39,40}$ The vast majority ( $83 \%$ ) of these expenditures are price discounts paid to tobacco retailers to reduce the cost for consumers. ${ }^{39}$ Additionally, increases in tobacco marketing within tobacco retailers has been found to increase average tobacco sales by $12 \%{ }^{41}$ to $28 \% .^{38,41}$

The most common and influential form of tobacco marketing found within the retail environment is considered point-of-sale (PoS) tobacco marketing. By definition, PoS tobacco marketing is advertising created around "impulse purchasing" and designed to capture the consumer's attention, especially at the place of payment usually a checkout counter. Approximately, $83 \%$ of the cigarette advertisements found in the retail environment are considered PoS tobacco marketing. ${ }^{34} \mathrm{PoS}$ tobacco advertising and promotions is a sophisticated marketing strategy, which has emerged as the primary marketing approach to target youth. ${ }^{42,43}$ PoS tobacco marketing is thought to influence youth both cognitively and affectively by promoting the perceived benefits and positive attitudes of tobacco use related to, key concerns of youth, such as social approval, peer bonding, autonomy, self-image, and adventure seeking. ${ }^{44}$

A recent (2011) Cochrane Review concluded that exposure to PoS tobacco marketing is associated with the likelihood that youth will initiate cigarette smoking. ${ }^{44}$ Experimental studies have suggested that exposure to retail marketing distorts youths' perceptions about the availability, use, and popularity of tobacco and these normative beliefs are precursors of smoking. ${ }^{45-49}$ Several empirical studies have liked retail tobacco marketing to youth smoking susceptibility ${ }^{50-52}$ Youths who are exposed to weekly retail tobacco marketing are more likely to experiment with smoking, ${ }^{53,54}$ and those who visit stores with tobacco advertising at least twice a week double their odds of initiating cigarette smoking. ${ }^{55}$ After controlling for schools differences and other covariates, another study found that middle school students who were exposed to retail tobacco marketing at least once a week had a $50 \%$ increase in the likelihood of ever smoking, 
similar to the effects of having a parent or household member who smokes. ${ }^{53} \mathrm{PoS}$ advertising is associated with youth experimentation and progressions to regular smoking, with current youth smokers being the most influenced by promotional offers. ${ }^{56}$

The availability of retail tobacco co-occurs with numerous demographic and socioeconomic factors associated with increased tobacco use. Peterson et al., (2005) found that counties with higher levels of tobacco retailer density and cigarette smoking prevalence have a tendency to have a higher percentage of minority residents than counties with lower tobacco retailer density and cigarette smoking prevalence. ${ }^{57}$ Meanwhile, another study comparing census tracts, found that tracts in the lowest quartile of household income have more than twice the number of tobacco retail outlets than tracts from the highest quartile. ${ }^{58}$ Furthermore, census tracts with the highest percentage of minority residents also have twice as many tobacco retailers than tracts with lower proportions of minorities. ${ }^{58}$ Another study by Chuang and colleagues, (2005) found that neighborhoods with a higher proportion of lower socioeconomic residents and a higher concentration of convenience store density smoke more cigarettes per day. ${ }^{59}$ The authors also found a higher percentage of heavy smokers live in either lower socioeconomic neighborhoods or neighborhoods with high convenience store density. ${ }^{59}$ While lower socioeconomic neighborhoods, have significantly higher levels of convenience store density no matter the method of measurement (e.g., density of stores, percentage of residents living near a store, or percentage of stores within a one-mile radius). ${ }^{59} \mathrm{~A}$ recent national study concluded that race, ethnic and socioeconomic factors are positively associated with tobacco retailer density and that these associations are not simply a function of higher population density among poor and minority populations. ${ }^{60}$ 


\subsubsection{Summary of Significance}

Tobacco-related health disparities remain a major public health burden among rural populations. Consequently, comprehensive tobacco-control strategies in rural communities, like Appalachia, need to be reexamined, because current strategies are still limited in identifying and addressing the complex interactions that influence tobacco use. The mission of comprehensive tobacco-control programs is to reduce disease, disability, and death related to tobacco use. ${ }^{61}$ Furthermore, the goals of comprehensive tobacco-control programs are to: prevent initiation among youth and young adults; promote quitting among adults and youth; eliminate exposure to secondhand smoke; and identify and eliminate tobacco-related health disparities among population groups ${ }^{61}$ Since rural populations experience disproportionate health and economic burdens associated with tobacco use, a focus on eliminating rural tobacco-related health disparities is necessary ${ }^{61}$ To address rural tobacco-related health disparities:

"Organizations need to identify rural areas and understand the unique public health and tobacco control challenges they face in order to implement comprehensive, systemic tobacco control programs that address the underlying social, economic, cultural, and geographic conditions of these area. ${ }^{\prime 19, p .12}$

Therefore, to reduce rural tobacco-related health disparities, research must first identify those specific rural populations disproportionately affected by tobacco. Once identified, future research can focus on assessing and evaluating the factors within these rural populations, which are contributing to the localized rural tobacco-related health disparities. It is only then, after tobacco control experts have a firm understanding of the way these factors influence rural tobacco-related health disparities within these targeted rural areas, can efforts shift to developing and 
implementing tailored tobacco prevention and cessation initiatives, polices, and/or regulations for these rural populations.

Eliminating tobacco-related health disparities should focus on preventing cigarette and other tobacco use before long-term consequences take hold, ${ }^{62}$ beginning with those who are at the greatest risk - youth. Additionally, a greater understanding of how the retail tobacco environment favorably influences tobacco use among youth is necessary in eliminating future tobacco-related health disparities. Research and advocacy groups have worked to understand the potential benefits of controlling the number of tobacco retailers (e.g., tobacco retailer density) and its distance from youth spaces such as schools (e.g., proximity of tobacco retailers), with only limited success. ${ }^{35,63-68}$ Importantly, Food and Drug Administration (FDA) rules prohibiting exterior tobacco advertising within 1,000 feet of schools and playgrounds was not included in the passage of the 2009 Tobacco Control Act, ${ }^{69}$ and was instead issued as part of an Advanced Notice of Proposed Rulemaking that has not yet been acted upon..$^{70}$ The idea is that these approaches reduce exposure to tobacco marketing, as well as availability of products and thus restricts youth access to tobacco products via commercial sources. This is supported by data showing that the density of tobacco retailers within an individual's environment greatly influences tobacco availability and thus youth uptake. ${ }^{58,68}$ For example, Novak et al., (2006) found that the density of neighborhood tobacco retailers increases the odds of youth smoking by $20 \%$ even after controlling for neighborhood-level demographics or by propensity score strata. ${ }^{67}$

Overall, available evidence suggests that higher tobacco retailer density provides greater physical access to tobacco products because 1) it increases access by reducing travel distances and related search costs that consumers face, reducing their overall net cost associated with purchasing tobacco and 2) the overall price of tobacco products decreases in the presence of competition 
among retailers. ${ }^{58}$ This is magnified by the fact that neighborhoods with a higher concentration of tobacco retailers also tend to have a higher proportion of youth. ${ }^{67}$

Future research examining the links between the availability of retail tobacco and youth smoking must begin to distinguish between the effects of 1) tobacco retailer density across the study area and 2) the immediate proximity of tobacco retailers to youth. Few studies have systematically contrasted the inter-relationships between tobacco retailer density versus proximity to schools and thus youth smoking behaviors. Henriksen and colleagues, (2008) found that high schools in neighborhoods with the highest density of tobacco retailers ( $>5$ retailers) had an adjusted average current smoking prevalence 3.2\% higher than schools in neighborhoods with the lower densities. ${ }^{71}$ However, the distance from school to the nearest tobacco retailer was not associated with current smoking. ${ }^{71}$ Another study found that adolescent smokers in high schools with the greatest number of surrounding tobacco retailers were more likely to buy their own cigarettes than have someone else purchase them. ${ }^{64} \mathrm{~A}$ follow up study by Chan and Leatherdale, (2011) found that the number of tobacco retailers within a 1-km radius of youths' schools was associated with non-smokers being more susceptible to future smoking. ${ }^{63}$ While a study among high school students by McCarthy et al., (2009) found a small relationship between tobacco retailer density within 1-mile surrounding schools and adolescent reported smoking initiation. ${ }^{66}$ However, the authors did not find an association between tobacco retailer density and established/current smoking. ${ }^{66}$ Moreover, a recent study by Lipperman-Kreda et al., (2014) did not find an association between the distance from school to the nearest tobacco retailer and current smoking. ${ }^{65}$ Additionally, the authors also observed no association between tobacco retailer density calculated by either a 0.75 -mile or 1 -mile radius buffer around schools and current smoking. ${ }^{65}$ 
Most research to date is school-centric, in that is focuses on the proximity of only one tobacco retailer per school and/or tobacco retailer density within some arbitrary distance around a school. Thus, this approach effectively ignores all outlets that do happen to fall within the specified school boundaries, failing to capture youth access as it occurs across the whole retail tobacco environment. An alternative approach is to use tobacco retailers themselves as the unit of analysis, including both their proximity to schools and the range of other factors that vary between outlets. For example, a study conducted my Kirchner and colleagues, (2014) found that each 100 meter decrease in the proximity to high schools among tobacco retailers within predominate African-American census block groups was associated with an increase in the likelihood of a youth tobacco sales violation. ${ }^{72}$ This is consistent with other data confirming that even though youth spend a majority of their time in or around schools, their homes and neighborhoods are also key environments for understanding youth tobacco use. ${ }^{73,74}$ Therefore, to understand how the retail tobacco environment affects youth smoking behaviors, it may be that research must focus on retail tobacco availability (e.g., density and/or proximity to) across the whole study area and not within defined arbitrary boundaries around specific youth spaces.

\subsection{Summary of Aims}

The overall project employs an ecological framework for reducing tobacco-related health disparities in the U.S. The proposed project aims to contribute in three principal ways to the field of tobacco control. First, it utilizes enhanced surveillance techniques to identify localized clusters of rural areas disproportionately affected by tobacco use, while also identifying significant atypical observations (e.g., rural populations with significantly lower rates of tobacco use given their level of rurality). Thus, Study 1 of this project entails an exploratory spatial data analysis to 
examine the spatial associations between rurality and smoking in the contiguous U.S. Secondly, utilizing primary data to address limitations in assessing the availability of retail tobacco around schools, Study 2 consists of a spatial analysis to examine the spatial relationship between tobacco retailers and public middle/high schools within three metropolitan and three nonmetropolitan counties of West Virginia. Finally, using primary data to address limitations of school-centric approaches in contrasting the inter-relationships between tobacco retailer density surrounding schools and tobacco retailers' proximity to schools, Study 3 employs a retailercentric approach to examine the effects of retail tobacco availability on schools within three metropolitan and three nonmetropolitan counties of West Virginia. 
Chapter 2 


\section{Chapter 2}

\subsection{Introduction}

While great strides have been made to reduce the overall use of tobacco in the United States (U.S.), tobacco use remains the leading preventable cause of death and disease. ${ }^{4}$ The annual burden attributable to cigarette smoking is measured in tens of billions of dollars in lost productivity and health care costs; and results in nearly a half-million lives lost. ${ }^{3}$ Currently, $18.1 \%(\sim 42.1$ million $)$ of all adults nationwide smoke cigarettes. ${ }^{5}$ Even though the overall prevalence of cigarette smoking has significantly declined since $2005,{ }^{5}$ overall reduction trends are beginning to level off.

Persistently high prevalence of cigarette smoking still exists among specific population groups in the U.S. Differences in the patterns, prevention, and treatment of tobacco use, and in the risk, incidence, mortality, and burden of tobacco-related illnesses among particular populations; as well as the related differences in infrastructure, access to resources, and exposure to environmental tobacco smoke define tobacco-related health disparities in the U.S. ${ }^{14}$ Historically, tobacco-related health disparities occur among underserved populations characterized by socioeconomic status (e.g., education, occupation, income, poverty) race and ethnicity. ${ }^{12}$ Other factors such as geographic location/isolation, sexual orientation, gender, marital status, and age also contribute to tobacco-related health disparities. ${ }^{13}$

The Surgeon General has noted that no single factor determines the pattern of cigarette smoking and other tobacco use among vulnerable populations; rather, it stems from complex interactions between multiple factors. These include socioeconomic status, cultural characteristics, acculturation, stress, biologic elements, targeted advertising, price of tobacco 
products, and varying capacities of communities to mount effective tobacco-control initiatives. ${ }^{15}$ Thus, among various racial/ethnic groups, educational attainment levels, socioeconomic status gradients, and geographical regions, very large disparities in tobacco use still remain. ${ }^{3}$ Compared to urban/metropolitan (metro) areas, rural/nonmetropolitan (nonmetro) areas suffer from disproportionately more tobacco-related health disparities, including greater initiation rates, current use, intensity of use, exposure to second hand smoke, and cessation failure. ${ }^{16,17}$ While cigarette smoking prevalence has declined slightly in U.S. urban areas, rural residents are showing increasing rates. ${ }^{17,18}$ Rural communities vary across social, economic, cultural, and geographic characteristics. ${ }^{19}$ These rural communities can be heterogeneous in other ways, by differing in population density and in their connectivity to and remoteness from urban areas. ${ }^{20}$ One implication of this heterogeneity is that each rural community has a specific combination of factors that lead to increased tobacco use. ${ }^{19}$ Two major factors that greatly influence tobacco use in most areas are lower socioeconomic status and educational attainment. ${ }^{16,21}$ Other factors specifically associated with rural tobacco use include low levels of medical coverage, reduced access to medical services due to geographic isolation, reduced availability of cessation resources, cultural attitudes that foster tobacco use. ${ }^{22,23}$

In the U.S., a rural area of primary concern is the Appalachian region. The Appalachian region includes all of West Virginia and parts of 12 other states; Alabama, Georgia, Kentucky, Maryland, Mississippi, New York, North Carolina, Ohio, Pennsylvania, South Carolina, Tennessee, and Virginia. ${ }^{24}$ Forty-two percent of Appalachia's population lives in a rural community, compared to $20 \%$ of the national population. ${ }^{24}$ Appalachia suffers disproportionately poorer health than the rest of the nation. This region has suffered from a long history of economic underdevelopment, which has led to high rates of poverty, disability, 
unemployment, as well as low rates of educational attainment. ${ }^{25,26}$ Moreover, the Appalachian culture is distinct compared to mainstream U.S. society. Appalachian people are more independent and self-reliant, due to their strong sense of individualism and strong family ties, ${ }^{27}$ which can be attributed to both their geographic isolation and their tendency to function within their own kin group. ${ }^{28}$ All of these factors increase the risk of tobacco use among Appalachians. Comprehensive tobacco control strategies are greatly needed in Appalachia, because current strategies have proven ineffective in addressing the complex interactions that influence tobacco use. Comprehensive tobacco-control address a range of factors at different points in the trajectory of tobacco use, such as preventing initiation among youth and young adults, promoting quitting among adults and youth, eliminating exposures to secondhand smoke, and identifying and eliminating tobacco-related disparities among population groups. ${ }^{61}$ Because rural populations already experience disproportionate health and economic burdens associated with tobacco use, a focus on eliminating tobacco-related health disparities in these communities is necessary. ${ }^{61}$ To develop effective comprehensive tobacco control strategies in rural areas, organizations must first identify where those rural communities disproportionately affected by tobacco use are located. Once organizations have identified these rural communities, they need to recognize and understand the unique public health and tobacco control challenges burdening these populations by implementing comprehensive tobacco control strategies that address the underlying social, economic, cultural, and geographic conditions found in these rural areas. ${ }^{19}$

The current study seeks to address this research gap in rural tobacco control strategies, by identifying those rural areas in the U.S. disproportionately affected by tobacco use. Exploratory spatial data analysis (ESDA) techniques (e.g., global and local measures) were used to assess the spatial association between a county's level of rurality and adult cigarette smoking. An ESDA 
explicitly focuses on the spatial dependence (e.g., spatial association) and spatial heterogeneity of the data. ${ }^{75}$ ESDA techniques aim to describe spatial distributions, discover patterns of spatial association, suggest different spatial regimes or other forms of spatial instability, and identify atypical observations. ${ }^{75,76}$ Utilizing this approach enhances current surveillance efforts by identifying those rural populations disproportionately affected by tobacco-related health disparities, and by pinpointing localized rural populations for further tobacco-related disease surveillance. The study assesses the following two research questions: 1) Is there an overall (e.g., global) spatial association between rurality and adult cigarette smoking? 2) Where are these significant positive and negative spatial associations (e.g., clusters) located? Since tobaccorelated health disparities increase in rural areas, we hypothesize that the overall spatial association between county-level rurality and county-level adult cigarette smoking prevalence in the contiguous U.S. will result in positive spatial association. Additionally, we hypothesize that a majority of Appalachian counties will be identified as significant spatial clusters, because Appalachia suffers disproportionately more tobacco-related health disparities than any other rural area in the U.S.

\subsection{Methods}

\subsubsection{County-Level Current Adult Cigarette Smoking}

Current adult cigarette smoking prevalence were calculated by utilizing publicly available Behavioral Risk Factor Surveillance System (BRFSS) survey data from 2000-2010. ${ }^{77}$ The BRFSS is an annual telephone-based health survey of adult (age $\geq 18$ years old) U.S. residents. State health departments administer the BRFSS, which collects data on various health risk behaviors by utilizing core questionnaires developed by the U.S. Centers for Disease Control and 
Prevention (CDC). The CDC then aggregates all BRFSS respondent data for each state to calculate the state-level prevalence for each health risk behavior. Further details regarding BRFSS questionnaires are available at www.cdc.gov/brfss/questionnaires.htm, while, details regarding BRFSS methodology are available at www.cdc.gov/brfss/publications/methodology/data_qvr.htm.

For each year (2000-2010), current cigarette smoking status was calculated by the responses to the following two BRFSS core questions. ${ }^{78}$ Each respondent was categorized as a current smoker if, he or she answered "Yes", to the question "Have you ever smoked at least 100 cigarettes in your entire life?" and also, responded "Every day" or "Some days", to the follow-up question "Do you now smoke cigarettes every day, some days, or not at all? Additionally, a unique identifier for each county or county equivalent in the U.S was created by concatenating BRFSS state and county codes. Utilizing SAS $9.3,{ }^{79}$ current smokers within each county identifier were summed across all years (2000-2010) to derive county-level current smokers. Since the present study only focuses on the contiguous U.S., we excluded counties in Alaska and Hawaii.

Current cigarette smoking prevalence were estimated for every county or county equivalent in the contiguous U.S. $(\mathrm{N}=3,109)$. The number of smokers found in each county determined the approach used to calculate a reliable prevalence estimate for each county. Spatial empirical Bayes smoothing was utilized to generate reliable prevalence estimates for counties that had a sample size of one to less than 50 smokers. An advantage of this Bayesian approach is that it addresses the small numbers problem in generating reliable estimates for these counties. ${ }^{80}$ This method of smoothing borrows information from adjacent neighborhoods to stabilize local estimates by using various spatial weights ${ }^{81} \mathrm{~A}$ k-nearest neighbor $(\mathrm{k}=8)$ spatial weight matrix 
was used to define each county's neighborhood structure, which defines each county's neighborhood as its eight-nearest (e.g., given distance) counties. Utilizing OpenGeoDa version 1.0.1 software, ${ }^{82}$ each county's prevalence rate was smoothed based on the similarities between the prevalence found in the county's defined neighborhood structure. For counties with a sample size of greater than or equal to 50 smokers, the county's prevalence rate was weighted by the final weight assigned to each respondent (e.g., BRFSS final weight variable). For counties that were missing or had a sample size of zero smokers, the corresponding state's weighted meanimputed prevalence rate from 2000-2010 was used to provide a reliable estimate of the county's adult smoking rate. Therefore, to summarize, current adult smoking prevalence were derived for all counties in the contiguous U.S. using either weighted ( $\geq 50$ smokers), unweighted spatially smoothed (1-49 smokers), or state weighted mean-imputed (missing/no smokers) prevalence.

A majority (43\%) of the county estimates used the respondent-weighted approach, while a third of the county estimates utilized spatial empirical Bayes smoothed raw prevalence. Additionally, almost a quarter (24\%) of the county prevalence estimates utilized the state's mean-imputed rate, because either the county was missing respondents, or the county had no reported smokers over the 10-year study timeframe.

\subsubsection{Rurality}

Rurality was based on the United States Department of Agriculture (USDA), Economic Research Service's (ERS) 2003 rural - urban continuum codes ${ }^{83}$ Rural - urban continuum codes provide a categorization of rurality that distinguishes metro counties by the population size of their metro area and nonmetro counties by their degree of urbanization and adjacency to a metro area(s) ${ }^{84}$ This classification scheme subdivides metro and nonmetro categories into three metro 
and six nonmetro groups, resulting in a nine-part ordinal variable (Table 2.1). ${ }^{84}$ Metro categories group counties based on the population size of their Metropolitan Statistical Area. ${ }^{84}$ Nonmetro categories classify counties based on the aggregate size of their urban population, which is further divided by whether or not they have some functional adjacency to a metro area ${ }^{84} \mathrm{~A}$ nonmetro county is adjacent if it physically adjoins one or more metro areas, and has at least $2 \%$ of its employed work force commuting to metro counties. ${ }^{84}$

Table 2.1: 2003 Rural - Urban Continuum Codes

\begin{tabular}{cl}
\hline Code & Metro Counties: \\
\hline $\mathbf{1}$ & Counties in metro areas of 1 million population or more \\
\hline $\mathbf{2}$ & Counties in metro areas of 250,000 to 1 million population \\
\hline $\mathbf{3}$ & Counties in metro areas of fewer than 250,000 population \\
\hline & Nonmetro Counties: \\
\hline $\mathbf{4}$ & Urban population of 20,000 or more, adjacent to a metro area \\
\hline $\mathbf{5}$ & Urban population of 20,000 or more, not adjacent to a metro area \\
\hline $\mathbf{6}$ & Urban population of 2,500 to 19,999, adjacent to a metro area \\
\hline $\mathbf{8}$ & Urban population of 2,500 to 19,999, not adjacent to a metro area \\
\hline $\mathbf{9}$ & Completely rural or $<2,500$ urban population, adjacent to a metro area \\
\hline
\end{tabular}

\subsubsection{Exploratory Spatial Data Analysis (ESDA)}

Besides examining the spatial distribution of current adult cigarette smoking prevalence in both the contiguous U.S. and the Appalachian region, the primary focus of the current ESDA was to examine the spatial association between county-level rurality and county-level current adult cigarette smoking prevalence in the contiguous U.S. The spatial association measures the extent to which the occurrence of an event in a spatial unit (e.g., county) constrains or makes more probable the occurrence of an event in a neighboring county, a concept derived from Tobler's first law of geography (i.e., "Everything is related to everything else, but near things are more related than distant things."). ${ }^{85}$ We used both global and local measures of spatial 
association to assess the spatial association between county-level rurality and county-level current adult cigarette smoking prevalence in the contiguous U.S.

A global measurement approach to spatial association examines the overall spatial dependence between the variables of interest over the entire geographic space (e.g., the contiguous U.S.). Moran's I statistic was used to assess the level and direction (e.g., positive or negative) of the overall pattern of dependence in the current ESDA. The Moran's I statistic is visualized by a Moran scatterplot, where the slope of the regression line corresponds to Moran's I. ${ }^{81,86}$ Similar to a correlation coefficient, its value varies between -1 and 1 . Specific to the current ESDA, we extended the traditional univariate Moran's I scatterplot to depict a bivariate spatial association, which measures the correlation between one variable at a location and a different variable at neighboring locations. ${ }^{81}$

Local indicators of spatial association (LISA) identify significant patterns of local spatial association (e.g., association around an individual location), and assesses the extent to which the global pattern of association is reflected uniformly throughout the data set (e.g., global diagnostic). ${ }^{76}$ LISA exploits the global Moran's I statistic to evaluate local clusters by deriving a local Moran's I statistic for each spatial unit and then evaluating the statistical significance of each local Moran's I statistic. ${ }^{87}$ A LISA analysis produces a significance and cluster map. The significance map depicts the locations with significant positive or negative local Moran's I statistics, while the LISA cluster map classifies those locations by the type of association. ${ }^{81}$ We examined the global Moran's I statistic and the LISA between county-level rurality and county-level current adult cigarette smoking prevalence for the contiguous U.S. utilizing the Space tools in OpenGeoDa. The neighborhood structure for each of these analyses was defined using the same $\mathrm{k}$-nearest neighbor $(\mathrm{k}=8)$ spatial weight matrix that was used to define the 
neighborhood structure in the spatial empirical Bayes smoothing process above. The significance of the global spatial association was determined by randomly generating a referenced distribution of Moran's I values based on 9,999 permutations. ${ }^{81}$ This permutation test yields a pseudo p-value based on the number of permutations selected to determine the level and direction of the global spatial association. ${ }^{81}$ Finally, LISA significance and cluster maps were combined to construct a 95\% significance level cluster map, which identifies four different clusters types based on the nature of the spatial association. High rurality - high smoking and low rurality - low smoking spatial cluster types (e.g., positive spatial association) identifies clustering of similar values, where rural/nonmetro counties are surrounded by counties with high prevalence of smoking and urban/metro counties are surrounded by counties with low prevalence of smoking respectively. ${ }^{81,87}$ High rurality - low smoking and low rurality - high smoking spatial clusters (e.g., negative spatial association) are termed spatial outliers (respectively, rural/nonmetro counties surrounded by counties with low prevalence of smoking and urban/metro counties surrounded by counties with high prevalence of smoking). ${ }^{81,87}$

\subsection{Results}

\subsubsection{County-Level Current Adult Cigarette Smoking}

Figure 2.1 shows the spatial distribution of the county-level estimates for current adult cigarette smoking prevalence derived from our various approaches. From 2000-2010, the average county adult smoking rate was $21.3 \%(\mathrm{SD}=4.31)$ in the contiguous U.S. The highest levels of adult cigarette smoking are found in the South and Midwest regions of the U.S., especially in the Appalachian states of Kentucky and West Virginia. Other states with high levels of adult cigarette smoking include Nevada, New Mexico, and Wyoming. The lowest levels of 
adult cigarette smoking are seen in Utah and California. Among U.S. counties, the highest county adult cigarette smoking prevalence (44.07\%) was observed in Shannon County, South Dakota, while the lowest adult smoking rate of $4.03 \%$ was found in Madison County, Idaho, a difference of $40 \%$. Table 2.2 shows the top- and bottom-ranked contiguous U.S. counties for current adult cigarette smoking.

The high levels of adult cigarette smoking seen in the Appalachian region (highlighted in Figure 2.1) are consistent with previous findings regarding adult cigarette smoking in Appalachia. ${ }^{17,20}$ The highest county prevalence of adult cigarette smoking are seen in the Central and North Central regions of Appalachia, while the lowest prevalence are observed in the Southern portion of Appalachia. In Appalachia, the average county adult cigarette smoking rate was $24.09 \%(\mathrm{SD}=4.48)$. We found a difference of around $28 \%$ separating the highest Appalachian county adult smoking rate of $42.33 \%$ (Adair County, Kentucky) from the lowest Appalachian county rate of $14.34 \%$ (Douglas County, Georgia). Table 2.3 lists the top- and bottom-ranked Appalachian counties for current adult cigarette smoking. 
Figure 2.1: County-Level Current Adult Cigarette Smoking Prevalence for the Contiguous United States, 2000-2010

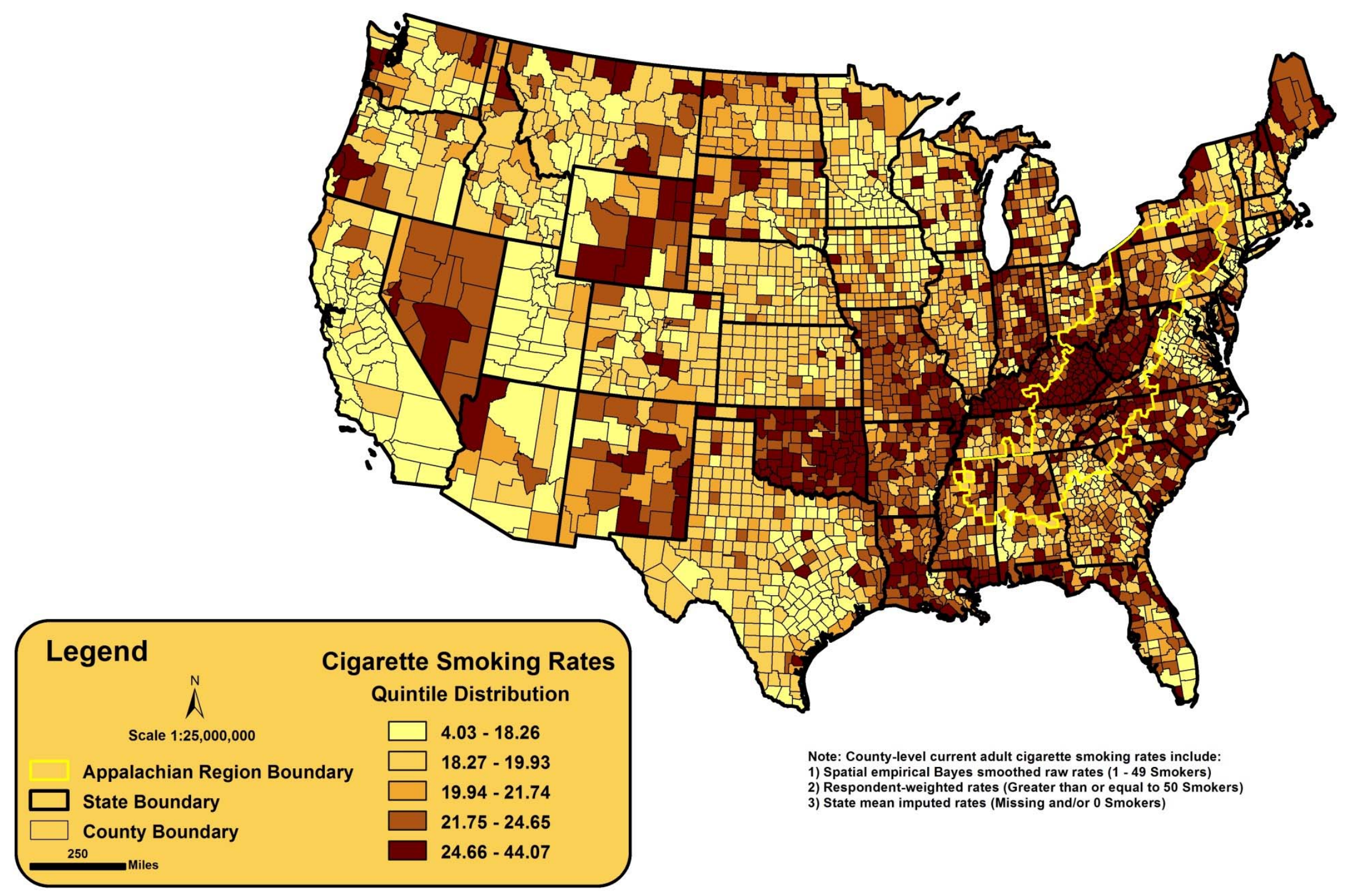


Table 2.2: Top- and bottom-ranked contiguous U.S. counties for current adult cigarette smoking prevalence, $2000-2010$

\begin{tabular}{lll}
\hline Rank & County & Current Adult Cigarette Smoking Prevalence (\%)* \\
\hline 1 & Madison County, ID & 4.03 \\
\hline 2 & Cache County, UT & 5.41 \\
\hline 3 & Utah County, UT & 6.00 \\
\hline 5 & Davis County, UT & 8.26 \\
\hline 6 & Summit County, UT & 8.34 \\
\hline 7 & Millard County, UT & 8.40 \\
\hline 8 & Wasatch County, UT & 8.82 \\
\hline 10 & Pitkin County, CO & 8.88 \\
\hline 3,100 & Douglas County, CO & 9.10 \\
\hline 3,101 & Washington County, UT & 9.25 \\
\hline 3,102 & Swain County, NC & 36.10 \\
\hline 3,103 & Washington County, MO & 37.02 \\
\hline 3,104 & Bracken County, KY & 38.04 \\
\hline 3,105 & Stokes County, NC & 38.25 \\
\hline 3,106 & Lewis County, KY & 39.07 \\
\hline 3,107 & Todd County, SD & 39.97 \\
\hline 3,108 & Rolette County, ND & 41.41 \\
\hline Cou & Dewey County, SD & 41.85 \\
\hline
\end{tabular}

* County-level current adult cigarette smoking prevalence are constructed from: 1) spatial empirical Bayes smoothed raw prevalence (1-49 smokers);

2) respondent - weighted rate ( $\geq 50$ smokers); and 3) state mean imputed prevalence (missing and/or 0 smokers). 
Table 2.3: Top- and bottom-ranked Appalachian counties for current adult cigarette smoking prevalence, $2000-2010$

\begin{tabular}{|c|c|c|}
\hline Rank & County & Current Adult Cigarette Smoking Prevalence (\%)* \\
\hline 1 & Douglas County, GA & 14.34 \\
\hline 2 & Centre County, PA & 14.65 \\
\hline 3 & Botetourt County, VA & 15.08 \\
\hline 4 & Forsyth County, GA & 15.23 \\
\hline 5 & Juniata County, PA & 15.64 \\
\hline 6 & Hardy County, WV & 16.08 \\
\hline 7 & Lumpkin County, GA & 16.09 \\
\hline 8 & Warren County, TN & 16.29 \\
\hline 9 & Mifflin County, PA & 16.33 \\
\hline 10 & Mineral County, WV & 16.35 \\
\hline 419 & Lawrence County, KY & 34.55 \\
\hline 420 & Bath County, KY & 34.62 \\
\hline 421 & Carter County, KY & 34.63 \\
\hline 422 & Mingo County, WV & 35.35 \\
\hline 423 & McDowell County, WV & 35.47 \\
\hline 424 & Wyoming County, WV & 35.83 \\
\hline 425 & Swain County, NC & 36.10 \\
\hline 426 & Stokes County, NC & 38.25 \\
\hline 427 & Lewis County, KY & 39.07 \\
\hline 428 & Adair County, KY & 42.33 \\
\hline
\end{tabular}

* County-level current adult cigarette smoking prevalence are constructed from: 1) spatial empirical Bayes smoothed raw prevalence (1-49 smokers);

2 ) respondent - weighted rate ( $\geq 50$ smokers); and 3) state mean imputed prevalence (missing and/or 0 smokers) 


\subsubsection{Spatial Association between Rurality and Current Adult Cigarette Smoking}

Overall, we found the global spatial association between county-level rurality and county-level current adult cigarette smoking prevalence to be significant (pseudo p-value $<$ 0.0001 ), but the spatial association was only slightly positive (Moran's I $=0.0438$ ). The LISA analysis identified 1,147 significant (pseudo p-value $<0.05$ ) county clusters. The LISA 95\% significance cluster map is shown in Figure 2.2. The four different cluster types identify areas where smoking prevalence within the focal county's neighborhood structure is significantly higher or lower given the level of rurality of the focal county. Positive spatial association was observed in 637 counties and was almost evenly distributed between high rurality - high smoking $(\mathrm{N}=319)$ and low rurality - low smoking $(\mathrm{N}=318)$ county clusters. A majority of the high rurality - high smoking county clusters are observed in Oklahoma, Missouri, Arkansas, Mississippi, West Virginia, and Kentucky. Low rurality - low smoking county clusters are mainly seen in the western half of the U.S., specifically in California, Oregon, Washington, Idaho, Utah, and Arizona. Additional low rurality - low smoking county clusters are seen along the northeast corridor of the U.S. from Virginia to Massachusetts; while, Texas and Minnesota also have numerous low rurality - low smoking spatial clusters. We identified 510 counties with negative spatial association. A majority (54\%) of these spatial outliers (e.g., high rurality - low smoking) have neighborhood structures with significantly lower prevalence of smoking given the very rural nature of the local county. High rurality - low smoking spatial outliers were mainly observed in the western part of the U.S. where low rurality - low smoking clusters exist. This effect was also seen within the Texas and Minnesota high rurality - low smoking spatial outliers. On the other hand, we observed a majority of the 235 counties with low rurality - high smoking in Oklahoma, Kentucky, Indiana, West Virginia, and North Carolina. 
Figure 2.2: Local Indicators of Spatial Association between Rurality and Current Adult Cigarette Smoking Prevalence

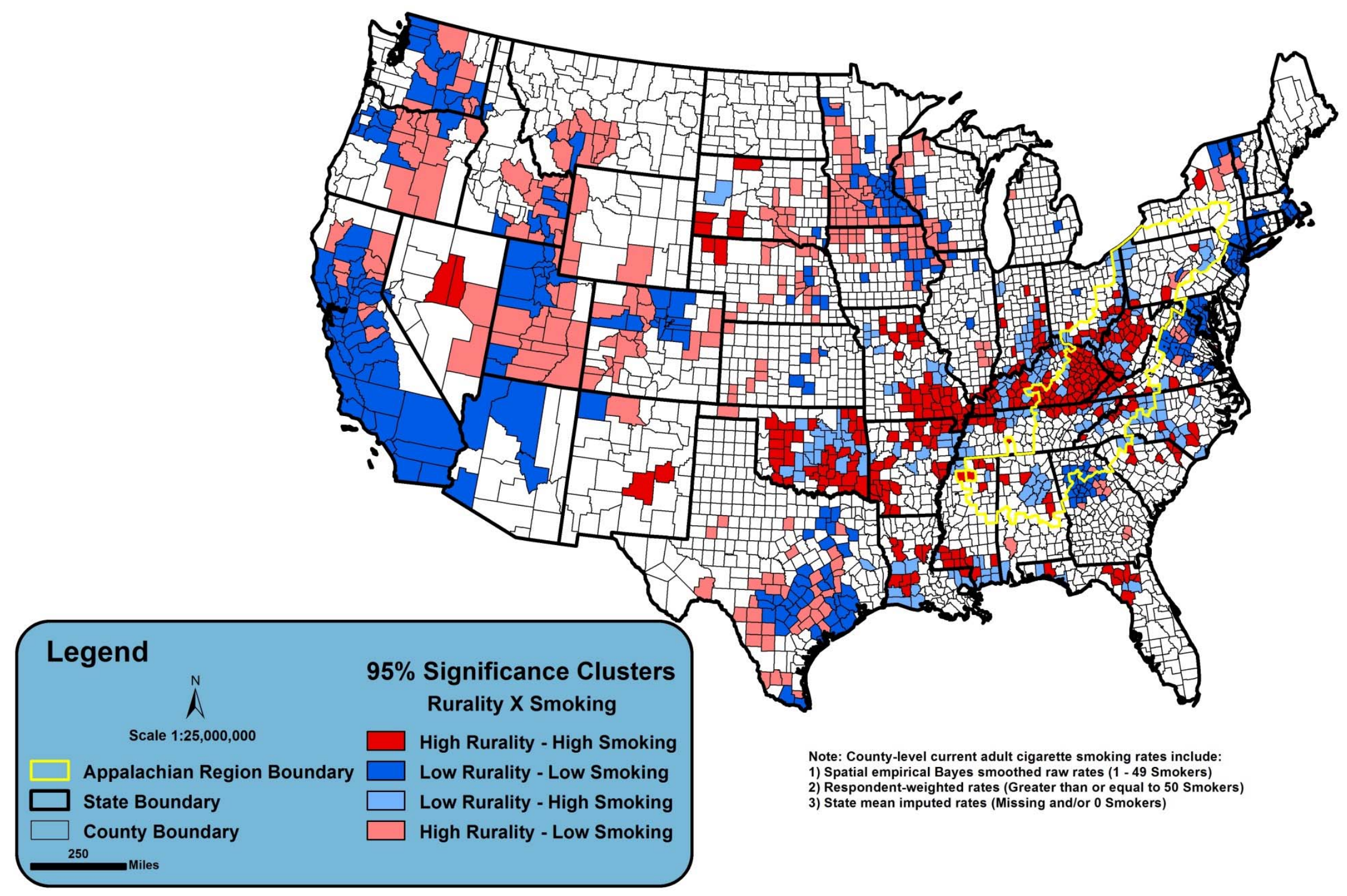




\subsection{Conclusions}

Overall, findings showed reliable county-level estimates of current adult cigarette smoking by aggregating publically available BRFSS data from 2000-2010, and successfully identified areas disproportionately affected by rural tobacco-related health disparities. This work complements the findings of a recent study that presented a small area estimation approach to estimating annual cigarette smoking prevalence for U.S. counties. ${ }^{88}$ This study found that the Appalachian region has some of the highest prevalence of cigarette smoking in the U.S, which confirms findings from other previous studies. ${ }^{21,25}$ Furthermore, ESDA techniques were able to assess the global and local spatial associations between rurality and adult smoking prevalence on a county scale. While the global estimate found the overall spatial association between countylevel rurality and county-level adult smoking prevalence to be slightly positive across the contiguous U.S., LISA was able to successfully identify where numerous spatial clusters (e.g., positive spatial association) and spatial outliers (e.g., negative spatial association) exist within the contiguous U.S. By identifying those rural populations that are disproportionately affected by tobacco use (e.g., high rurality - high smoking spatial clusters), provides tobacco control experts the ability to accurately assess and evaluate those factors that are contributing to tobacco-related health disparities within these specific rural clusters. Once tobacco control specialists have an understanding of how those factors are associated with the tobacco-related health disparities found in these localized rural populations, they can begin to develop and disseminate tailored tobacco prevention and cessation initiatives that clearly address the tobacco burdens these rural areas face. 
The ability to identify clusters of significant spatial outliers (e.g., negative spatial association) is perhaps the most intriguing finding, because this type of clustering identifies areas where the inverse spatial relationship (e.g., dissimilar values) exists. These spatial outliers identify whether a rural/nonmetro county is surrounded by counties with significantly lower prevalence of smoking (e.g., high rurality - low smoking) than would normally be observed or where an urban/metro county is surrounded by counties with significantly higher prevalence of smoking (e.g., low rurality - high smoking) than would normally be observed. This finding is particularly interesting because, tobacco control specialists can compare the various tobacco control policies, programs and initiatives found in these spatial outliers (e.g., high rurality - low smoking) and determine whether they, if any, can be tailored, disseminated, and implemented to the counties that are disproportionately affected by tobacco-related health disparities (e.g., high rurality - high smoking). Additionally, tobacco control experts can focus on examining the factors that are contributing to this low prevalence of smoking in these rural/nonmetro areas. For example, in the high rurality - low smoking spatial outliers of the Pacific Northwest, what factors contribute to that particular population having significantly lower prevalence of adult smoking given the rural nature of the population and how does this rural area differ in terms of demographics, resources, and tobacco control policies, programs, and initiatives from Central Appalachia. The most obvious candidate would be spatial clustering of educational and income disparities, which differ greatly between Central Appalachia and the Pacific Northwest, and are tightly linked to smoking prevalence. Another contributing factor may be the religious composition of the population, especially when considering the spatial outliers (e.g., high rurality - low smoking) found in in Utah and southeast Idaho. In 2013, six in 10 Utah residents identify themselves as Mormon and only $5 \%$ of this population smoked. ${ }^{89}$ Cultural beliefs can also 
mitigate rates of smoking in rural populations. For example, the high rurality - low smoking spatial outliers found in Northern Appalachia are possibly a result of the large Amish and Mennonite populations living there. Similarly, tobacco control policies, program, and initiatives that significantly reduce tobacco-related health disparities in urban/metro areas (e.g., low rurality - low smoking spatial clusters) should be tailored, disseminated and implemented in urban/metro areas with significantly higher prevalence of smoking (e.g., low rurality - high smoking spatial outliers).

This ESDA approach was successful in examining both global and local measures of spatial association between county-level rurality and county-level adult cigarette smoking prevalence; however, several limitations exist. First, our methodical approach does not provide inference into causality; therefore, we cannot conclude that a county's level of rurality causes the county's adult population to smoke. Second, while our approach to construct county-level adult smoking prevalence estimates was not as methodically sound as the small area estimation methods used by Dwyer-Lindgren et al., 2014, ${ }^{88}$ it was still able to generate reliable point estimates of adult smoking prevalence for each county in the contiguous U.S. Furthermore, since we used the aggregated state mean-imputed estimates for those counties that were missing respondents in our approach the effect size of the global spatial association was underestimated. Lastly, a county's level of rurality, defined by its rural-urban continuum code, was treated as a continuous variable given the number of levels and ordinal nature of this variable. ${ }^{90}$

In conclusion, tobacco use will plateau until we target those who have the most risk for tobacco-related health disparities - rural populations. ${ }^{91}$ In this study, we successfully identified those rural areas. Additionally, we successfully identified areas where the inverse of the relationship exists (e.g., spatial outliers), in these specific rural areas, the prevalence of smoking 
is significantly lower than expected given the rural nature of the populations. Further research is needed to understand "what" and "why" these factors and/or policies are inhibiting tobacco use within these specific rural populations. Due to the heterogeneity of rural areas, research must now focus on identifying and evaluating the factors contributing to the tobacco-related health disparities within these specific rural areas. Only after tobacco control experts have a firm understanding of the way these factors influence tobacco-related health disparities within these targeted rural areas can efforts shift to creating tailored tobacco prevention and cessation initiatives, policies, and/or regulations for these rural populations. Overall, this approach will help inform and guide health policy decisions by providing state policymakers with the ability to target their resources to those rural populations disproportionately affected by tobacco-related health disparities. 


\section{Chapter 3}




\section{Chapter 3}

\subsection{Introduction}

Youth tobacco use remains a public health epidemic. Currently, 15.7\% of all high school students (e.g., 2.7 million) in the United States (U.S.) smoke cigarettes. ${ }^{8}$ Unless youth smoking rates decline, 5.6 million of today's youth (under18) will eventually die from the consequences

of cigarette smoking. ${ }^{3}$ Emerging evidence suggest that youth smoking research must address the environmental factors that favorably influence tobacco use. Currently, $18.1 \%$ of high school students (e.g., grades 9 -12) who currently smoke cigarettes directly purchase their cigarettes from stores or gas stations. ${ }^{8}$ Some youth smokers buy their cigarettes directly from retailers or other youth smokers, or have someone else buy them, while other youth smokers obtain their cigarettes freely via social sources (e.g., friends and classmates). A study based on the California Tobacco Survey found that more than $80 \%$ of youths who have ever smoked had previously acquired cigarettes from others, with the majority being acquired from their friends. ${ }^{92}$

A recent (2011) Cochrane Review concluded that exposure to tobacco retailers and their subsequent tobacco marketing practices is associated with the likelihood that youths initiate cigarette smoking. ${ }^{44}$ The density of tobacco retailers within an individual's environment greatly influences tobacco availability and thus youth uptake. ${ }^{58,68}$ Neighborhoods with a higher concentration of tobacco retailers also have a higher proportion of youth. ${ }^{67}$ Among youths, retail tobacco availability has been found to be associated with smoking initiation. ${ }^{68}$ Henriksen and colleagues (2008) found that high schools in neighborhoods with the highest density of tobacco retailers ( $>5$ retailers) had an adjusted average current smoking prevalence $3.2 \%$ higher than schools in neighborhoods with lower densities. ${ }^{71}$ Moreover, Novak et al., (2006) found that the 
density of neighborhood tobacco retailers increases the odds of youth smoking by $20 \%$ even after controlling for either neighborhood-level demographics or by propensity score strata. ${ }^{67}$ Available evidence suggests that higher tobacco retailer density provides greater physical access to tobacco products because 1) it increases access by reducing travel distances and related search costs that consumers face, reducing their overall net cost associated with purchasing tobacco and 2) the overall price of tobacco products decreases in the presence of competition among retailers. ${ }^{58}$

Tobacco retailer density co-occurs with numerous demographic and socioeconomic factors associated with increased tobacco use. Peterson et al., (2005) found that counties clustered together on the basis of tobacco retailer density and smoking prevalence, as well as those with higher levels of tobacco retailer density and cigarette smoking, have a tendency to have a higher percentage of minority residents. ${ }^{57}$ Meanwhile, a study comparing census tracts found that tracts in the lowest quartile of household income have more than twice the number of tobacco retailers than tracts from the highest quartile. ${ }^{58}$ Another study by Chuang and colleagues, (2005) found that neighborhoods with a higher proportion of lower socioeconomic residents and a higher density of convenience stores, people smoke more cigarettes per day ${ }^{59}$ The authors also found a higher percentage of heavy smokers live in either low socioeconomic neighborhoods or neighborhoods with high convenience store density. ${ }^{59}$ Furthermore, lower socioeconomic neighborhoods have significantly higher levels of convenience store concentration using several methods of measurement (e.g., density of stores, percentage of residents living near a store, or percentage of stores within a one-mile radius). ${ }^{59} \mathrm{~A}$ recent national study concluded that race, ethnic and socioeconomic factors are positively associated with tobacco retailer density and that 
these associations are not simply a function of higher population density among poor and minority populations. ${ }^{60}$

Tobacco retailer density also directly influences the presence and amount of tobacco marketing found within an individual's environment. Since the Master Settlement Agreement, ${ }^{29}$ the prevalence of interior and exterior tobacco advertising has increased significantly in tobacco retailers. ${ }^{32,33}$ In 2011 , the tobacco industry spent $\$ 8.37$ billion on tobacco marketing nationwide. ${ }^{39}$ These expenditures pay for traditional retail tobacco advertising (e.g., exterior/interior signage/advertisements and branded/non-branded functional items), price discounts for consumers (e.g., "Buy two, get one free"), and retail promotional allowances (e.g., shelving and incentive payments to retailers for displaying cigarettes in prime location, especially around the counter). ${ }^{39,40}$ Additionally, price discounts paid to tobacco retailers to reduce the price for consumers accounted for a vast majority (83.6\%) of the expenditures. ${ }^{39}$ Increases in tobacco marketing within tobacco retailers has been found to increase average tobacco sales by $12 \%$ to $28 \% .^{38,41}$ In 2001 , Feighery and colleagues found that the average number of tobacco advertisements varies among different types of tobacco retailers. ${ }^{34}$ They found that liquor stores tend to have the greatest number of tobacco advertisements followed by small stores (e.g., including small drug stores and markets) and convenience stores (e.g., including those that sold gasoline). ${ }^{34}$ Tobacco retailers that are popular among youths, display three times the amount of exterior and interior cigarette marketing and twice as much shelf space for Marlboro, Camel and Newport brand cigarettes, which account for more than $80 \%$ of the cigarettes bought by youths. ${ }^{35,36}$ Thus, retail tobacco marketing increases youths' exposure to tobacco because an estimated $75 \%$ of youths shop at a convenience store at least once a week and on average shop twice as long as adults. ${ }^{37,38}$ 
The most common and influential form of tobacco marketing found within the tobacco retail environment is considered PoS tobacco marketing. Approximately $83 \%$ of the cigarette advertisements displayed in all types of tobacco retailers are considered PoS tobacco marketing. ${ }^{34}$ By definition, PoS tobacco marketing is advertising created around "impulse purchasing" and is designed to capture the consumer's attention, especially at the place of payment - checkout counter. PoS tobacco marketing influences youth behavior both cognitively and affectively by promoting the perceived benefits and positive attitudes of tobacco use related to, key concerns of youths, such as social approval, peer bonding, autonomy, self-image, and adventure seeking. ${ }^{44}$ Furthermore, experimental studies have suggested that exposure to retailer tobacco marketing distorts youths' perceptions about the availability, use, and popularity of tobacco and these normative beliefs are precursors of smoking. ${ }^{45-49}$ Several empirical studies have linked retail tobacco marketing practices to youth smoking susceptibility. ${ }^{50-52}$ Meanwhile, youths exposed to weekly tobacco marketing in stores are more likely to experiment with smoking. ${ }^{53,54}$ Youths who visit stores with tobacco advertising at least twice a week double their odds of initiating cigarette smoking. ${ }^{55}$ After controlling for school differences and other covariates, middle school students who are exposed to retail tobacco marketing at least once a week or more had a 50\% increase in the likelihood of ever smoking, similar to the effects of having a parent or household member who smokes. ${ }^{53}$ Moreover, PoS advertising is associated with encouraging youth to try smoking, while cigarette promotions are associated with influencing adolescents experimenting with cigarettes to progress to regular smoking, with current youth smokers being the most influenced by promotional offers. ${ }^{56}$ 
The purpose of the current study is 1) to visualize tobacco retailer density around public middle/high schools and 2) to examine the spatial relationship that exists between the location of tobacco retailers and public middle/high schools within six West Virginia counties that have divergent levels of rurality, defined as either metropolitan (e.g., metro) or nonmetropolitan (e.g., nonmetro). We hypothesize that schools in nonmetro counties will have relatively less access to tobacco/tobacco marketing than metro counties. West Virginia is an ideal site to implement this study, because the state has the highest rate of youth cigarette smoking $(19.6 \%)$ in the nation. ${ }^{8}$ The annual tobacco industry marketing expenditures in this rural state are $\$ 120.4$ million. ${ }^{93} \mathrm{~A}$ weighted Kernel Density Estimation (KDE) approach assessed the availability of tobacco retailers in each county. This novel approach advances the literature on current density approaches by weighting each tobacco retailer by its respective tobacco marketing. The resulting density surface will visualize a school's access to "influential" tobacco retailers across the whole study area. To our knowledge, this is the first study that examines tobacco retailer density while accounting for tobacco marketing. Furthermore, a bivariate Ripley’s K-function will examine the spatial relationship between the locations of tobacco retailers and schools within each county to test the hypothesis that the locations are independent of each other.

\subsection{Methods}

\subsubsection{Metro and Nonmetro West Virginia Counties}

Three metro and three nonmetro counties were systematically selected from all the counties $(\mathrm{N}=55)$ in West Virginia based on criteria for a future study. We selected metro and nonmetro counties based on: 1) metro/nonmetro status and 2) program evaluation data from a youth smoking cessation program disseminated in West Virginia (e.g., number of program 
offerings and total number of participants). Only counties with program offering from 2008 2013 were considered for inclusion.

The U.S. Department of Agriculture, Economic Research Service's 2003 rural - urban continuum codes classified each county as either metro or nonmetro. ${ }^{83}$ This categorization of rurality, distinguishes metro counties by the population size of their Metropolitan Statistical Area and nonmetro counties by their degree of urbanization (e.g., aggregate size of their urban population) and adjacency to a metro area(s). ${ }^{84} \mathrm{~A}$ nonmetro county is adjacent if it physically adjoins one or more metro areas and has at least $2 \%$ of its employed work force commuting to a metro county ${ }^{84}$ Based on these criteria, the resulting nine-part ordinal classification scheme subdivides metro and nonmetro categories into three metro and six nonmetro groups ${ }^{84}$ Figure 3.1 identifies the location of the three metro counties (e.g., Lincoln, Ohio, Monongalia) and three nonmetro counties (e.g., Fayette, Greenbrier, Randolph) in West Virginia that were selected for this study. 
Figure 3.1: The Geographical Location of Study Specific Metropolitan and Nonmetropolitan Counties in West Virginia

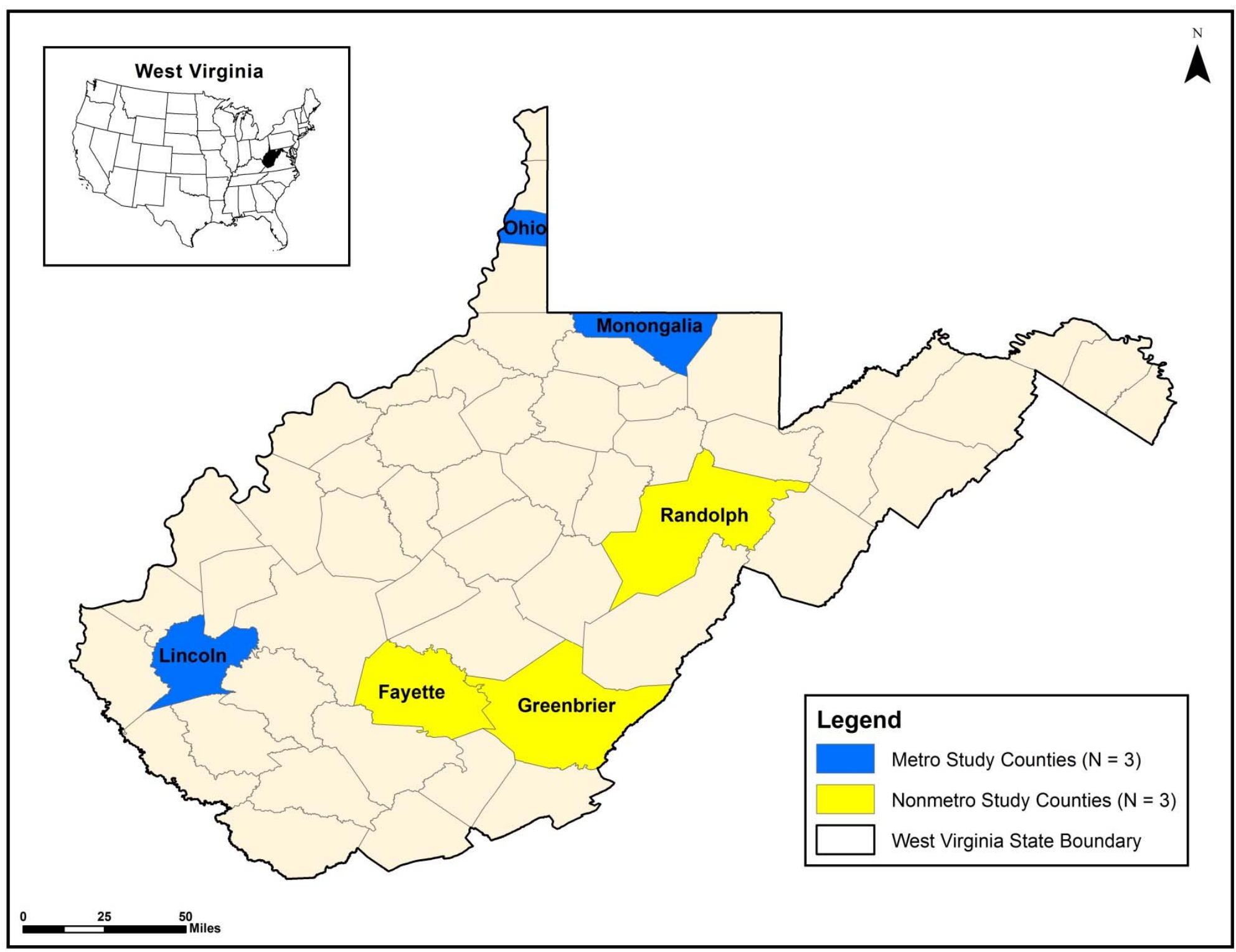




\subsubsection{Tobacco Retailer Data}

Tobacco retailers within each of the three metro and nonmetro West Virginia counties were identified using North American Industry Classification System (NAICS) codes. Developed by the Office of Management and Budget, NAICS is the standard used by Federal statistical agencies to classify the primary activity of all business establishments. ${ }^{94}$ For each of the six West Virginia counties, 2012 NAICS geocoded data was obtained from the NAICS Association's U.S. Business Directory. ${ }^{95}$ The following retail categories and corresponding NAICS codes were included: supermarkets and other grocery stores (NAICS: 445110); convenience stores (NAICS: 445120); beer, wine and liquor stores (NAICS: 445310); pharmacies and drug stores (NAICS: 446110); gasoline stations with convenience stores (NAICS: 447110); other gasoline stations (NAICS: 447190); and tobacco stores (NAICS: 453991). The final NAICS dataset included $\mathrm{N}=354$ retail outlets that potentially sold tobacco.

To ensure the comprehensiveness of the NAICS dataset, a trained field worker visited each retail outlet between August, 2013 - November, 2013 and assessed whether the outlet 1) sold tobacco; 2) was named correctly; and 3) was geocoded accurately. Retail outlets that did not sell tobacco, or were no longer in business, or were a proprietor's home address were excluded $(\mathrm{N}=155)$ from the final tobacco retailer dataset. To ensure the spatial accuracy of each tobacco retailer, during each visit, the field worker would verify the outlet's geocoded location utilizing the GIS Pro iPad application. ${ }^{96}$ Utilizing the aerial imagery in this application, the field worker would correct the location of any tobacco retailers that were inaccurately geocoded. To, correct, or orthorectify, an outlet, the field worker would move the outlet's point location to the outlet's rooftop on the aerial image, which would update the outlet's GPS coordinates (e.g., latitude and longitude) automatically. A 127 tobacco retailers were orthorectified. While field validating the 
original NAICS dataset, field workers renamed $(\mathrm{N}=54)$ outlets and identified $(\mathrm{N}=77)$ additional tobacco retailers matching the NAICS categories above that were not included in the original dataset. For each of the field identified tobacco retailers, the field worker would record the store's name, GPS coordinates (e.g., latitude and longitude), and NAICS category to add the outlet to the final tobacco retailer dataset. An additional web search provided the retailer's address and telephone number. Additionally, the field worker quantified the amount of exterior tobacco marketing (e.g., branded and non-branded signage, advertisements and functional items) for each outlet utilizing a hand counter. To ensure the reliability of this measurement, the field worker counted the total amount of exterior tobacco marketing multiple times. Once concordance was observed between two consecutive counts, the measurement was assumed reliable. The final comprehensive tobacco retailer dataset contained $(\mathrm{N}=276)$ retail outlets.

\subsubsection{School Data}

For each of the six counties, school data (e.g., school type, school name, grade levels, county, street address, and telephone number) was obtained from the West Virginia's Department of Education's School Directory website. ${ }^{97}$ Only public middle/high schools (e.g., any public school with grade levels $\geq 6$ th grade) were included in this study. Middle/high school addresses were batch geocoded using the World geocoding services in Esri's ArcGIS for Desktop Advanced version 10.2 software. ${ }^{98}$ Similarly, to ensure the spatial accuracy of the batch geocoded school addresses, each school was rooftop orthorectified using ArcGIS aerial imagery using the same process as tobacco retailers. The final school dataset contained a total of $(\mathrm{N}=33)$ public middle/high schools. 


\subsubsection{Tobacco Retailer Density}

For each county, a density surface of tobacco retailers was generated using kernel density estimation (KDE). To examine each school's access to tobacco retailers, we used a static bandwidth KDE approach. This non-parametric method extrapolates point location data over a study area by calculating the density of the points using a specified bandwidth (e.g., a circle of a given radius centered at the focal point location) and results in a smooth, continuous density surface where every location (i.e., every 30 meter pixel) in the study area has an assigned density value. ${ }^{99}$ A recent national study examining individuals' access to retail outlets provided the basis for the static bandwidth used in this KDE analysis. ${ }^{100}$ This previous study optimized the static bandwidth used in their KDE analysis by constructing various density surfaces utilizing an array of distance-based bandwidths. ${ }^{100}$ Bandwidth selection (e.g., 5-mile bandwidth) was based on the density surface that optimized the kurtosis of the density surface (e.g., not too peaked or too smoothed), given the underlying point distribution. ${ }^{100}$ However, unlike the previous study's density surface, the current KDE analysis weighted each tobacco retailer based on the amount of exterior tobacco marketing each outlet exhibited. Population weighting each outlet by the outlet's amount of exterior tobacco marketing determined the number of times to count the point (e.g., an outlet with a value of seven tobacco marketing items would be counted as seven points) in the KDE analysis. To standardize the population values used for each county's density surface, we weighted each outlet using the break values (e.g., 0, 7, 17, and 75) from the quartile distribution of exterior tobacco marketing. The spatial analyst density toolset in ArcGIS generated the weighted density surface for each county. To produce each county's weighted density surface in ArcGIS, a Gaussian kernel with an empirically validated "optimized” fixed 5mile bandwidth was used. The resulting density surfaces had a cell size of 30 meters. Overlaying 
each county's school location data, on top of the weighted density surface provides the ability to evaluate each school's access to influential tobacco retailers in the county.

\subsubsection{Bivariate K-Function}

For each county, a bivariate Ripley's K-function was used to examine the spatial association between tobacco retailers and schools under the assumption of independence. The bivariate K-function estimates the expected number of tobacco retailers within a specified distance of a school. Under the assumption of independence, the locations of tobacco retailers should be random with respect to the locations of schools, regardless of whether the schools are random, clustered, or regular. Departures from independence will result in either attraction (e.g., the location of tobacco retailers and schools tend to occur close together) or repulsion (e.g., the location of tobacco retailers and schools tend to not occur close together). Additionally, to control for edge effects we utilized a common extension of Ripley's estimator:

$$
\widehat{K}_{i j}(t)=\left(\hat{\lambda}_{i} \hat{\lambda}_{j} \mathrm{~A}\right)^{-1} \sum_{i} \sum_{j} \omega\left(i_{k}, j_{t}\right) I\left(d_{i_{k}, j_{t}}<t\right),
$$

where $\hat{\lambda}_{i}$ and $\hat{\lambda}_{j}$ are the density of two independent point patterns $i$ and $j$ across study area A; and $\omega\left(i_{k}, j_{t}\right)$ is the fraction of the circumference of a circle centered at the $k^{\prime}$ th location of process $i$ with radius $d_{i_{k}, j_{t}}$ that lies inside the study area A was used. For each county, the bivariate Ripley's K-function between the locations of tobacco retailers and schools was calculated utilizing the Spatstat package in the R statistical programming environment. ${ }^{101,102}$ Using random shift simulation, upper and lower simulation envelopes (e.g., confidence limits based on 99 simulations), we assessed the significance of the spatial association between locations of tobacco retailers and schools in each county. 


\subsection{Results}

\subsubsection{Tobacco Retailers and Schools}

Overall, there was an average of 46 tobacco retailers $(\mathrm{SD}=14.42)$ per county. Table 3.1 provides a summary of the tobacco retailers within each metro and nonmetro county. Convenience stores $(40.22 \%)$ were the most common type of tobacco retailer; followed by supermarkets/grocery stores $(24.28 \%)$ and other gasoline stations $(16.3 \%)$. Each county also observed this similar pattern. Within metro and nonmetro counties, there were $142($ Mean $=$ 47.33, $\mathrm{SD}=18.41)$ and $134(\mathrm{Mean}=44.67, \mathrm{SD}=8.58)$ tobacco retailers respectively. Overall, field inspectors observed 2,913 $($ Mean $=10.55, \mathrm{SD}=13.33)$ pieces of exterior tobacco marketing. The amount of exterior tobacco marketing ranged from zero to 75 pieces per store. Among metro and nonmetro tobacco retailers, there was 1,719 $($ Mean $=12.11, \mathrm{SD}=14.88)$ and $1,194($ Mean $=8.91, \mathrm{SD}=11.23)$ total pieces of tobacco marketing respectively. Of the schools identified in this study, 17 were middle schools and 16 were high schools. Table 3.2 provides an overview of the schools within each metro and nonmetro county. Overall, the total number of middle/high schools was almost evenly distributed $(\mathrm{N}=17$ vs. $\mathrm{N}=16)$ between metro and nonmetro counties. 
Table 3.1: Summary of Tobacco Retailers within Metro and Nonmetro West Virginia Study Counties

\begin{tabular}{|c|c|c|c|c|c|c|c|c|c|c|c|c|c|c|}
\hline \multirow[b]{3}{*}{ NAICS Description } & \multicolumn{6}{|c|}{ Metro Counties } & \multicolumn{6}{|c|}{ Nonmetro Counties } & & \\
\hline & \multicolumn{2}{|c|}{ Monongalia } & \multicolumn{2}{|c|}{ Ohio } & \multicolumn{2}{|c|}{ Lincoln } & \multicolumn{2}{|c|}{ Randolph } & \multicolumn{2}{|c|}{ Fayette } & \multicolumn{2}{|c|}{ Greenbrier } & \multicolumn{2}{|c|}{ Overall } \\
\hline & $\mathrm{N}$ & $(\%)$ & $\mathrm{N}$ & $(\%)$ & $\mathrm{N}$ & $(\%)$ & $\mathrm{N}$ & $(\%)$ & $\mathrm{N}$ & $(\%)$ & $\mathrm{N}$ & $(\%)$ & $\mathrm{N}$ & $(\%)$ \\
\hline Beer, Wine, Liquor Stores & 2 & $(2.9)$ & 4 & $(8.2)$ & 0 & $(0)$ & 0 & $(0)$ & 2 & $(3.64)$ & 1 & $(2.22)$ & 9 & $(3.26)$ \\
\hline Convenience Stores & 28 & $(40.58)$ & 12 & $(24.5)$ & 11 & $(45.83)$ & 11 & $(32.35)$ & 28 & $(50.91)$ & 21 & $(46.67)$ & 111 & $(40.22)$ \\
\hline Other Gasoline Stations & 9 & $(13.04)$ & 13 & $(26.5)$ & 1 & $(4.17)$ & 10 & $(29.41)$ & 5 & $(9.09)$ & 7 & $(15.56)$ & 45 & $(16.3)$ \\
\hline Pharmacies \& Drug Stores & 6 & $(8.7)$ & 4 & $(8.2)$ & 2 & $(8.33)$ & 3 & $(8.82)$ & 6 & $(10.91)$ & 4 & $(8.89)$ & 25 & $(9.06)$ \\
\hline Supermarkets \& Grocery Stores & 19 & $(27.54)$ & 9 & $(18.4)$ & 8 & $(33.33)$ & 8 & $(23.53)$ & 12 & $(21.82)$ & 11 & $(24.44)$ & 67 & $(24.28)$ \\
\hline Tobacco Stores & 5 & $(7.25)$ & 7 & $(14.2)$ & 2 & $(8.33)$ & 2 & $(5.88)$ & 2 & $(3.64)$ & 1 & $(2.22)$ & 19 & $(6.88)$ \\
\hline Total & 69 & $(100)$ & 49 & $(100)$ & 24 & $(100)$ & 34 & $(100)$ & 55 & $(100)$ & 45 & $(100)$ & 276 & $(100)$ \\
\hline
\end{tabular}

Table 3.2: Summary of Schools within Metro and Nonmetro West Virginia Study Counties

\begin{tabular}{|c|c|c|c|c|c|c|c|c|c|c|c|c|c|c|}
\hline \multirow[b]{3}{*}{ Schools } & \multicolumn{6}{|c|}{ Metro Counties } & \multicolumn{6}{|c|}{ Nonmetro Counties } & & \\
\hline & \multicolumn{2}{|c|}{ Monongalia } & \multicolumn{2}{|c|}{ Ohio } & \multicolumn{2}{|c|}{ Lincoln } & \multicolumn{2}{|c|}{ Randolph } & \multicolumn{2}{|c|}{ Fayette } & \multicolumn{2}{|c|}{ Greenbrier } & \multicolumn{2}{|c|}{ Overall } \\
\hline & $\mathrm{N}$ & $(\%)$ & $\mathrm{N}$ & $(\%)$ & $\mathrm{N}$ & $(\%)$ & $\mathrm{N}$ & $(\%)$ & $\mathrm{N}$ & $(\%)$ & $\mathrm{N}$ & $(\%)$ & $\mathrm{N}$ & $(\%)$ \\
\hline Middle Schools & 4 & $(57.14)$ & 4 & $(80)$ & 4 & $(80)$ & 1 & $(20)$ & 2 & $(28.57)$ & 2 & $(50)$ & 17 & $(51.52)$ \\
\hline High Schools & 3 & $(42.86)$ & 1 & $(20)$ & 1 & $(20)$ & 4 & $(80)$ & 5 & $(71.43)$ & 2 & $(50)$ & 16 & $(48.48)$ \\
\hline Total & 7 & $(100)$ & 5 & (100) & 5 & $(100)$ & 5 & $(100)$ & 7 & $(100)$ & 4 & $(100)$ & 33 & $(100)$ \\
\hline
\end{tabular}




\subsubsection{Tobacco Retailer Density}

Figure 3.2 illustrates tobacco retailer density, weighted by exterior tobacco marketing, for each county. Each county had at least one or more centralized areas where tobacco retailer density was the highest. These density hot spots can be attributed to the underlying built environment (e.g., structure) of the cities and towns found within each county (e.g., tobacco retailers tend to cluster within cities and towns). Therefore, a county's tobacco retailer density is determined by the number and size (e.g., land area and/or population density) of its cities/towns, and is independent of its metro or nonmetro status. For example, this can be observed by examining the tobacco retailer density between Monongalia (e.g., metro) and Greenbrier (e.g., nonmetro) counties. The large hot-spot of tobacco retailer density found in Monongalia county is directly related to one of West Virginia's largest cities - Morgantown, WV (2010 Population: 29,660). ${ }^{103}$ While the two small hot spots in Greenbrier county can be attributed to the city of Lewisburg, WV (2010 Population: 3,830) and the town of Rainelle, WV (2010 Population: 1,505), which are some of the smaller cities/towns in West Virginia. Additionally, this determines whether the density surface within each county will have a monocentric or polycentric urban pattern. A monocentric urban pattern is apparent in a county if it has only one predominantly, large centralized city/town. Two of the three metro counties observed this monocentric urban pattern. In Monongalia county (e.g., see description above) and Ohio county, home to Wheeling, WV (2010 Population: 28,486) have a monocentric urban pattern of tobacco retailer density because of the overall size of their cities compared to the overall size of the county. While a county with several localized similarly sized cities/towns will form a polycentric urban pattern. An example of a county taking on a polycentric urban pattern is Lincoln County. Schools also clustered within the underlying structure of the cities and towns within each county. 
Approximately 39\% of middle/high schools were located in areas where the weighted tobacco retailer density was above the mean density average for all middle/high schools. As expected though, roughly $77 \%$ of these schools were located in metro counties. Additionally, weighting tobacco retailer density by exterior tobacco marketing caused each county's density surface to shift slightly towards school locations. This illustrates that youth in these schools not only have a higher access to tobacco products, but also tobacco marketing is more frequent in these locations as well. 
Figure 3.2: Tobacco Retailer Density Weighted by Exterior Tobacco Marketing

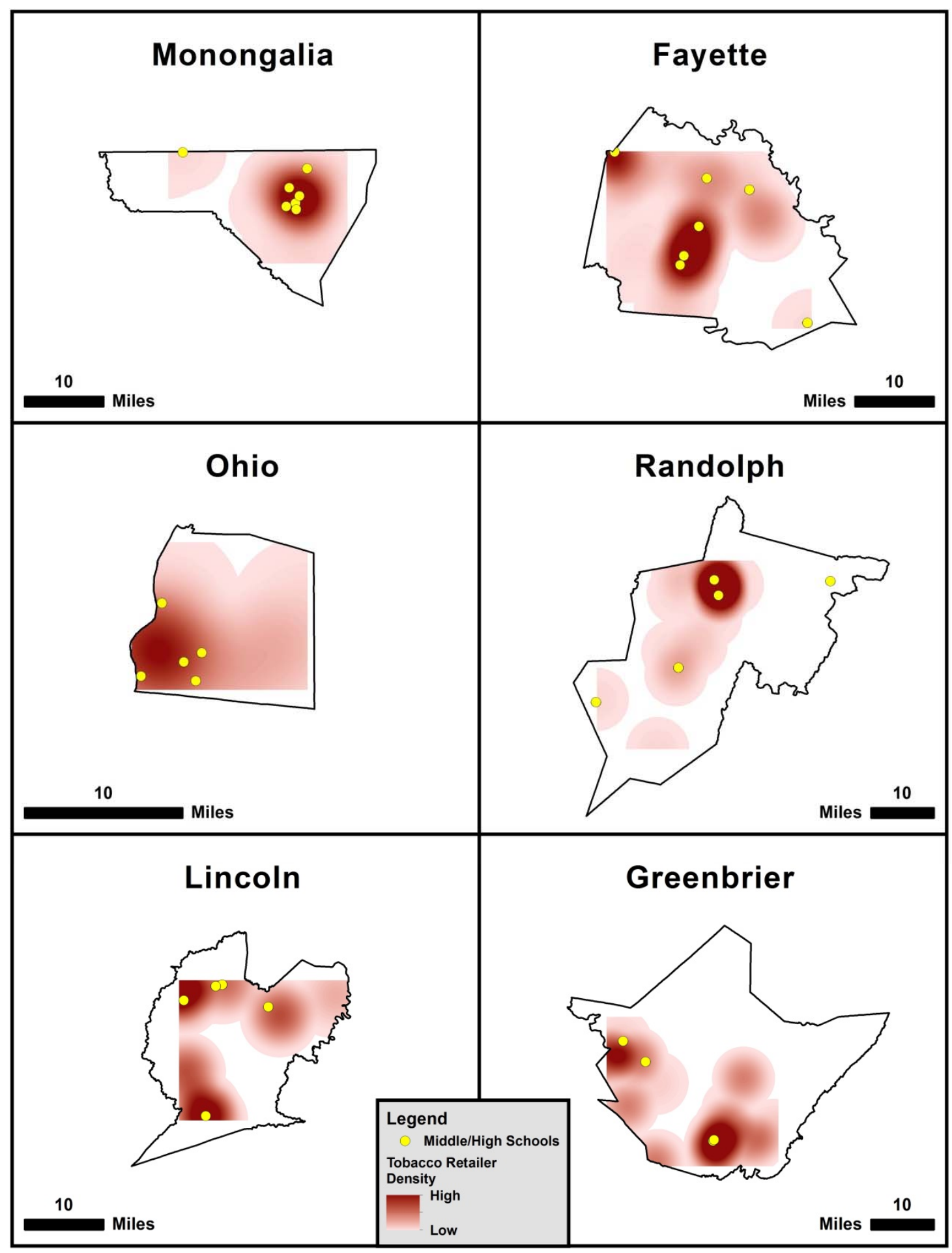




\subsubsection{Bivariate Ripley’s K-Function}

Plotting the observed bivariate Ripley's K-Function estimate over increasing distances (e.g., solid black line) against the simulated confidence envelope of the theoretical estimate (e.g., grey area) determined the spatial relationship between the locations of tobacco retailers and schools for each county. (Figure 3.3) In each county, the locations of tobacco retailers and schools exhibited a significant spatial interaction (e.g., occurred close together), because the observed bivariate Ripley's K-function estimate was greater than the simulated $99 \%$ confidence envelope of the theoretical estimate (e.g., there were more school/retailer pairs at this distance apart than would be expected under the null hypothesis of no interaction). Within each of three metro counties, the spatial interaction between tobacco retailers and schools was significant across all distances larger than $1 \mathrm{~km}$. While only one nonmetro county, Greenbrier County, observed a significant spatial interaction between tobacco retailers and schools across all distances larger than $1 \mathrm{~km}$. A significant spatial interaction between tobacco retailers and schools was seen in both Fayette and Randolph counties, however the spatial interaction was only observed over the distances between $1 \mathrm{~km}-10 \mathrm{~km}$ and $1 \mathrm{~km}-13 \mathrm{~km}$ respectively. To assess the distance at which the spatial interaction reached significance in each county, we zoomed in on each of the plots. (Figure 3.4) In metro counties (e.g., Monongalia, Ohio, and Lincoln), the spatial interaction between tobacco retailers and schools reached significance starting at distances of $400 \mathrm{~m}, 500 \mathrm{~m}$, and $800 \mathrm{~m}$ respectively. While two of the three nonmetro counties (e.g., Fayette and Randolph) reached significance at distances (e.g., $400 \mathrm{~m}$ and $450 \mathrm{~m}$ ) comparable to metro counties, one county (e.g., Greenbrier) did not reach significance until the distance was greater than $1 \mathrm{~km}$. 
Figure 3.3: Bivariate Ripley's K-Function Plots of the Spatial Relationship between Tobacco Retailers and Schools
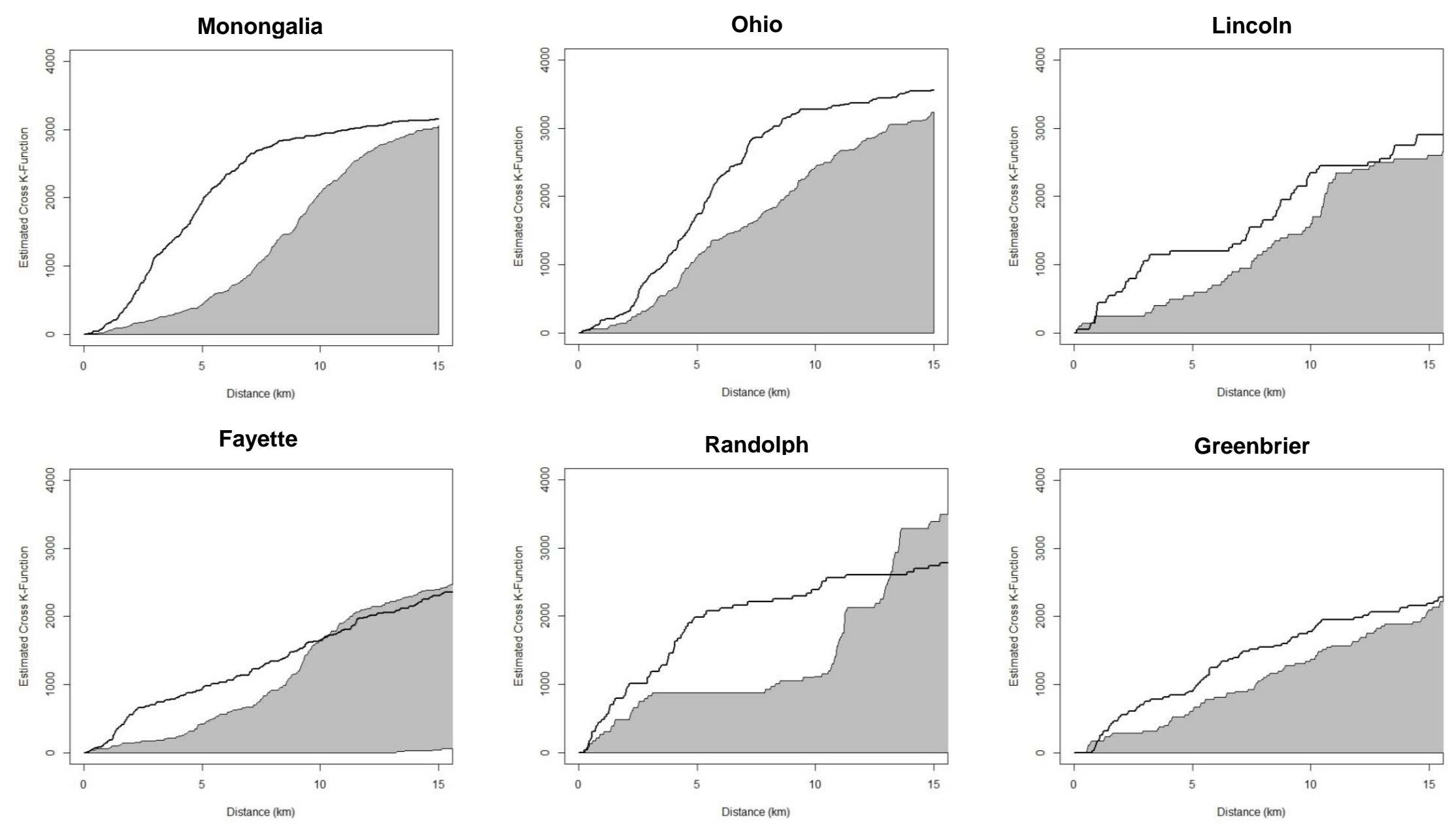

Note: Each of the Ripley's bivariate K-function plots (Above) indicates that a significant spatial interaction exists between the locations of tobacco retailers and middle/high schools, because the observed Bivariate K-function estimate (Dark Solid Line) rises above the simulated 99\% confidence envelope (Grey Shaded Area) in each plot. Each county observed a significant spatial interaction at a distance of approximately $1 \mathrm{~km}$. Only Fayette and Randolph counties did not maintain a significant spatial interaction across all distances. 


\section{Figure 3.4: High Resolution View of the Bivariate Ripley’s K-Function Plots}
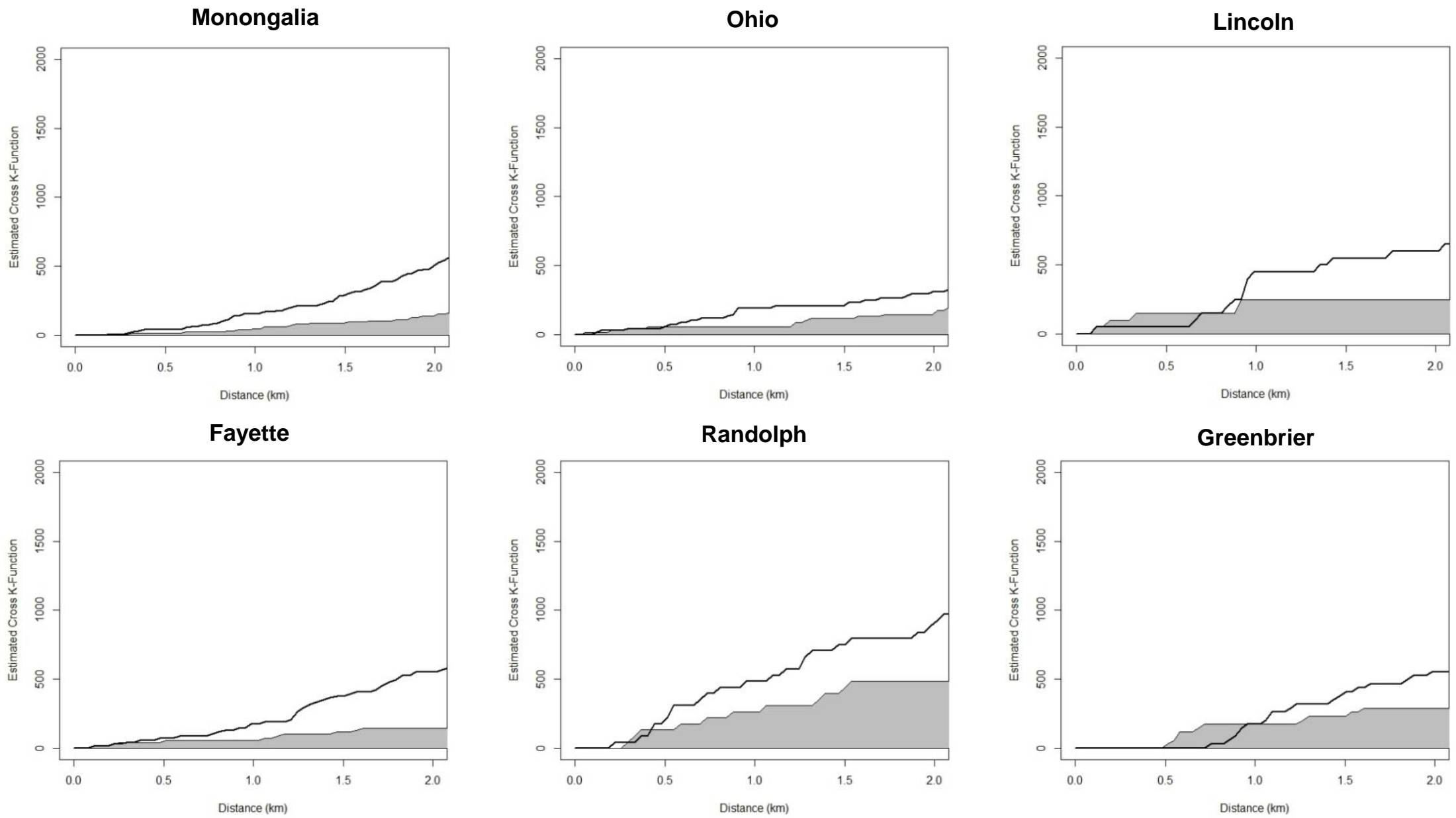

Note: The bivariate Ripley's K-function plots (Above) is a rescaled view of the Ripley's K-function plots seen in Figure 3. These plots assess the distance at which the spatial interaction between the locations of tobacco retailers and middle/high schools first reaches significance. This is the distance when the observed bivariate Ripley's K-function estimate (Dark Solid Line) first rises above the simulated 99\% confidence envelope (Grey Shaded Area). Monongalia, Ohio, and Lincoln counties (e.g., metro counties) reached significance at a distance of approximately $400 \mathrm{~m}, 500 \mathrm{~m}$, and $800 \mathrm{~m}$, respectively. While nonmetro counties (e.g., Fayette, Randolph, and Greenbrier) first reached significance at a distance of approximately $400 \mathrm{~m}, 450 \mathrm{~m}$, and $1.1 \mathrm{~km}$, respectively. 


\subsection{Conclusions}

While previous studies have assessed tobacco retailer density around schools, ${ }^{43,64,71}$ the density approach used in these studies (e.g., counting the number of tobacco retailers within an arbitrary boundary around each school) does not measure the overall access of tobacco retailers across the study area. The current study utilizes a novel approach (e.g., weighted KDE) to assess a youths' access to tobacco from schools. ${ }^{99}$ The resulting tobacco retailer density in each county did align with findings from a national report on the PoS of tobacco. ${ }^{104}$ The report concluded that tobacco retailer density is highly correlated with population density and tobacco retailers are frequently clustered together based on the built environment, ${ }^{104}$ which provides the rationale of the tobacco retailer density hot spots seen in each county.

The current study also identified the overall spatial relationship between the locations of tobacco retailers and schools. A significant spatial interaction between the tobacco retailers and schools was observed in each county. The findings from this spatial interaction can guide future to tobacco control policies, such as banning PoS advertising near schools. Currently, tobacco control experts call for implementing a 1,000-foot ban of PoS advertising around schools. ${ }^{105}$ However, this chosen distance-based ban is spatially arbitrary given the locations of tobacco retailers around schools. The authors' point out that a 1,000-foot ban on PoS advertising in New York City and St. Louis would affect $51 \%$ and $22 \%$ of tobacco retailers, respectively, but a 350foot ban would have nearly a nonexistent affect in some parts of the country. ${ }^{105}$ Therefore, this distance-based ban is subjective and dependent upon the built environment in which the ban is being proposed. Based on this study's findings, tobacco control experts can derive an empirically based distance to use in implementing PoS advertising bans, which would utilize the distance at which the significant spatial interaction between tobacco retailers and schools was observed. For 
instance, a PoS advertising ban around schools in Monongalia County would be based on the distance (e.g., $400 \mathrm{~m}$ or $\sim 1,300$ feet) when the spatial interaction between tobacco retailers and school reached significance. Additionally, this approach provides the ability to tailor PoS advertising bans depending on whether the ban is being proposed for a city, county, or state; because the distance at which the spatial interaction reaches significance is determined by the locations of tobacco retailers and schools within the city, county, or state.

There are some strengths and limitations to these findings. The major limitation of this study is its cross-sectional design. While the descriptive nature of the tobacco retailer density in each county provides insight into the access of tobacco around each school, inferences cannot ascertain whether smoking is more prevalent in the most heavily impacted schools. Additionally, we did not include all possible tobacco retailers due to the categorization of NAICS data to identify retailers that sold tobacco. For example, some department and discount department stores (e.g., Wal-Mart, Costco, Family Dollar, and Dollar Tree) may be tobacco retailers. However, the strength of field-validating identified retailers to determine whether the retailer sold tobacco increased the reliability of the tobacco retailer dataset. Adding missing retailers matching the selected NAICS descriptions that sold tobacco ensured the comprehensiveness of the tobacco retailer dataset. In addition, ortho-rectifying the location of tobacco retailers and schools enhanced the overall spatial accuracy of both datasets. Lastly, we did not account for the underlying population density within each county, which could confound the spatial relationship between the locations of schools and tobacco retailers, because tobacco retailers and schools tend to be located with densely populated areas.

Overall, this is the first study to examine the spatial relationship that exists between locations of tobacco retailers and schools. The current study advances the literature on density 
approaches by weighting each tobacco retailer by its tobacco marketing, which visualized a schools' access to 'influential" tobacco retailers. To our knowledge, no other study has examined tobacco retailer density by weighting for tobacco marketing in its estimates. Each county's density surface took on an urban pattern (e.g., either monocentric or polycentric) that was reflective of the county's underlying built environment structure and this pattern was independent of the county's metro/nonmetro status. In concluding, since a significant spatial interaction exists between tobacco retailers and schools independent of their metro/nonmetro status, findings from this study can guide future policy work regarding zoning ordinances around schools within cities. Where the distance at which a significant spatial interaction was observed between tobacco retailers and schools would be used as a recommendation into the distance future tobacco retailers should be restricted around schools. 


\section{Chapter 4}




\section{Chapter 4}

\subsection{Introduction}

The 1998 Master Settlement Agreement aimed to prevent youth smoking by restricting tobacco sponsorships and promotional activities, banning tobacco billboards, and the use of cartoons in all advertising, while advertising provisions included limiting the size of exterior

signs to no more than 14 square feet. ${ }^{29}$ Since these restrictions, tobacco companies have become more dependent on the retail environment to market their products. ${ }^{30,31}$ For example, the prevalence of interior and exterior tobacco advertising has increased significantly in tobacco retailers since the Master Settlement Agreement. ${ }^{32,33}$ The prevalence of cigarette promotions (e.g., multipack promotions, gift-with-purchase promotions, and cents-off promotions) and functional objects has also increased significantly in tobacco retailers. ${ }^{33}$

In 2001, Feighery and colleagues found that the average number of tobacco advertisements varies among different types of tobacco retailers. ${ }^{34}$ They found that liquor stores tend to have the greatest number of tobacco advertisements followed by small stores (e.g., small drug stores and markets) and convenience stores (e.g., including those that sold gasoline). ${ }^{34}$ Other studies have found that retail outlets popular among youth, display three times the amount of exterior and interior tobacco marketing and reserve twice as much shelf space for Marlboro, Camel and Newport brand cigarettes, which are the brands that account for more than $80 \%$ of the cigarettes bought by youth. ${ }^{35,36}$ Taken together with estimates that $75 \%$ of youth shop at a convenience store at least once a week and on average shop twice as long as adults, ${ }^{37,38}$ available data make it clear that youth and young adults experience disproportionate exposures to tobacco products and marketing. 
In 2011 , the tobacco industry spent $\$ 8.37$ billion on tobacco marketing nationwide. ${ }^{39}$ These expenditures pay for traditional retail tobacco advertising (e.g., exterior/interior signage/advertisements and branded/non-branded functional items), price discount for consumers (e.g., "Buy two, get one free"), and retail promotional allowances (e.g., shelving and incentive payments to retailers for displaying cigarettes in prime locations, especially around the counter). ${ }^{39,40}$ The vast majority $(83.6 \%)$ of these expenditures are price discounts paid to tobacco retailers to reduce the cost for consumers. ${ }^{39}$

The most common and influential form of tobacco marketing found within the retail environment is considered PoS tobacco marketing. By definition, PoS tobacco marketing is advertising created around "impulse purchasing" and designed to capture the consumer's attention, especially at the place of payment usually a checkout counter. Approximately, $83 \%$ of the cigarette advertisements found in the retail environment are considered PoS tobacco marketing. ${ }^{34}$ PoS tobacco advertising and promotions is a sophisticated marketing strategy, which has emerged as the primary marketing approach to target youth. ${ }^{42,43}$ PoS tobacco marketing is thought to influence youth both cognitively and affectively by promoting the perceived benefits and positive attitudes of tobacco use related to, key concerns of youth, such as social approval, peer bonding, autonomy, self-image, and adventure seeking. ${ }^{44}$

A recent (2011) Cochrane Review concluded that exposure to PoS tobacco marketing is associated with the likelihood that youth will initiate cigarette smoking. ${ }^{44}$ Experimental studies have suggested that exposure to retail marketing distorts youths' perceptions about the availability, use, and popularity of tobacco and these normative beliefs are precursors of smoking. ${ }^{45-49}$ Several empirical studies have linked retail tobacco marketing to youth smoking susceptibility. ${ }^{50-52}$ Youths who are exposed to weekly retail tobacco marketing are more likely to 
experiment with smoking, ${ }^{53,54}$ and those who visit stores with tobacco advertising at least twice a week double their odds of initiating cigarette smoking. ${ }^{55}$ After controlling for school differences and other covariates, another study found that middle school students who were exposed to retail tobacco marketing at least once a week had a 50\% increase in the likelihood of ever smoking, similar to the effects of having a parent or household member who smokes ${ }^{53} \mathrm{PoS}$ advertising is associated with youth experimentation and progression to regular smoking, with current youth smokers being the most influenced by promotional offers. ${ }^{56}$

Research and advocacy groups have worked to understand the potential benefits of controlling the number of tobacco retailers (e.g., tobacco retailer density) and its distance from youth spaces such as schools (e.g., proximity of tobacco retailers), with only limited success. ${ }^{35,63-}$ ${ }^{68}$ Importantly, Food and Drug Administration (FDA) rules prohibiting exterior tobacco advertising within 1,000 feet of schools and playgrounds was not included in the passage of the 2009 Tobacco Control Act, ${ }^{69}$ and was instead issued as part of an Advanced Notice of Proposed Rulemaking that has not yet been acted upon. ${ }^{70}$ The idea is that these approaches reduce exposure to tobacco marketing, as well as availability of products, and thus restricts youth access to tobacco products via commercial sources. This is supported by data showing that the density of tobacco retailers within an individual's environment greatly influences tobacco availability and thus youth uptake. ${ }^{58,68}$ For example, Novak et al., (2006) found that the density of neighborhood tobacco retailers increases the odds of youth smoking by $20 \%$ even after controlling for neighborhood-level demographics or by propensity score strata ${ }^{67}$ Overall, available evidence suggests that higher tobacco retailer density provides greater physical access to tobacco products because 1) it increases access by reducing travel distances and related search costs that consumers face, reducing their overall net cost associated with purchasing tobacco and 
2) the overall price of tobacco products decreases in the presence of competition among retailers. ${ }^{58}$ This is magnified by the fact that neighborhoods with a higher concentration of tobacco retailers also tend to have a higher proportion of youth. ${ }^{67}$

Future research examining the links between the availability of retail tobacco and youth smoking must begin to distinguish between the effects of 1) tobacco retailer density across the study area and 2) the immediate proximity of tobacco retailers to youth. Few studies have systematically contrasted the inter-relationships between tobacco retailer density versus proximity to schools and thus youth smoking behaviors. Henriksen and colleagues, (2008) found that high schools in neighborhoods with the highest density of tobacco retailers ( $>5$ retailers) had an adjusted average current smoking prevalence 3.2\% higher than schools in neighborhoods with lower densities. ${ }^{71}$ However, the distance from school to the nearest tobacco retailer was not associated with current smoking. ${ }^{71}$ Another study found that adolescent smokers in high schools with the greatest number of surrounding tobacco retailers were more likely to buy their own cigarettes than have someone else purchase them. ${ }^{64} \mathrm{~A}$ follow up study by Chan and Leatherdale, (2011) found that the number of tobacco retailers within a 1-km radius of youths' schools was associated with non-smokers being more susceptible to future smoking. ${ }^{63}$ While a study among high school students by McCarthy et al., (2009) found a small relationship between tobacco retailer density within 1-mile surrounding schools and adolescent reported smoking initiation. ${ }^{66}$ However, the authors did not find an association between tobacco retailer density and established/current smoking. ${ }^{66}$ Moreover, a recent study by Lipperman-Kreda et al., (2014) did not find an association between the distance from school to the nearest tobacco retailer and current smoking. ${ }^{65}$ Additionally, the authors also observed no association between tobacco 
retailer density calculated by either a 0.75 -mile or 1-mile radius buffers around schools and current smoking. ${ }^{65}$

Most research to date is school-centric, in that it focuses on the proximity of only one tobacco retailer per school and/or tobacco retailer density within some arbitrary distance around a school. Thus, this approach effectively ignores all outlets that do not happen to fall within the specified school boundaries, failing to capture youth access as it occurs across the whole retail tobacco environment. An alternative approach is to use tobacco retailers themselves as the unit of analysis, including both their proximity to schools and the range of other factors that vary between outlets. For example, a study conducted by our group found that each 100 meter decrease in proximity to high schools among tobacco retailers within predominate AfricanAmerican census block groups was associated with an increase in the likelihood of a youth tobacco sales violation. ${ }^{72}$ This is consistent with other data confirming that even though youth spend a majority of their time in or around schools, their homes and neighborhoods are also key environments for understanding youth tobacco use. ${ }^{73,74}$ Therefore, to understand how the retail tobacco environment affects youth smoking behaviors, it may be that research must focus on retail tobacco availability (e.g., density and/or proximity to) across the whole study area and not within defined arbitrary boundaries around specific youth spaces.

The primary purpose of this study is to understand the relationship between tobacco retailer density and tobacco retailers' proximity to a public middle/high school among every tobacco outlet located within six counties of West Virginia. These counties are characterized by divergent levels of rurality, defined as either metropolitan (e.g., metro) or nonmetropolitan (e.g., nonmetro). The secondary aim of this study is to examine how tobacco retailer characteristics (e.g., metro/nonmetro status, store type, amount of exterior tobacco marketing, and cigarette 
pack price) vary across levels of tobacco retailer density and proximity. A Kernel Density Estimation (KDE) approach assessed the accessibility of tobacco retailers within each county. This approach estimates the tobacco retailer density within the given radius for every grid cell (e.g., 30 meter) in the resulting density surface, which covers the extent of every tobacco retailer within each county. Street network-based distance from each tobacco retailer to the nearest public middle/high school determined the access (e.g., proximity) for each tobacco retailer in each county. Our main hypothesis is that tobacco retailer density will be positively associated with a tobacco retailer's proximity to a public middle/high school, independent of the county's metro/nonmetro status. While we additionally hypothesize that tobacco retailer characteristics will differ by levels of tobacco retailer density and proximity within metro and nonmetro counties of West Virginia. To our knowledge, this is the first study to examine the relationship between tobacco retailer density and proximity to public middle/high schools utilizing a retailercentric approach. Additionally, this study provides the ability to examine this relationship among metro and nonmetro tobacco retailers. While also being able to examine how specific store characteristics differ by levels of density and proximity.

\subsection{Methods}

\subsubsection{Metro and Nonmetro West Virginia Counties}

Three metro and three nonmetro counties were systematically selected from all counties $(\mathrm{N}=55)$ in West Virginia based on criteria for a future study. We selected metro and nonmetro counties based on: 1) metro/nonmetro status and 2) program evaluation data from a youth smoking cessation program disseminated in West Virginia (e.g., number of program offerings 
and total number of participants). Only counties with program offering from 2008 - 2013 were considered for inclusion.

The U.S. Department of Agriculture, Economic Research Service's 2003 rural-urban continuum codes classified each county as either metro or nonmetro. ${ }^{83}$ This categorization of rurality, distinguishes metro counties by the population size of their Metropolitan Statistical Area and nonmetro counties by their degree of urbanization (e.g., aggregate size of their urban population) and adjacency to a metro area(s). ${ }^{84} \mathrm{~A}$ metro county is adjacent if it physically adjoins one or more metro areas and has at least $2 \%$ of its employed work force commuting to a metro county. ${ }^{84}$ Based on these criteria, the resulting nine-part ordinal classification scheme subdivides metro and nonmetro categories into three metro and six nonmetro groups ${ }^{84}$ Figure 4.1 identifies the location of the three metro counties (e.g., Lincoln, Ohio, Monongalia) and three nonmetro counties (e.g., Fayette, Greenbrier, Randolph) in West Virginia that were selected for this study. 
Figure 4.1: The Geographical Location of Study Specific Metropolitan and Nonmetropolitan Counties in West Virginia

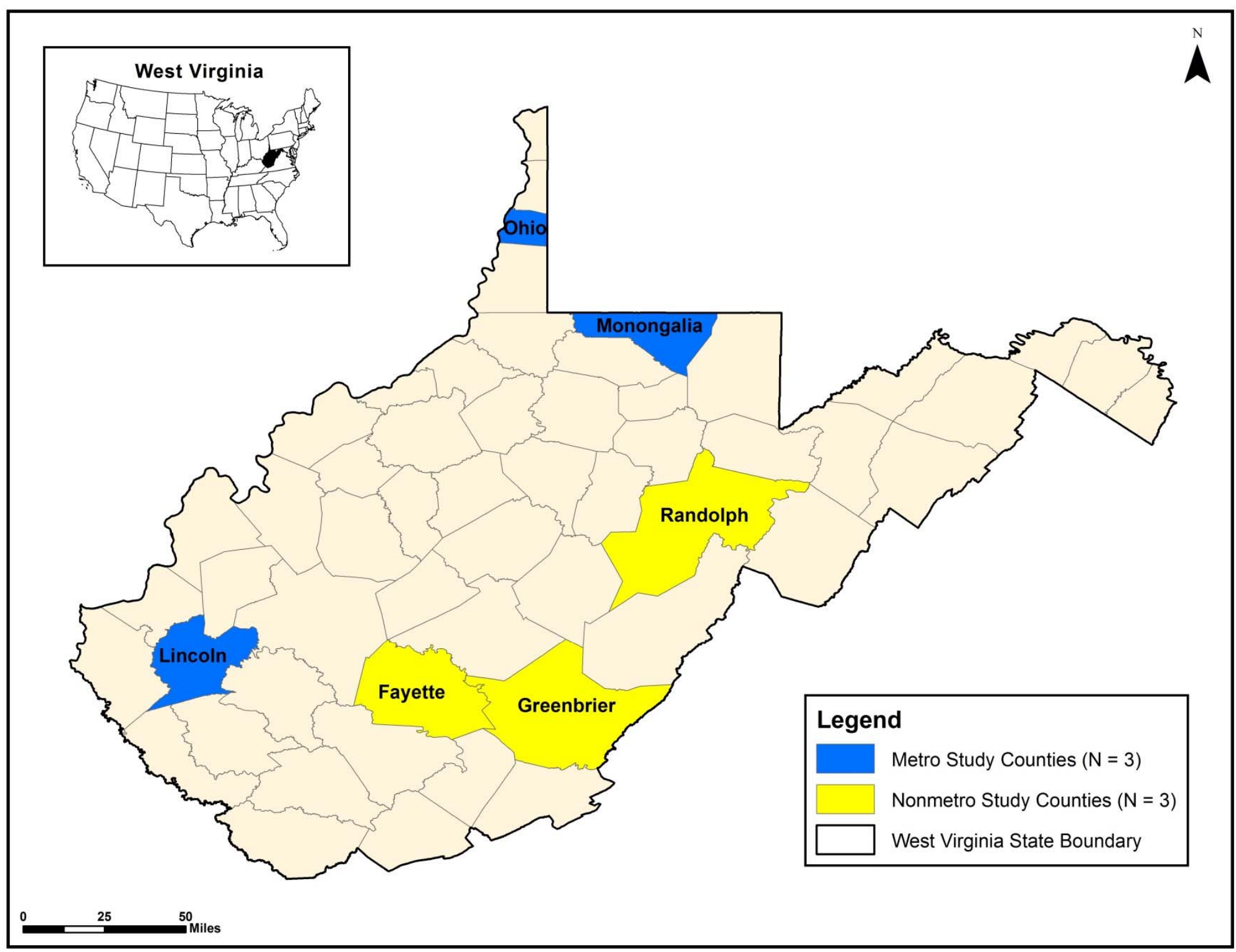




\subsubsection{Tobacco Retailer Data}

Tobacco retailers within each of the three metro and nonmetro West Virginia counties were identified using North American Industry Classification System (NAICS) codes. Developed by the Office of Management and Budget, NAICS is the standard used by Federal statistical agencies to classify the primary activity of all business establishments. ${ }^{94}$ For each of the six West Virginia counties, 2012 NAICS geocoded data was obtained from the NAICS Association's U.S. Business Directory. ${ }^{95}$ The following retail categories and corresponding NAICS codes were included: supermarkets and other grocery stores (NAICS: 445110); convenience stores (NAICS: 445120); beer, wine and liquor stores (NAICS: 445310); pharmacies and drug stores (NAICS: 446110); gasoline stations with convenience stores (NAICS: 447110); other gasoline stations (NAICS: 447190); and tobacco stores (NAICS: 453991). The final NAICS dataset included 354 retail outlets that potentially sold tobacco.

To ensure the comprehensiveness of the NAICS dataset, a trained field worker visited each retail outlet between August, 2013 - November, 2013 and assessed whether the outlet 1) sell tobacco; 2) was name correctly; and 3) was geocoded accurately. Retail outlets that did not sale tobacco, or were no longer in business, or were a proprietor's home address were excluded $(\mathrm{N}=155)$ from the final tobacco retailer dataset. To ensure the spatial accuracy of each tobacco retailer, during each visit, the field worker would verify the outlet's geocoded location utilizing the GIS Pro iPad application. ${ }^{96}$ Utilizing the aerial imagery in this application, the field worker would correct the location of any tobacco retailers that were inaccurately geocoded. To correct or “orthorectify" an outlet, the field worker would move the outlet's point location to the outlet's rooftop on the aerial image, which would update the outlet's GPS coordinates (e.g., latitude and longitude) automatically. Field workers orthorectified $(\mathrm{N}=127)$ tobacco retailers. While field 
validating the original NAICS dataset, field workers renamed 54 outlets and identified 77 additional tobacco retailers matching the NAICS categories above that were not included in the original dataset. For each of the field identified tobacco retailers, the field worker would record the store's name, GPS coordinates (e.g., latitude and longitude), and NAICS category to add the outlet to the final tobacco retailer dataset. An additional web search provided the retailer's address and telephone number. The final comprehensive tobacco retailer dataset contained 276 retail outlets.

Each field worker also collected additional tobacco marketing measures within each tobacco retailer. Field workers quantified the amount of exterior tobacco marketing (e.g., branded and non-branded signage, advertisements and functional items) for each outlet utilizing a hand counter. To ensure the reliability of this measurement, the field worker counted the total amount of exterior tobacco marketing multiple times. Once concordance was observed between two consecutive counts, the measurement was assumed reliable. Lastly, the field worker recorded the lowest observed pack price for regular- and menthol-flavored cigarettes within each tobacco retailer.

\subsubsection{School Data}

For each of the six counties, school data (e.g., school type, school name, grade levels, county, street address, and telephone number) was obtained from the West Virginia's Department of Education's School Directory website. ${ }^{97}$ Only public middle/high schools (e.g., any public school with grade levels $\geq 6$ th grade) were included in this study. Middle/high school addresses were batch geocoded using the World geocoding services in Esri's ArcGIS for Desktop Advanced version 10.2 software. ${ }^{98}$ Similarly, to ensure the spatial accuracy of the batch 
geocoded school addresses, each school was rooftop orthorectified using ArcGIS aerial imagery using the same process as tobacco retailers. The final school dataset contained 33 public middle/high schools.

\subsubsection{Tobacco Retailer Density}

For each county, a density surface of tobacco retailers was generated using kernel density estimation (KDE). To examine the availability of tobacco retailers (e.g., retail tobacco access) across each county, we used a static bandwidth KDE approach. This non-parametric method extrapolates point location data over a study area by calculating the density of the points using a specified bandwidth (e.g., a circle of a given radius centered at the focal point location) and results in a smooth, continuous density surface where every location (i.e., every 30 meter pixel) in the study area has an assigned density value. ${ }^{99} \mathrm{~A}$ recent national study examining individuals' access to retail outlets provided the basis for the static bandwidth used in this KDE analysis. ${ }^{100}$ This previous study optimized the static bandwidth used in their KDE analysis by constructing various density surfaces utilizing an array of distance-based bandwidths. ${ }^{100}$ Bandwidth selection (e.g., 5-mile bandwidth) was based on the density surface that optimized the kurtosis of the density surface (e.g., not too peaked or too smoothed), given the underlying point distribution of tobacco retailers. ${ }^{100}$ The spatial analyst density toolset in ArcGIS generated the density surface of tobacco retailers within each county. To produce the density surface of tobacco retailers within each county in ArcGIS, a Gaussian kernel with an empirically validated "optimized" fixed 5mile bandwidth was used. The resulting density surfaces had a cell size of 30 meters. The density value for the location of each outlet was determined from the density surface of tobacco retailers using the spatial analyst extraction toolset in ArcGIS. 


\subsubsection{Tobacco Retailer Proximity to Public Middle/High Schools}

Esri's street network data linked the location of every tobacco retailer and public middle/high school in each county, allowing us to calculate proximity based on the "network route" extending from each tobacco retailer to the nearest public middle/high school. Because proximity was based on the existing street network, each network route defines the area through which a youth would gain walkable access to each outlet. Each outlet's proximity was calculated to the nearest public middle/high school in miles utilizing a closest facility analysis in the network analysts extension of ArcGIS. To properly measure the walking distance from each outlet to the nearest public middle/high school, all street network restrictions were removed (e.g., one-way streets and non-routable roads).

\subsubsection{Statistical Analyses}

Summary statistics were conducted on all study variables, such as: metro status, county, store type, lowest pack price, lowest menthol pack price, total exterior tobacco marketing, tobacco retailer density, and proximity to nearest school. Due to positive skewness, the distributions of the density of tobacco retailers and proximity to nearest school required transformations. Transforming each variable into an ordinal, four-level factor; normalized the distribution for each variable. Among the overall sample and within metro and nonmetro subsamples, Chi-square tests and sieve diagrams evaluated the independence between the observed levels of tobacco retailer density and proximity. Three-way fixed-effect ANOVA models and interaction plots assessed the effects and interactions of proximity - density groups, metro status, and store type on various tobacco retailer characteristics (e.g., exterior tobacco 
marketing, non-menthol pack price, and menthol pack price). Multiple comparisons tests utilizing Tukey's Honest Significant Difference assessed any significant group differences.

\subsection{Results}

\subsubsection{Tobacco Retailer Characteristics}

Overall, there was an average of 46 tobacco retailers $(\mathrm{SD}=14.42)$ per county. Table 4.1 provides a summary of the tobacco retailers within each metro and nonmetro county. Convenience stores (40.22\%) were the most common type of tobacco retailer; followed by supermarkets/grocery stores (24.28\%) and other gasoline stations (16.3\%). Each county also observed this similar pattern. Within metro and nonmetro counties, there were $142($ Mean $=$ $47.33, \mathrm{SD}=18.41)$ and $134($ Mean $=44.67, \mathrm{SD}=8.58)$ tobacco retailers respectively. Among tobacco retailers, the average proximity to the nearest school was approximately 3 miles. On average, metro tobacco retailers were located closer to a school $($ Mean $=2.51, \mathrm{SD}=3.51)$ than nonmetro tobacco retailers $($ Mean $=3.51, \mathrm{SD}=2.57$ ). Each tobacco retailer had an average outlet density of 0.57 retailers per square mile. Among counties, the average density of tobacco retailers ranged from 0.16 retailers per square mile in Lincoln County to 1.04 retailers per square mile in Monongalia County. Metro and nonmetro tobacco retailers had an average density of 0.79 and 0.33 retailers per square mile respectively. Overall, field inspectors observed 2,913 $($ Mean $=10.55, \mathrm{SD}=13.33)$ pieces of exterior tobacco marketing. The amount of exterior tobacco marketing ranged from zero to 75 pieces per store. Among metro and nonmetro tobacco retailers, there was $1,719($ Mean $=12.11, \mathrm{SD}=14.88)$ and $1,194(\mathrm{Mean}=8.91, \mathrm{SD}=11.23)$ total pieces of tobacco marketing respectively. The average lowest pack price for non-menthol (Mean $=\$ 3.29, \mathrm{SD}=\$ 0.29)$ and menthol $($ Mean $=\$ 3.30, \mathrm{SD}=\$ 0.30)$ flavored cigarettes were almost 
identical. The average difference in price between metro (Mean $=\$ 3.26, \mathrm{SD}=\$ 0.30)$ and nonmetro $($ Mean $=\$ 3.31, \mathrm{SD}=\$ 0.27)$ tobacco retailers for a pack of non-menthol cigarettes was $\$ 0.05$. While a $\$ 0.06$, difference existed between metro $($ Mean $=\$ 3.27, \mathrm{SD}=\$ 0.31)$ and nonmetro $($ Mean $=\$ 3.33, \mathrm{SD}=\$ 0.28)$ tobacco retailers for a pack of menthol flavored cigarettes. Because of the similarities in the pack price of non-menthol and menthol flavored cigarettes, our results only focus on the pack price for non-menthol flavored cigarettes. 


\section{Table 4.1: Summary of Tobacco Retailers within Metro and Nonmetro West Virginia Study Counties}

\begin{tabular}{|c|c|c|c|c|c|c|c|c|c|c|c|c|c|c|}
\hline \multirow[b]{3}{*}{ NAICS Description } & \multicolumn{6}{|c|}{ Metro Counties } & \multicolumn{6}{|c|}{ Nonmetro Counties } & & \\
\hline & \multicolumn{2}{|c|}{ Monongalia } & \multicolumn{2}{|c|}{ Ohio } & \multicolumn{2}{|c|}{ Lincoln } & \multicolumn{2}{|c|}{ Randolph } & \multicolumn{2}{|c|}{ Fayette } & \multicolumn{2}{|c|}{ Greenbrier } & \multicolumn{2}{|c|}{ Overall } \\
\hline & $\mathrm{N}$ & $(\%)$ & $\mathrm{N}$ & $(\%)$ & $\mathrm{N}$ & $(\%)$ & $\mathrm{N}$ & $(\%)$ & $\mathrm{N}$ & $(\%)$ & $\mathrm{N}$ & $(\%)$ & $\mathrm{N}$ & $(\%)$ \\
\hline Beer, Wine, Liquor Stores & 2 & $(2.9)$ & 4 & $(8.2)$ & 0 & $(0)$ & 0 & $(0)$ & 2 & (3.64) & 1 & $(2.22)$ & 9 & $(3.26)$ \\
\hline Convenience Stores & 28 & $(40.58)$ & 12 & $(24.5)$ & 11 & $(45.83)$ & 11 & $(32.35)$ & 28 & $(50.91)$ & 21 & $(46.67)$ & 111 & $(40.22)$ \\
\hline Other Gasoline Stations & 9 & $(13.04)$ & 13 & $(26.5)$ & 1 & $(4.17)$ & 10 & $(29.41)$ & 5 & $(9.09)$ & 7 & $(15.56)$ & 45 & $(16.3)$ \\
\hline Pharmacies \& Drug Stores & 6 & $(8.7)$ & 4 & $(8.2)$ & 2 & $(8.33)$ & 3 & $(8.82)$ & 6 & $(10.91)$ & 4 & $(8.89)$ & 25 & $(9.06)$ \\
\hline Supermarkets \& Grocery Stores & 19 & $(27.54)$ & 9 & $(18.4)$ & 8 & $(33.33)$ & 8 & $(23.53)$ & 12 & $(21.82)$ & 11 & $(24.44)$ & 67 & $(24.28)$ \\
\hline Tobacco Stores & 5 & $(7.25)$ & 7 & $(14.2)$ & 2 & $(8.33)$ & 2 & $(5.88)$ & 2 & $(3.64)$ & 1 & $(2.22)$ & 19 & $(6.88)$ \\
\hline Total & 69 & $(100)$ & 49 & $(100)$ & 24 & $(100)$ & 34 & $(100)$ & 55 & $(100)$ & 45 & $(100)$ & 276 & $(100)$ \\
\hline
\end{tabular}




\subsubsection{Tobacco Retailer Density and Proximity}

A Chi-square test of independence was performed to examine the relationship between levels of tobacco retailer proximity to school groups (e.g., Less than or equal to 1-mile; $1-2$ miles; 2-5 miles; Greater than 5 miles) and quintile levels of tobacco retailer density. The relationship between these variables was significant, Chi-square $=116.54, \mathrm{p}$-value $<0.001 . \mathrm{A}$ sieve diagram explored the frequencies and pattern of association between the proximity and density classes. (Figure 4.2) The overall pattern of association supports our main hypothesis, in that as tobacco retailer's proximity to school decreases the overall tobacco retailer density increases. Over $70 \%$ of tobacco retailers $(\mathrm{N}=198)$ observed the hypothesized pattern of association. However, the pattern of association was not observed within 78 tobacco retailers. Among these tobacco retailers, $58 \%(\mathrm{~N}=45)$ had a proximity to school distance of less than 2 miles, but were located in areas were tobacco retailer density was the lowest. Additionally, $42 \%$ $(\mathrm{N}=33)$ of those 78 tobacco retailers, had a proximity to school distance of greater than 2 miles and were also located in areas tobacco retailer density was the highest. 
Figure 4.2: Frequency of Tobacco Retailers within Proximity and Density Levels

\section{Proximity and Density}

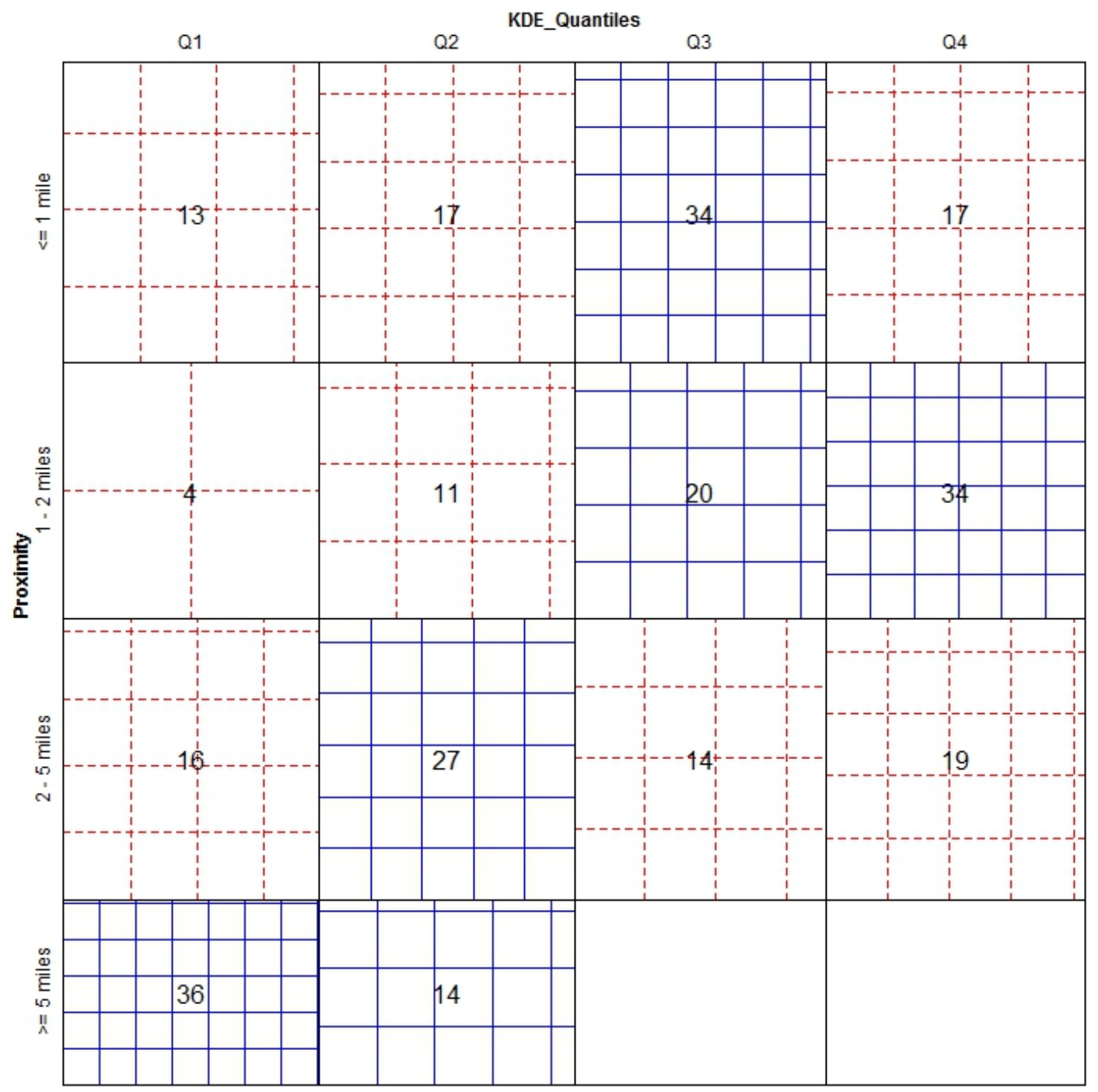

Note: The sieve diagram (Above), illustrates the pattern of association (e.g., blue-shaded cells) between the proximity and density levels among tobacco retailers. The value in each cell represents the total number of tobacco retailers within that cell. 
Based on these findings, we decided to reexamine the relationship between these proximity and density levels, but within metro and nonmetro subsamples. Due to small cell size, there was not enough data to perform Chi-square tests. However, the sieve diagram for each subsample still allows for the examination of the overall pattern of association between the proximity and density levels of metro and nonmetro tobacco retailers. (Figure 4.3) Among metro tobacco retailers, the pattern of association between the proximity and density levels does not reflect the overall pattern. Within the metro sieve plot, we see no difference between density levels as tobacco retailer's proximity to a school increases (e.g., greater than 2 miles). As expected, tobacco retailer density overall was lower among nonmetro tobacco retailers, but the overall pattern of association resembles our hypothesized pattern still.

Because of the dependent relationship that existed between the original proximity and density categories, we dichotomized proximity and density. A 1-mile network route distance determined the final proximity category for each retailer. While the final density group for each retailer was determined by, the median split of tobacco retailer density. Subsequent analyses utilize the following proximity - density groups: Close Proximity - Low Density, Close Proximity - High Density, Far Proximity - Low Density, and Far Proximity - High Density. Among tobacco retailer characteristics, the average number of exterior tobacco marketing items and the average pack price of cigarettes did not differ between proximity - density groups. 
Figure 4.3: Frequency of Metropolitan and Nonmetropolitan Tobacco Retailers within Proximity and Density Levels

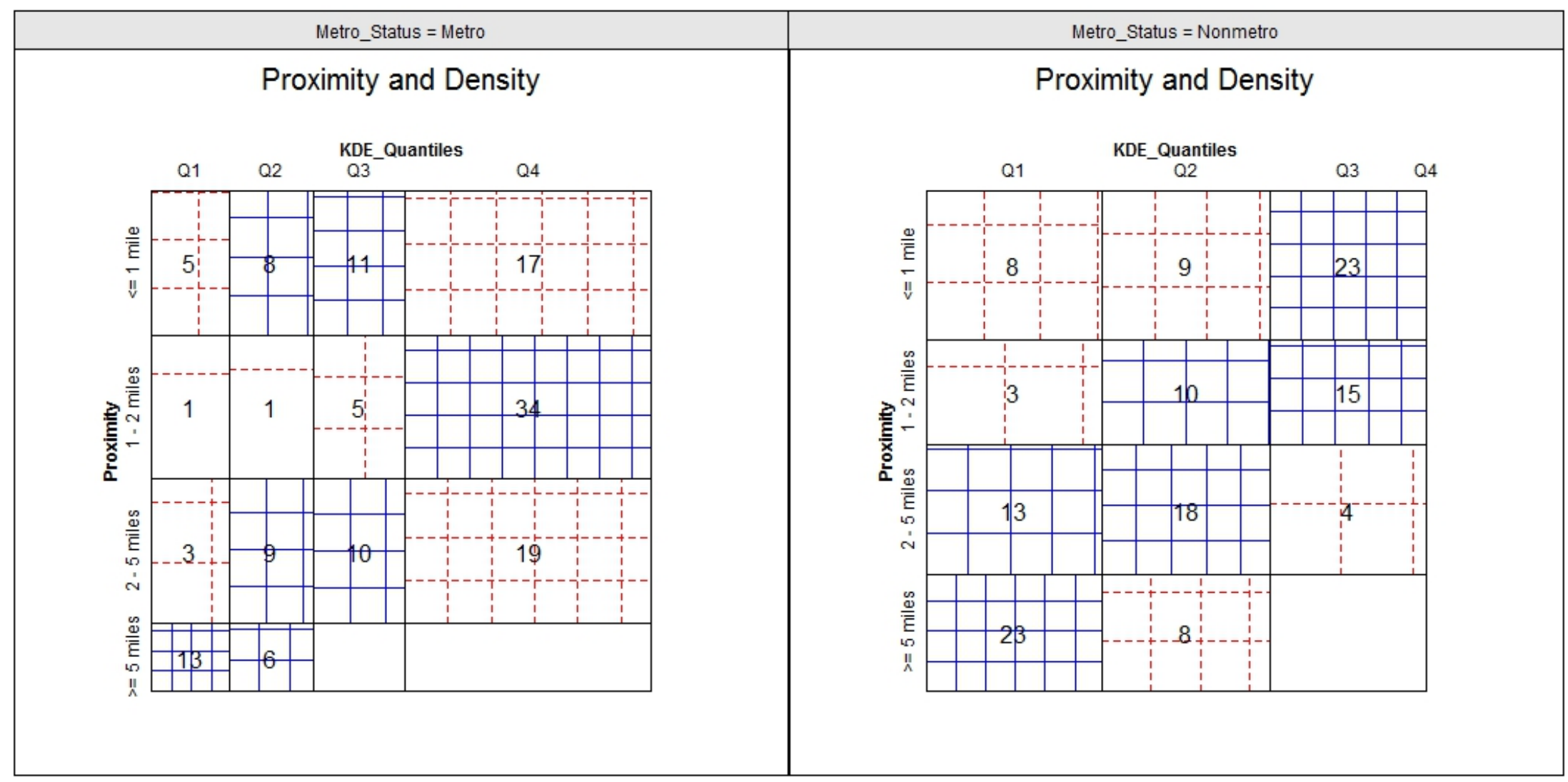

Note: The sieve diagram (Above), illustrates the pattern of association (e.g., blue-shaded cells) between the proximity and density levels among metropolitan (Left) and Nonmetropolitan (Right) tobacco retailers. The value in each cell represents the total number of tobacco retailers within that cell. If any rows or columns were empty (e.g., with no count data), it was excluded from the sieve diagram. 


\subsubsection{Tobacco Retailer Proximity - Density Groups and Store Characteristics}

Three-way fixed-effect ANOVA models and interaction plots assessed the effects and interactions of proximity - density groups, metro status, and store type on various tobacco retailer characteristics (e.g., exterior tobacco marketing, non-menthol pack price, and menthol pack price). We discuss the results for only exterior tobacco marketing and non-menthol pack price below. Additionally, for comparative purposes, we reclassified each tobacco retailer into one of three store types: 1) pharmacies, 2) tobacco stores, or 3) other stores (e.g., beer and liquor outlets, convenience stores, gas stations, and supermarkets). Table 4.2 shows the results of the three-way fixed effects ANOVA for exterior tobacco marketing. A significant two-way interaction $(F(6,254)=3.528$, p-value $<0.01)$ existed between proximity - density groups and store type. To explore this interaction we plotted the mean of exterior tobacco marketing across the two- way combinations of factors (e.g., proximity - density groups and store type). (Figure 4.4) Among all tobacco retailers, the two-way interaction plot of exterior tobacco marketing shows that tobacco stores within a close proximity to a school and in areas of lower tobacco retailer density have on average 3 times more exterior tobacco marketing than other store types. However, when tobacco density is higher, there is no difference in the average number of exterior tobacco marketing items between tobacco stores and other stores relative to their close proximity to schools. 
Table 4.2: Results of 3-way ANOVA for Exterior Tobacco Marketing

\begin{tabular}{|c|c|c|c|c|c|c|}
\hline Effects & Df & Sum of Squares & Mean Square & $\begin{array}{c}\mathbf{F} \\
\text { value }\end{array}$ & $P$ value & \\
\hline Proximity - Density Groups & 3 & 988 & 329.4 & 2.205 & 0.08799 & \\
\hline Metro Status & 1 & 268 & 268 & 1.793 & 0.1817 & \\
\hline Store Type & 2 & 5871 & 2935.4 & 19.647 & $1.70 \mathrm{E}-08$ & $* * *$ \\
\hline Proximity - Density Groups : Metro Status & 3 & 678 & 226 & 1.512 & 0.21178 & \\
\hline Proximity - Density Groups : Store Type & 6 & 3163 & 527.2 & 3.528 & 0.00226 & $* *$ \\
\hline Metro Status : Store Type & 2 & 95 & 47.5 & 0.318 & 0.72797 & \\
\hline Proximity - Density Groups : Metro Status : Store Type & 4 & 28 & 6.9 & 0.046 & 0.99592 & \\
\hline Residuals & 254 & 37950 & 149.4 & & & \\
\hline
\end{tabular}

Significance codes: $p<0.001^{\prime * * * \prime} p<0.01^{\prime * * \prime} p<0.05^{\prime * \prime}$ 
Figure 4.4: Proximity - Density Groups and Store Type Interaction Plot of Exterior Tobacco Marketing

\section{Exterior Tobacco Marketing}

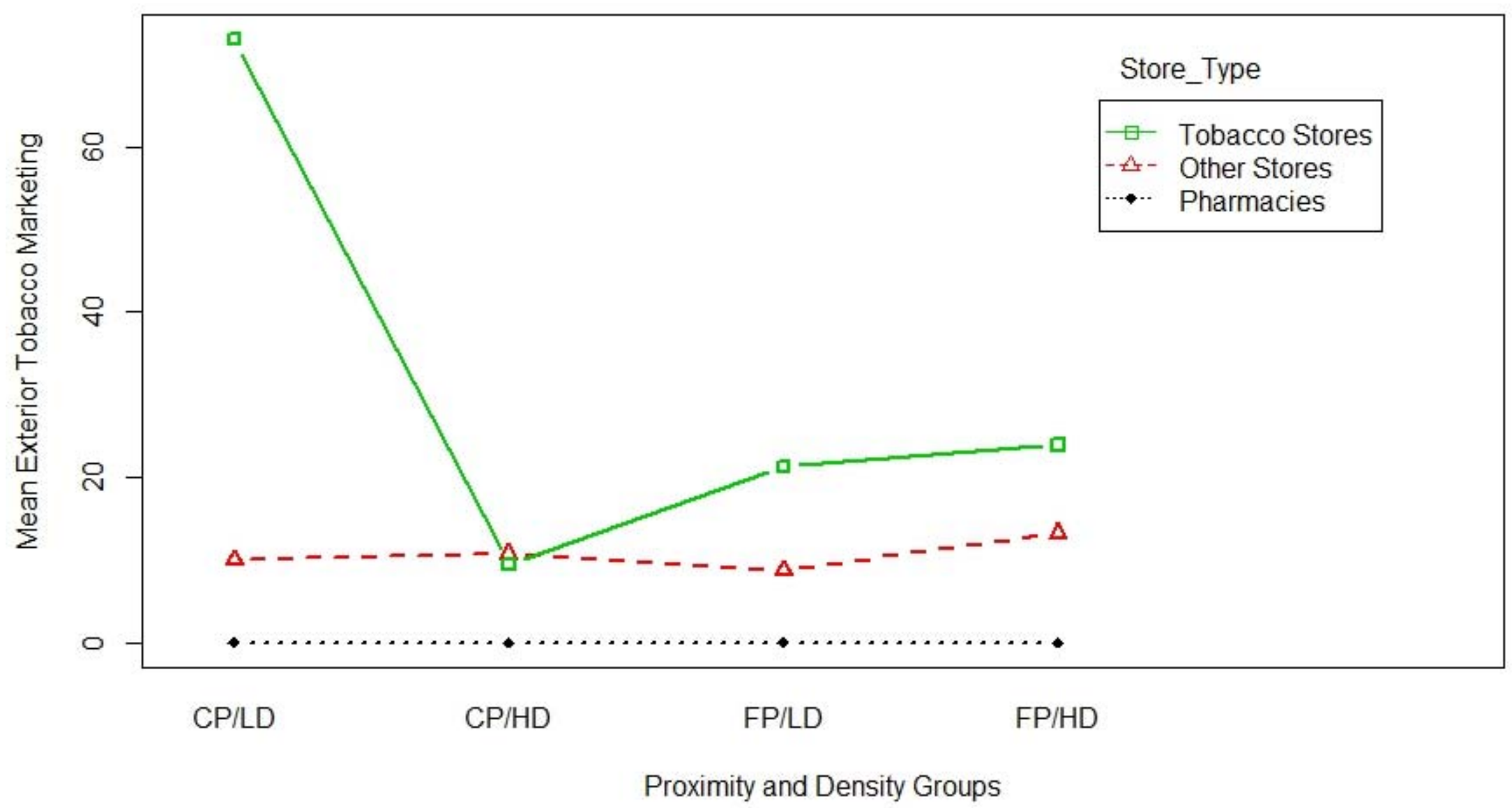

Proximity and Density Groups: Close Proximity - Low Density (CP/LD); Close Proximity - High Density (CP/HD); Far Proximity - Low Density (FP/LD); Far Proximity - High Density (FP/HD) 
Table 4.3 shows the results of the three-way fixed effects ANOVA for non-menthol pack price. The 3-way interaction between proximity - density groups, metro status, and store type on non-menthol pack price was significant, $F(4,254)=5.593$, p-value $<0.001$. To visualize the three-way interaction, we subsampled the data by metro status and then created two (e.g., metro and nonmetro), two-way interaction plots of the mean non-menthol pack price across proximity density groups and store types. (Figure 4.5 and 4.6) Among metro tobacco retailers, the two-way interaction plot shows that the average cost of a pack of non-menthol cigarettes in pharmacies is on average more expensive than any other store type. (Figure 4.5) Additionally, the average cost of a pack of non-menthol cigarettes increases as the distance from a school increases. However, the average pack price of non-menthol cigarettes decreases in tobacco stores and other stores as proximity increases, given relative levels of density. This finding illustrates that density alone does not affect the price of cigarettes, but rather is a function of density and proximity.

Interestingly, the average pack price of non-menthol cigarettes did not differ between store types within the Close Proximity - High Density group. The nonmetro two-way interaction plot of the average pack price of non-menthol cigarettes across proximity - density groups and store types showed the same overall effects as the metro two-way plot. (Figure 4.6) For example, the average pack price for non-menthol cigarettes in pharmacies was higher than the other store types across all proximity - density groups. Additionally, nonmetro pharmacies and tobacco stores observed the similar metro proximity effect (e.g., given relative levels of density, price decreases as distance increases) for the average pack price of non-menthol cigarettes. However, among nonmetro other store types, this effect was reversed (e.g., given relative levels of density, price increases as distance increases). 
Table 4.3: Results of 3-way ANOVA for Non-Menthol Pack Price

\begin{tabular}{|c|c|c|c|c|c|c|}
\hline Effects & Df & Sum of Squares & Mean Square & $\begin{array}{c}\mathbf{F} \\
\text { value }\end{array}$ & $P$ value & \\
\hline Proximity - Density Groups & 3 & 0.626 & 0.2086 & 2.98 & 0.032033 & $*$ \\
\hline Metro Status & 1 & 0.009 & 0.0087 & 0.125 & 0.724378 & \\
\hline Store Type & 2 & 2.165 & 1.0827 & 15.467 & $4.59 \mathrm{E}-07$ & *** \\
\hline Proximity - Density Groups : Metro Status & 3 & 0.218 & 0.0726 & 1.037 & 0.376651 & \\
\hline Proximity - Density Groups : Store Type & 6 & 0.139 & 0.0231 & 0.331 & 0.92053 & \\
\hline Metro Status : Store Type & 2 & 0.045 & 0.0226 & 0.324 & 0.723894 & \\
\hline Proximity - Density Groups : Metro Status : Store Type & 4 & 1.566 & 0.3915 & 5.593 & 0.000249 & $* * *$ \\
\hline Residuals & 254 & 17.78 & 0.07 & & & \\
\hline
\end{tabular}

Significance codes: $p<0.001^{\prime * * * \prime} p<0.01^{* * *} p<0.05^{\prime * 1}$ 
Figure 4.5: Proximity - Density Groups and Store Type Interaction Plot of Metropolitan Non-Menthol Pack Price

\section{Metro Interaction of Price}

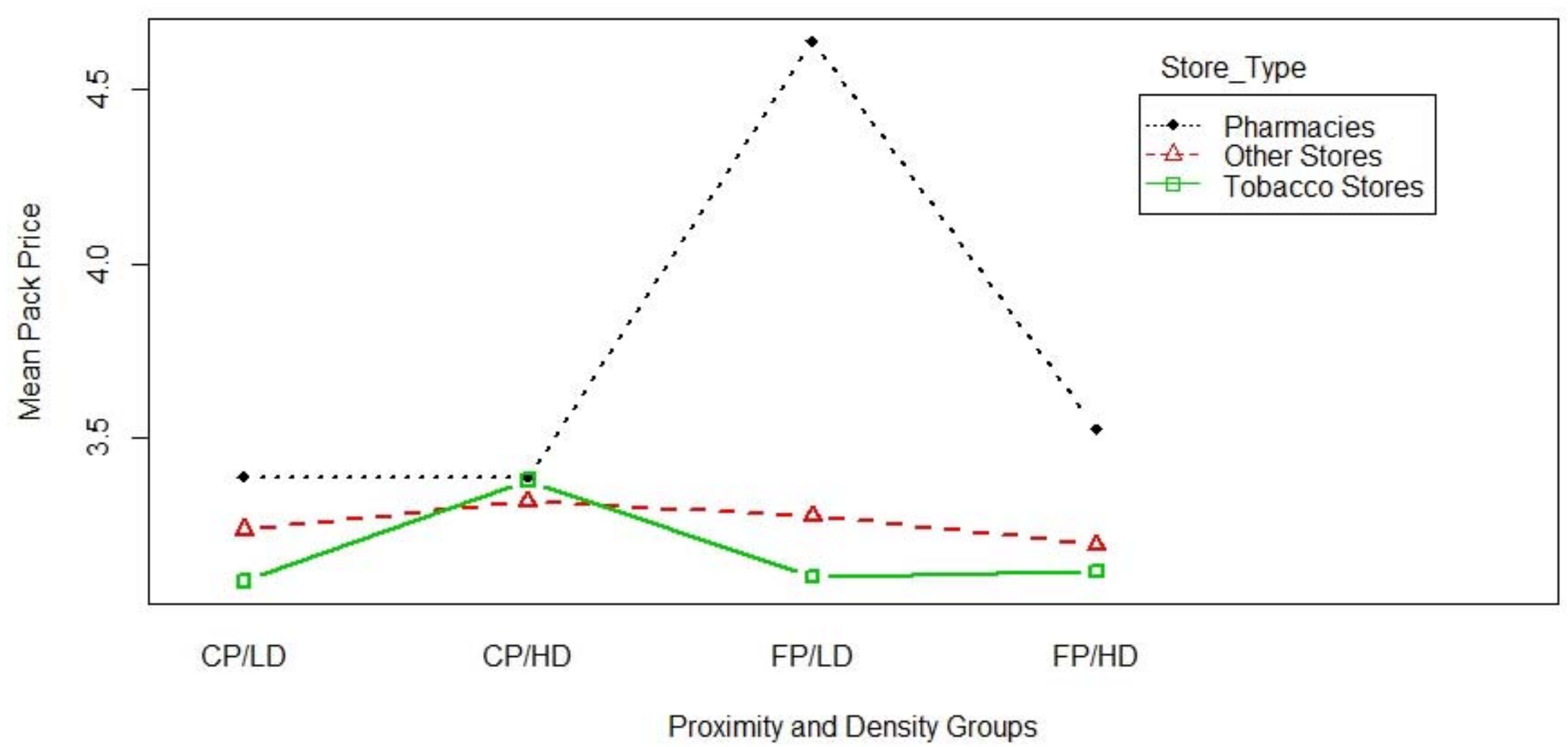

Proximity and Density Groups: Close Proximity - Low Density (CP/LD); Close Proximity - High Density (CP/HD); Far Proximity - Low Density (FP/LD); Far Proximity - High Density (FP/HD) 
Figure 4.6: Proximity - Density Groups and Store Type Interaction Plot of Nonmetropolitan Non-Menthol Pack Price

\section{Nonmetro Interaction of Price}

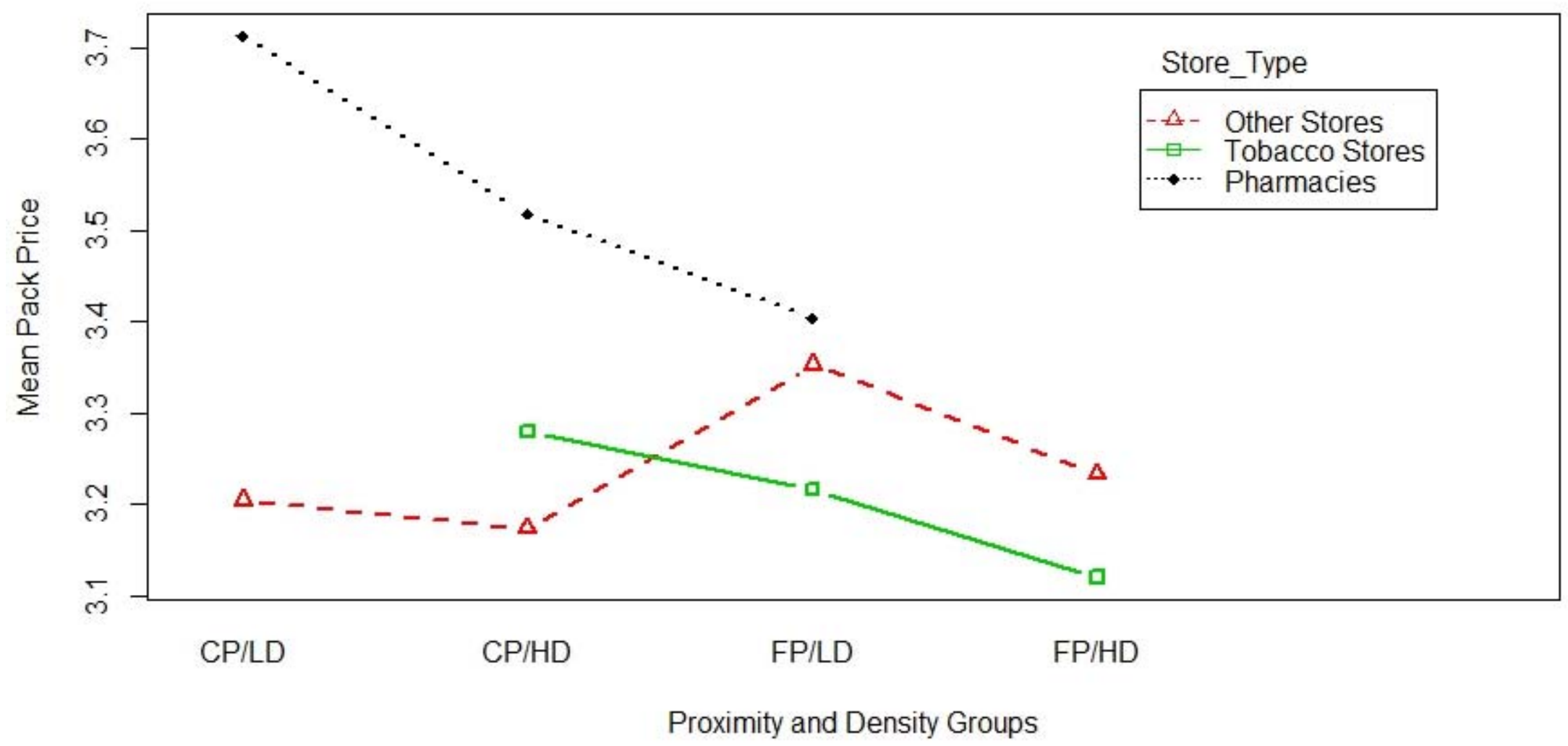

Proximity and Density Groups: Close Proximity - Low Density (CP/LD); Close Proximity - High Density (CP/HD); Far Proximity - Low Density (FP/LD); Far Proximity - High Density (FP/HD) 


\subsection{Conclusions}

Numerous school-centric studies have examined the relationship between tobacco retailer density and proximity to schools on youth smoking behaviors. ${ }^{35,63-68}$ However, these studies fail to capture youth access (e.g., density and proximity to) as it occurs across the whole retail tobacco environment. By study design, they effectively ignore all outlets that do not fall within their specified school boundaries. The current study addresses this limitation by utilizing tobacco retailers themselves as the unit of analysis. Additionally, utilizing retailers as the unit of analysis increases our study's statistical power. The current study also used a novel approach (e.g., KDE) to examine the overall access to retail tobacco (e.g., tobacco retailer density) ${ }^{99}$ Likewise, the current study utilized street networks to assess the proximity from each tobacco retailer to the nearest school. This method improves upon current radius-based proximity approaches by measuring proximity along the network routes in which youth would gain walkable access retail tobacco.

This retailer-centric approach identified the significant relationship between tobacco retailer density and tobacco retailers' proximity to schools. In terms of retailer characteristics, exterior tobacco marketing significantly differed by the interaction between proximity - density groups and store type. Tobacco stores on average had more exterior tobacco marketing than other store types in lower density tobacco retailers' close to schools. However, these store types displayed similar amounts of exterior tobacco marketing when tobacco retailer density and distance to schools was the highest. Among tobacco retailers farthest from schools, the average amount of exterior tobacco marketing increased when levels of tobacco retailer density increased. Meanwhile, the average pack price of non-menthol cigarettes significantly differed by the interaction between proximity - density groups, metro status, and store type. The average 
pack price for non-menthol cigarettes was roughly the same price across all types of metro tobacco retailers when proximity to schools was the closest and tobacco retailer density was the highest. The metro (Figure 4.5) and nonmetro (Figure 4.6) interaction plots both show that as tobacco retailer density increases the overall price of cigarettes decreases. However, this association is also a function of proximity given relative levels of density. For example, the average pack price for non-menthol cigarettes in metro tobacco stores and other store types located in high-density areas decreases as the distance from schools increases. Nonmetro tobacco stores also observed this same proximity pattern in the average pack price of non-menthol cigarettes. This finding suggests that farther proximity from schools and higher tobacco retailer density reduces the cost of tobacco products for youths, thus increasing their access to retail tobacco. However, this finding confirms previous substance abuse findings, ${ }^{73,74}$ in that, the school, home, and neighborhood environments are all crucial in understanding youth tobacco use.

There are some strengths and limitations to these findings. The major limitation of this study is its cross-sectional design. Therefore, inferences regarding the direct impact of the effects of proximity - density groups and store type on tobacco retailer exterior tobacco marketing, as well as, the effects of proximity - density groups, metro status, and store type on pack price of non-menthol cigarettes cannot be determined. Additionally, we did not include all possible tobacco retailers due to the categorization of NAICS data used to identify potential tobacco retailers. For example, some department and discount department stores (e.g., Wal-Mart, Costco, Family Dollar, and Dollar Tree) may be tobacco retailers. However, the strength of fieldvalidating identified retailers to determine whether the retailer sold tobacco increased the reliability of the tobacco retailer dataset. While adding missing retailers matching the selected 
NAICS descriptions that sold tobacco ensured the comprehensiveness of the tobacco retailer dataset. In addition, ortho-rectifying the location of tobacco retailers and schools enhanced the overall spatial accuracy of both datasets.

Overall, this is the first study to examine the inter-relationships between tobacco retailer density versus proximity to schools and thus youth smoking behaviors utilizing a retailer-centric approach. This study also used appropriate methods to assess tobacco retailer density (e.g., KDE) and tobacco retailers' proximity to schools (e.g., network routes). Additionally, a significant relationship between increasing levels of tobacco retailer density and tobacco retailer proximity to schools confirmed our study's main hypothesis. We also found significant interactions between proximity - density groups and store types and different retailer characteristics. Furthermore, we found that the pack price of non-menthol cigarettes decreases as a function of proximity given relative levels of density. Therefore, based on the rationale and findings from the current study, policies that restrict the availability of retail tobacco via commercial sources (e.g., zoning restrictions and regulations) or that reduce the exposure to PoS tobacco marketing (e.g., prohibiting exterior marketing around schools and playgrounds) could prove beneficial in reducing youth tobacco use. 


\section{Chapter 5}




\section{Chapter 5}

\subsection{Summary}

The goal of this dissertation was to reduce tobacco-related heath disparities. Specifically, we utilized three interconnected studies to 1) identify those rural areas disproportionately affected by tobacco use; 2) assess the accessibility of retail tobacco around schools; and 3) contrast the inter-relationships between tobacco retailer density surrounding schools and tobacco retailers' proximity to school. Study 1 utilized a novel approach to estimate county-level adult cigarette smoking prevalence from publically available state surveillance data. The findings from the current study complement the findings from a recent study that utilized suppressed surveillance data from the CDC to estimate annual cigarette smoking prevalence for U.S. counties. ${ }^{88}$ Additionally, the threshold (e.g., $\geq 50$ smokers) used to determine whether the final BRFSS weight was used to estimate a county's smoking prevalence is similar to the minimum sample size used by the Robert Wood Johnson Foundation's County Health Ranking and Roadmaps project. ${ }^{106}$ Furthermore, for those counties with small sample sizes of smokers (e.g., 1-49 smokers) utilized a spatial empirical Bayes smoothing approach to normalize (e.g., smooth) local county prevalence estimates by averaging across the local estimates within its neighborhood structure (e.g., $k=8$ nearest neighbors). Therefore, the novel approach used in Study 1 to estimate county-level smoking prevalence appears to be a valid method to estimate county-level current adult smoking prevalence using publically available data.

Study 1 was also successful in identifying those specific rural areas disproportionately affected by tobacco use. While research has identified rural populations as a key population regarding tobacco-related health disparities, ${ }^{16-18,21-23}$ no study to date has identified where those 
specific rural populations exists. Current state-based surveillance systems are unable to visualize these regional disparities, because tobacco-related health disparities transect their boundaries. Therefore, current surveillance efforts should focus on the smallest geographic scale possible when identifying "where" tobacco-related health disparities occur. The ESDA, in Study 1, enhances current tobacco control surveillance approaches by utilizing county-level smoking prevalence estimates constructed from state-level surveillance data, which provides the ESDA the ability to answer the "where" question. Besides identifying those rural populations of concern (e.g., high rurality - high smoking), the ESDA also identifies where significant atypical observations (e.g., spatial outliers) exist and these clusters prove to be the most intriguing finding from the current ESDA. For example, what factors are inhibiting tobacco use within rural communities with significantly lower rates of smoking than would be expected given their rural nature? Is this a result of socioeconomic and/or cultural factors, which can be seen in the spatial outliers of the Pacific Northwest; or is it a result of tobacco-control regulations and/or polices, such as those found in California. Since, each rural population has a specific combination of factors that influence tobacco use,$^{19}$ state-based assumptions that generalize rural tobacco-related health disparities overlook the specific factors contributing to the tobacco-related health disparities within each rural population. Therefore, to reduce tobacco-related health disparities within the specific rural populations acknowledged in Study 1, future research must focus on understanding "what" regional factors are contributing to the tobacco-related health disparities within these specific rural populations. Once these factors have been evaluated, tobacco control experts can begin to develop, and then implement, tailored tobacco control initiatives and/or polices that reduce the tobacco burden that these rural populations face. 
Study 2 utilizes a novel approach to examine the accessibility (e.g., tobacco retailer density) of retail tobacco surrounding schools. While previous studies have assessed tobacco retailer density around schools, ${ }^{43,64,71}$ the density approach used in these studies (e.g., counting the number of tobacco retailers within an arbitrary boundary around each school) does not measure the overall access of tobacco retailers across the overall study area. By study design, these studies effectively ignore all outlets that do not fall within their specified boundaries. The current study addresses this limitation by utilizing tobacco retailers themselves as the unit of analysis. Therefore, the weighted KDE approach used in Study 2 assesses a school's accessibility to retail tobacco across whole study area. Evaluating tobacco retailer density across the whole study area is important, because even though youth spend a majority of their time in school, their homes and neighborhoods are also key environments for understanding youth tobacco use. ${ }^{73,74}$ Furthermore, utilizing a weighted KDE approach also advances the literature on density approaches, by weighting each tobacco retailer based on its amount of exterior tobacco marketing provides this study the ability to assess a school's accessibility to "influential" tobacco retailers. To date, no other study has examined tobacco retailer density while accounting for tobacco marketing within its estimates.

In Study 2, the tobacco retailer density surface in each county took on either a monocentric or polycentric urban pattern, which was dependent on the underlying built environment structure found in each county. However the observed urban pattern in each county was found to be independent of its metropolitan/nonmetropolitan status. Overall, the resulting tobacco retailer density surface in each county aligned with findings from a national report on the PoS of tobacco. ${ }^{104}$ The report concluded that tobacco retailer density is highly correlated with population density and tobacco retailers are frequently clustered together based on the built 
environment, which provides the rationale of the tobacco retailer density hot spots seen in each county. ${ }^{104}$ Additionally, Study 2 successfully examined the spatial association between the locations of tobacco retailers and schools. In each county, findings suggest a significant spatial interaction (e.g., tend to occur together) exists between these locations. These findings though, could have been confounded by the underlying structure of the built environment or by the county's population density. For example, based on the same rationale used above for tobacco retailers, the location of schools could be highly correlated with population density and their locations could be clustered within the underlying built environment. Therefore, the observed spatial interaction between the locations of tobacco retailers and schools could be an artifact of each county's built environment.

Study 3 utilized a retailer-centric approach to successfully contrast the inter-relationships between tobacco retailer density surrounding schools and tobacco retailers' proximity to school. Few studies have systematically contrasted the inter-relationships between tobacco retailer density versus proximity to schools and thus smoking behaviors. ${ }^{63-66,71}$ However, these schoolcentric studies only focus on the proximity of only one tobacco retailer per school and/or tobacco retailer density within some arbitrary distance around a school. Thus, this approach fails to capture youth access as it occurs across the whole retail tobacco environment, because it ignores all tobacco retailers that do not constrain to the arbitrary defined boundary. Study 3 also assesses tobacco retailer density and tobacco retailers' proximity to schools utilizing approaches that address limitations found in school-centric approaches. For example, Study 3 utilizes a similar density approach (e.g., KDE) as Study 2 to assess the availability of retail tobacco around schools. Additionally, this study used street network data to calculate proximity, which improves 
upon current radius-based proximity by measuring proximity along the "network routes" in which youth would gain walkable access to retail tobacco.

Study 3 also identified a significant relationship between tobacco retailer density and tobacco retailers' proximity to schools (e.g., as tobacco retailer density increases the proximity to a school decreases). Based on this finding, Study 3 then examined the effects of proximity density groups on tobacco retailer characteristics (e.g., exterior tobacco marketing and nonmenthol pack price). Based on the findings, exterior tobacco marketing significantly differed by the interaction effect between proximity - density groups and store type. Specifically, tobacco stores on average displayed more exterior tobacco marketing that any other store type in lower density tobacco retailers' close to schools. However, tobacco retailers' closest to schools displayed similar amounts of exterior tobacco marketing when tobacco retailer density was the highest and this finding was independent of store type. Meanwhile, the average pack price of non-menthol cigarettes significantly differed by the interaction between proximity - density groups, metro status, and store type. The metro (Figure 4.5) and nonmetro (4.6) interaction plots both show that as tobacco retailer density increases the overall price of cigarettes decreases. However, this association is also a function of proximity given relative levels of density. For example, the average pack price for non-menthol cigarettes in metro tobacco stores and other store types located in high-density areas decreases as the distance from schools increases. Nonmetro tobacco stores also observed this same proximity pattern in the average pack price of non-menthol cigarettes. This finding suggests that farther proximity from schools and higher tobacco retailer density reduces the cost of tobacco products for youths, thus increasing their access to retail tobacco. Based on these findings, tobacco retailers closest to schools rely more on tobacco marketing then price to target youth. However, the current study does not account for 
price discounts (e.g., "Buy two, get on free"), which account for a vast majority of tobacco marketing expenditures. ${ }^{39}$ Therefore, even though the individual pack price might be on average $\$ 0.10$ higher in those tobacco retailers' closet to schools, the overall net price might be lower if these retailers rely more on price discounts to target youth. However, this finding confirms previous substance abuse findings, ${ }^{73,74}$ in that, the school, home, and neighborhood environments are all crucial in understanding youth tobacco use.

\subsection{Significance}

The significance of the current work is determined by its implications for future health policies. The findings from Study 1 can help guide and inform health policy decisions by providing policymakers with the ability to target their resources those rural populations disproportionately affected by tobacco-related health disparities. Given the current economy, states have reduced their spending, which has caused tobacco control resources (e.g., funding) to be limited. Currently, 40 states and the District of Columbia fail to fund their tobacco prevention and cessation programs at even 50 percent of the CDC-recommended level. ${ }^{107}$ Therefore, being able to specifically target resources to those rural populations disproportionately affected by tobacco use, increases the effectiveness of the resources spent to reduce rural tobacco-related health disparities.

The significance of Study 2 and Study 3 will be examined together since both inform policy implications for the retail tobacco environment. Despite the new regulatory authority clarified by the Tobacco Control Act, ${ }^{69}$ policy activity regarding the retail tobacco environment remains limited. Study 2 and Study 3 provide policy implications in the areas of tobacco retailer licensing, tobacco retailer density, and PoS advertising. Tobacco retailer licensing relies on the 
simple concept that retailers selling tobacco products must comply with federal regulations and state laws or risk losing the privilege of selling these products. ${ }^{108}$ Currently, the FDA conducts compliance check inspections of tobacco retailers to determine their compliance with federal regulations. ${ }^{109}$ If a tobacco retailer is found to be in violation of any federal regulation they are issued a warning letter (e.g., first offense), with subsequent violations resulting in civil money penalties. ${ }^{109}$ However, tobacco retailer licensing policies can only be effective if a state requires licensing. Currently, West Virginia does not require tobacco retailer licensing, even though, the FDA has been conducting tobacco retailer compliance checks in West Virginia since 2011.

In terms of tobacco retailer density, research and advocacy groups have worked to understand the potential benefits of controlling the number of tobacco retailers (e.g., tobacco retailer density) and its distance from youth spaces (e.g., proximity of tobacco retailers), with only limited success. ${ }^{35,63-68}$ Therefore, these approaches aim to reduce the availability of products and thus restrict youth access to tobacco products via commercial sources. This is supported by data showing that the density of tobacco retailers within an individual's environment greatly influences tobacco availability and thus youth uptake. ${ }^{58,68}$ Therefore, based on the findings from Study 2 and Study 3, policies that would 1) prohibit tobacco sales in locations youth frequent (e.g., near schools or parks); 2) restrict retailers operating within a certain distance of other tobacco retailers; and 3) restrict tobacco retailers into certain zones (e.g., banning tobacco retailers in residential zones) would reduce youth smoking behaviors, because the accessibility of retail tobacco would be restricted and/or prohibited in spaces where youth frequented.

In regards to PoS advertising, the Food and Drug Administration (FDA) rules prohibiting exterior tobacco advertising within 1,000 feet of schools and playgrounds was not included in the passage of the 2009 Tobacco Control Act, ${ }^{69}$ and was instead issued as part of an Advanced 
Notice of Proposed Rulemaking that has not yet been acted upon. ${ }^{70}$ Therefore, based on the findings from Study 2 and Study 3, PoS advertising policies that would 1) limit the placement of advertisements at certain store locations (e.g., 1,000 feet of schools); 2) limit the placement of outdoor store advertisements; and 3) limit the manner of outdoor retail advertising would reduce youths' exposures to tobacco marketing, thus reducing youth smoking behaviors. Overall, there are numerous policy implications for the retail tobacco environment. Even though current policies are limited, these potential policies could prove beneficial in reducing tobacco-related health disparities in the U.S.

\subsection{Strengths and Weaknesses}

Overall, the major limitation of each of each study is its cross-sectional design. Therefore, in Study 1 we cannot conclude that a county's level of rurality causes the county's adult population to smoke. Additionally, while the descriptive nature of the tobacco retailer density in each county, in Study 2, provides insight into the access of tobacco around each school, inferences regarding the direct impact of tobacco accessibility on schools cannot be determined. Lastly, in Study 3, inferences regarding the direct impact of the effects of proximity - density groups, metro status, and store type on tobacco retailer characteristics (e.g., exterior tobacco marketing and non-menthol pack price) cannot be determined.

In regards to the limitations of the data used in this dissertation, Study 1 utilized publically available CDC BRFSS data to estimate county-level adult smoking prevalence. Since BRFSS is state-based surveillance system, disaggregating the data down to the county-level results in small sample sizes. Additionally, because Study 1 used publically available data, any data that was initially suppressed to de-identify individuals is missing. However, the final 
county-level adult smoking prevalence estimates were found to complement the findings from a recent study that utilized suppressed surveillance data from the CDC to estimate annual cigarette smoking prevalence for U.S. counties. ${ }^{88}$ Additionally, the threshold (e.g., $\geq 50$ smokers) used to determine whether the final BRFSS weight was used to estimate a county's smoking prevalence is similar to the minimum sample size used by the Robert Wood Johnson Foundation's County Health Ranking and Roadmaps project. ${ }^{106}$ Furthermore, for those counties with small sample sizes of smokers (e.g., 1-49 smokers) utilized a spatial empirical Bayes smoothing approach to normalize (e.g., smooth) local county prevalence estimates by averaging across the local estimates within its neighborhood structure (e.g., $k=8$ nearest neighbors). Therefore, the countylevel smoking prevalence estimates used in Study 1 appear to be a valid.

Additionally, Study 2 and Study 3 did not include all possible tobacco retailers. This limitation was due the categorization of the NAICS data used to identify potential tobacco retailers. For example, some department and discount department stores (e.g., Wal-Mart, Costco, Family Dollar, and Dollar Tree) may be tobacco retailers. However, the strength of fieldvalidating identified retailers to determine whether the retailer sold tobacco increased the reliability of the tobacco retailer dataset. While adding missing retailers matching the selected NAICS descriptions that sold tobacco ensured the comprehensiveness of the tobacco retailer dataset. In addition, ortho-rectifying the location of tobacco retailers and schools enhanced the overall spatial accuracy of both datasets. 


\subsection{Conclusions}

Tobacco use remains the leading preventable cause of death and disease in the U.S. ${ }^{3}$ Tobacco use will plateau though, until we target those who have the most risk for tobacco related-health disparities - rural populations ${ }^{91}$ While Study 1 successfully identified those rural populations disproportionately affected by tobacco, future research is still needed to understand what specific factors are contributing to the tobacco-related health disparities in these rural populations. Only then, can we begin to address these factors through tailored prevention and cessation initiatives, thus reducing the burden of tobacco. Additionally, efforts should focus on preventing cigarette and other tobacco use before long-term consequence take hold, beginning with youth who are at greater risk. ${ }^{62}$ Moreover, evidence suggests that youth smoking research must address the environmental factors that favorably influence tobacco use. Therefore, based on the findings in Study 2 and Study 3, polices that restrict the availability of retail tobacco (e.g., zoning restrictions) or that reduce the exposures to PoS tobacco marketing (e.g., prohibiting exterior tobacco marketing around schools and playgrounds) could prove beneficial in reducing youth tobacco use, thus eliminating future tobacco-related health disparities. 


\section{REFERENCES}

1. Institute of Medicine. Ending the Tobacco Problem: A Blueprint for the Nation. Washington, DC: National Academies Press; 2007.

2. U.S. Department of Health and Human Services. Ending the Tobacco Epidemic: A Tobacco Control Strategic Action Plan for the U.S. Department of Health and Human Services. Washington, DC: Office of the Assistant Secretary for Health; 2010.

3. U.S. Department of Health and Human Services. The Health Consequences of Smoking 50 Years of Progress. In: A Report of the Surgeon General, ed. Atlanta, GA: U.S. Department of Health and Humna Services, Centers for Disease Contorl and Prevention, National Center for Chronic Disease Prevention and Health Promotion, Office on Smoking and Health; 2014.

4. U.S. Department of Health and Human Services. The Health Consequences of Smoking: A Report of the Surgeon General. Atlanta, GA: U.S. Department of Health and Human Services, Centes for Disease Control and Prevention, National Center for Chronic

Disease Prevention and Health Promotion, Office on Smoking and Health; 2004.

5. Centers for Disease Control and Prevention. Current Cigarette Smoking Among Adults United States, 2005-2012. Morb Mortal Wkly Rep. 2014;63(02):29934.

6. Centers for Disease Control and Prevention. Healthy People 2010 Final Review. Atlanta, GA: U.S. Department of Health and Human Services, Centers for Disease Control and Prevention, National Center for Health Statistics; 2011. 
7. Substance Abuse and Mental Health Services Administration. Results from the 2012 National Survey on Drug Use and Health: National Findings. Rockville, MD: U.S. Department of Health and Human Services, Substance Abuse and Mental Health Services Administration; 2013.

8. Centers for Disease Control and Prevention. Youth Risk Behavior Surveillance - United States, 2013. Morb Mortal Wkly Rep. 2014;63(4):13-17.

9. Centers for Disease Control and Prevention. Tobacco Use Among Middle and High School Students - United States, 2000 - 2009. Morb Mortal Wkly Rep. 2010;59(33):10631068.

10. Mowery PD, Farrelly MC, Haviland ML, Gable JM, Wells HE. Progression to Established Smoking Among US Youths. Am J Public Health. 2004;94(2):331-337.

11. Centers for Disease Control and Prevention. Cigarette Use Among High School Students - United States, 1991-2009. Morb Mortal Wkly Rep. 2010;59(26):797-801.

12. LaVeist $\mathrm{T}$. Disentangling race and socioeconomic status: A key to understanding health inequalities. Journal of Urban Health. 2005;82(0):iii26-iii34.

13. Moolchan ET, Fagan P, Fernander AF, et al. Addressing tobacco-related health disparities. Addiction. 2007;102:30-42.

14. Fagan P, King G, Lawrence D, et al. Eliminating Tobacco-Related Health Disparities: Directions for Future Research. Am J Public Health. 2004;94(2):211-217. 
15. U.S. Department of Health and Human Services. Tobacco Use Among U.S. Racial/Ethnic Minority Groups - African Americans, American Indians and Alaska Natives, Asian Americans and Pacific Islanders, and Hispanics: A Report of the Surgeon General. Atlanta, GA: U.S. Department of Health and Human Services, Centers for Disease Control and Prevention, National Center for Chronic Disease Prevention and Health Promotion, Office on Smoking and Health; 1998.

16. Fagan P, Moolchan ET, Lawrence D, Fernander A, Ponder PK. Identifying health disparities across the tobacco continuum. Addiction. 2007;102:5-29.

17. Vander Weg MW, Cunningham CL, Howren MB, Cai X. Tobacco use and exposure in rural areas: Findings from the Behavioral Risk Factor Surveillance System. Addictive Behaviors. 2011;36(3):231-236.

18. Doescher MP, Jackson JE, Jerant A, Gary Hart L. Prevalence and Trends in Smoking: A National Rural Study. The Journal of Rural Health. 2006;22(2):112-118.

19. American Legacy Foundation. Tobacco Control in Rural America. 2009; http://www.legacyforhealth.org/content/download/595/7129/file/Tobacco_Control_in_Ru ral_America.pdf. Accessed December 10, 2014.

20. Institue of Medicine. Executive Summary. Quality Through Collaboration: The Future of Rural Health. Washington, DC: The National Academies Press; 2005.

21. Wewers ME, Ahijevych KL, Chen MS, Dresbach S, Kihm KE, Kuun PA. Tobacco Use Characteristics Among Rural Ohio Appalachians. Journal of Community Health. $2000 ; 25(5): 377-388$. 
22. Hutcheson TD, Greiner KA, Ellerbeck EF, Jeffries SK, Mussulman LM, Casey GN. Understanding Smoking Cessation in Rural Communities. The Journal of Rural Health. 2008;24(2):116-124.

23. Northridge ME, Vallone D, Xiao H, et al. The Importance of Location for Tobacco Cessation: Rural-Urban Disparities in Quit Success in Underserved West Virginia Counties. The Journal of Rural Health. 2008;24(2):106-115.

24. Appalachian Regional Commission. The Appalachian Region. 2014; http://www.arc.gov/appalachian_region/TheAppalachianRegion.asp. Accessed May 20, 2014.

25. Ahijevych K, Kuun P, Christman S, Wood T, Browning K, Wewers ME. Beliefs about tobacco among appalachian current and former users. Applied Nursing Research. 2003;16(2):93-102.

26. Lyson TA, Falk WW. Forgotten Place: Uneven Development in Rural America. Lawrence, Kansas: University Press of Kansas; 1993.

27. Ergood B. Toward a definition of Appalachia In: Ergood B, Kuhre BE, eds. Appalachia Social Context: Past and Present. 3rd ed. Dubuque, Iowa: Kendall Hunt Publishing; 1993.

28. Simon JM. Health care of the elderly in Appalachia... subculture of the Appalachian people. Journal of Gerontological Nursing. 1987;13(7):32-35.

29. National Association of Attorneys General. The Master Settlement Agreement. 1998; http://www.naag.org/backpages/naag/tobacco/msa/msapdf/MSA\%20with\%20Sig\%20Pages\%20and\%20Exhibits.pdf/download. Accessed December 10, 2014. 
30. Feighery EC, Ribisl KM, Schleicher NC, Clark PI. Retailer participation in cigarette company incentive programs is related to increased levels of cigarette advertising and cheaper cigarette prices in stores. Preventive Medicine. 2004;38(6):876-884.

31. Pollay RW. More than meets the eye: on the importance of retail cigarette merchandising. Tobacco Control. 2007;16(4):270-274.

32. Celebucki CC, Diskin K. A longitudinal study of externally visible cigarette advertising on retail storefronts in Massachusetts before and after the Master Settlement Agreement. Tobacco Control. 2002;11(suppl 2):ii47-ii53.

33. Wakefield MA, Terry-McElrath YM, Chaloupka FJ, et al. Tobacco Industry Marketing at Point of Purchase After the 1998 MSA Billboard Advertising Ban. Am J Public Health. 2002;92(6):937-940.

34. Feighery EC, Ribisl KM, Schleicher N, Lee RE, Halvorson S. Cigarette advertising and promotional strategies in retail outlets: results of a statewide survey in California. Tobacco Control. 2001;10(2):184-188.

35. Henriksen L, Feighery EC, Schleicher NC, Haladjian HH, Fortmann SP. Reaching youth at the point of sale: cigarette marketing is more prevalent in stores where adolescents shop frequently. Tobacco Control. 2004;13(3):315-318.

36. Kaufman NJ, Castrucci BC, Mowery P, Gerlach KK, Emont S, Orleans CT. Changes in Adolescent Cigarette-Brand Preference, 1989 to 1996. American Journal of Health Behavior. 2004;28(1):54-62.

37. Chanil D. Profile of the Convenience Store Customer. Convenience Store News. 2001;37(2):57. 
38. Point-of-Purchase Advertising Institute. The Point-of-Purchase Advertising Industry Fact Book. Englewood, NJ: Point-of-Purchase Advertising Institute; 1992.

39. U.S. Federal Trade Commission. Federal Trade Commission Cigarette Report for 2011. 2013. http://www.ftc.gov/sites/default/files/documents/reports/federal-trade-commissioncigarette-report-2011/130521cigarettereport.pdf. Accessed Decmeber 10, 2014.

40. Feighery EC, Ribisl KM, Clark PI, Haladjian HH. How tobacco companies ensure prime placement of their advertising and products in stores: interviews with retailers about tobacco company incentive programmes. Tobacco Control. 2003;12(2):184-188.

41. Anon. The 1999 Annual Report of the Promotion Industry, a PROMO Magazine Special Report. Overland Park, KS: Intertec Publishing; 1999.

42. Lavack AM, Toth G. Tobacco point-of-purchase promotion: examining tobacco industry documents. Tobacco Control. 2006;15(5):377-384.

43. Lovato CY, Hsu HCH, Sabiston CM, Hadd V, Nykiforuk CIJ. Tobacco point-of-purchase marketing in school neighbourhoods and school smoking prevalence: a descriptive study. Canadian Journal of Public Health. 2007;98(4):265-270.

44. Lovato C, Watts A, Stead Lindsay F. Impact of tobacco advertising and promotion on increasing adolescent smoking behaviours. Cochrane Database of Systematic Reviews. 2011(10).

45. Donovan RJ, Jancey J, Jones S. Tobacco point of sale advertising increases positive brand user imagery. Tobacco Control. 2002;11(3):191-194.

46. Evans RI, Dratt LM, Raines BE, Rosenberg SS. Social influences on smoking initiation: Importance of distinguishing descriptive versus mediating process variables. Journal of Applied Social Psychology. 1988;18(11, Pt 1):925-943. 
47. Flay BR, Hu FB, Richardson J. Psychosocial predictors of different stages of cigarette smoking among high school students. Preventive Medicine. 1998;27(5 part 3):A9-18.

48. Graham JW, Marks G, Hansen WB. Social influence processes affecting adolescent substance use. Journal of Applied Psychology. 1991;76(2):291-298.

49. Henriksen L, Flora JA, Feighery E, Fortmann SP. Effects on Youth of Exposure to Retail Tobacco Advertising. Journal of Applied Social Psychology. 2002;32(9):1771-1789.

50. Altman DG, Levine DW, Coeytaux R, Slade J, Jaffe R. Tobacco Promotion and Susceptibility to Tobacco Use among Adolescents Aged 12 through 17 Years in a Nationally Representative Sample. American Journal of Public Health. 1996;86(11):1590-1593.

51. Feighery E, Borzekowski DLG, Schooler C, Flora J. Seeing, wanting, owning: the relationship between receptivity to tobacco marketing and smoking susceptibility in young people. Tobacco Control. 1998;7(2):123-128.

52. Weiss JW, Cen S, Schuster DV, et al. Longitudinal Effects of Pro-Tobacco and AntiTobacco Messages on Adolescent Smoking Susceptibility. Nicotine \& Tobacco Research. 2006;8(3):455-465.

53. Henriksen L, Feighery EC, Wang Y, Fortmann SP. Association of Retail Tobacco Marketing With Adolescent Smoking. Am J Public Health. 2004;94(12):2081-2083.

54. Schooler C, Feighery E, Flora JA. Seventh graders' self-reported exposure to cigarette marketing and its relationship to their smoking behavior. American Journal of Public Health. 1996;86(9):1216-1221. 
55. Henriksen L, Schleicher NC, Feighery EC, Fortmann SP. A Longitudinal Study of Exposure to Retail Cigarette Advertising and Smoking Initiation. Pediatrics. 2010;126(2):232-238.

56. Slater SJ, Chaloupka FJ, Wakefield M, Johnston LD, O'Malley PM. The impact of retail cigarette marketing practices on youth smoking uptake. Archives of Pediatrics \& Adolescent Medicine. Vol 161. Chicago; USA: American Medical Association; 2007:440-445.

57. Peterson NA, Lowe JB, Reid RJ. Tobacco Outlet Density, Cigarette Smoking Prevalence, and Demographics at the County Level of Analysis. Substance Use \& Misuse. 2005;40(11):1627-1635.

58. Schneider JE, Reid RJ, Peterson NA, Lowe JB, Hughey J. Tobacco outlet density and demographics at the tract level of analysis in Iowa: implications for environmentally based prevention initiatives. Prevention Science: The Official Journal Of The Society For Prevention Research. 2005;6(4):319-325.

59. Chuang Y, Cubbin C, Ahn D, Winkleby MA. Effects of neighbourhood socioeconomic status and convenience store concentration on individual level smoking. Journal of Epidemiology \& Community Health. 2005;59(7):568-573.

60. Rodriguez D, Carlos HA, Adachi-Mejia AM, Berke EM, Sargent JD. Predictors of tobacco outlet density nationwide: a geographic analysis. Tobacco Control. 2013;22(5):349-355 . 
61. Centers for Disease Control and Prevention. Best Practices for Comprehensive Tobacco Control Programs - 2007. Atlanta, GA: U.S. Department of Health and Human Services, Centers for Disease Control and Prevention, National Center for Chronic Disease Prevetion and Health Promotion, Office on Smoking and Health; 2007.

62. Centers for Disease Control and Prevention. CDC Health Disparities and Inequalities Report - United States, 2011. Morbidity and Mortality Weekly Report. 2011;60(Supplement):109-113.

63. Chan $\mathrm{W}$, Leatherdale $\mathrm{S}$. Tobacco retailer density surrounding schools and youth smoking behaviour: a multi-level analysis. Tobacco Induced Diseases. 2011;9(1):9.

64. Leatherdale ST, Strath JM. Tobacco Retailer Density Surrounding Schools and Cigarette Access Behaviors Among Underage Smoking Students. Annals of Behavioral Medicine. 2007;33(1):105-111.

65. Lipperman-Kreda S, Mair C, Grube J, Friend K, Jackson P, Watson D. Density and Proximity of Tobacco Outlets to Homes and Schools: Relations with Youth Cigarette Smoking. Prevention Science. 2014;15(5):738-744.

66. McCarthy WJ, Mistry R, Lu Y, Patel M, Zheng H, Dietsch B. Density of Tobacco Retailers Near Schools: Effects on Tobacco Use Among Students. American Journal of Public Health. 2009;99(11):2006-2013.

67. Novak SP, Reardon SF, Raudenbush SW, Buka SL. Retail Tobacco Outlet Density and Youth Cigarette Smoking: A Propensity-Modeling Approach. American Journal of Public Health. 2006;96(4):670-676. 
68. Pokorny SB, Jason LA, Schoeny ME. The Relation of Retail Tobacco Availability to Initiation and Continued Smoking. Journal of Clinical Child \& Adolescent Psychology. 2003;32(2):193.

69. U.S. Food and Drug Administration. Family Smoking Prevention and Tobacco Control Act. H.R. 1256.2009.

70. U.S. Food and Drug Administration. Outdoor Advertising Provision. Guidance, Regualtions and Compliance. 2010; http://www.fda.gov/TobaccoProducts/GuidanceComplianceRegulatoryInformation/ucm3 59946.htm. Accessed December 10, 2014.

71. Henriksen L, Feighery EC, Schleicher NC, Cowling DW, Kline RS, Fortmann SP. Is adolescent smoking related to the density and proximity of tobacco outlets and retail cigarette advertising near schools? Preventive Medicine. 2008;47(2):210-214.

72. Kirchner TR, Villanti AC, Cantrell J, et al. Tobacco retail outlet advertising practices and proximity to schools, parks and public housing affect Synar underage sales violations in Washington, DC. Tobacco Control. 2014.

73. Connell C, Gilreath T, Aklin W, Brex R. Social-Ecological Influences on Patterns of Substance Use Among Non-Metropolitan High School Students. Am J Community Psychol. 2010;45(1-2):36-48.

74. Duncan S, Duncan T, Strycker L. A Multilevel Analysis of Neighborhood Context and Youth Alcohol and Drug Problems. Prevention Science. 2002;3(2):125-133.

75. Anselin L. Exploratory Spatial Data Analysis and Geographic Infromation Systems. New Tools for Spatial Analysis; 1994; Luxembourg. 
76. Anselin L. GIS Research Infrastructure for Spatial Analysis of Real Estate Markets. Journal of Housing Research. 1998;9(1):113-133.

77. Centers for Disease Control and Prevention. Behavioral Risk Factor Surveillance System Survey Data. Atlanta, Georgia: U.S. Deparment of Health and Human Services, Centers for Disease Control and Prevention; 2000-2010.

78. Centers for Disease Control and Prevention. Behavioral Risk Factor Surveillance System Survey Questionnaire. Atlanta, Georgia: U.S. Deparment of Health and Human Services, Centers for Disease Control and Prevention; 2000-2010.

79. SAS [computer program]. Version 9.3. Cary, NC: SAS Institute Inc.; 2014.

80. Cromley E, McLafferty S. GIS and Public Health. New York, NY: The Guilford Press; 2002.

81. Anselin L, Syabri I, Youngihn K. GeoDa: An Introduction to Spatial Data Analysis. Geographical Analysis. 2006;38(1):5-22.

82. OpenGeoDa [computer program]. Version 1.0.1. Tempe, AZ: GeoDa Center; 2001.

83. U.S. Department of Agriculture, Economic Research Service. Rural-Urban Continuum Codes. Data Sets. 2004; http://www.ers.usda.gov/data-products/rural-urban-continuumcodes.aspx. Accessed December 10, 2014.

84. U.S. Department of Agriculture, Economic Research Service. Measuring Rurality: RuralUrban Continuum Codes. Briefing Rooms. 2004; http://webarchives.cdlib.org/sw1wp9v27r/http:/ers.usda.gov/Briefing/Rurality/RuralUrbC on/. Accessed December 10, 2014.

85. Tobler WR. A Computer Movie Simulating Urban Growth in the Detroit Region. Economic Geography. 1970;46:234-240. 
86. Anselin L. The Moran scatterplot as an ESDA too to assess local instability in spatial association. Spatial Analytical Perspectives on GIS in Environmental and SocioEconomic Sciences. 1996:111-125.

87. Anselin L. Local Indicators of Spatial Association-LISA. Geographical Analysis. 1995;27(2):93-115.

88. Dwyer-Lindgren L, Mokdad A, Srebotnjak T, Flaxman A, Hansen G, Murray C. Cigarette smoking prevalence in US counties: 1996-2012. Population Health Metrics. 2014;12(1):5.

89. McCarthy J. In U.S., Smoking Rate Lowest in Utah, Highest in Kentucky. State of the States 2014; http://www.gallup.com/poll/167771/smoking-rate-lowest-utah-highestkentucky.aspx. Accessed December 10, 20014.

90. Tabachnick BG, Fidell LS. Using Multivariate Statistics. 5th ed. United States of America: Pearson; 2007.

91. Warner KE, Burns DM. Hardening and the hard-core smoker: concepts, evidence, and implications. Nicotine \& Tobacco Research. 2003;5(1):37.

92. White MM, Gilpin EA, Emery SL, Pierce JP. Facilitating Adolescent Smoking: Who Provides the Cigarettes? American Journal of Health Promotion. 2005;19(5):355-360.

93. Campaign for Tobacco-Free Kids. The Toll of Tobacco in West Virginia. Toll of Tobacco in the United States 2014; http://www.tobaccofreekids.org/facts_issues/toll_us/west_virginia. Accessed December $10,2014$.

94. U.S. Census Bureau. Introduction to NAICS. North American Industry Classification System 2014; http://www.census.gov/eos/www/naics/. Accessed December 10, 2014. 
95. NAICS Association. U.S. Business Directory. 2012; http://www.naics.com/us-businessdirectory/. Accessed December 10, 2014.

96. GIS Pro [computer program]. Version 1.8. Provo, UT: Garafa LLC; 2011.

97. WV Department of Education. WV School Directory. 2014; http://wvde.state.wv.us/ed_directory/. Accessed Accessed December 10, 2014.

98. $\quad$ ArcGIS for Desktop Advanced [computer program]. Version 10.2: ESRI; 2014.

99. Carlos H, Shi X, Sargent J, Tanski S, Berke E. Density estimation and adaptive bandwidths: A primer for public health practitioners. International Journal of Health Geographics. 2010;9(1):39.

100. Kirchner TR, Gao H, Anesetti-Rothermel A, Carlos H, House B. Longitudinal Human Mobility and Rea-time Access to a National Density Surface of Retail Outlets. UrbComp'14; August 24, 2014; New York, NY.

101. The Spatstat Package [computer program]. Version 1.38-1. CRAN: R Foundation for Statistical Computing; 2014.

102. R: A Language and Environment for Statistical Computing [computer program]. Vienna, Austria: R Foundation for Statistical Computing; 2014.

103. U.S. Census Bureau. 2010 Census Summary File 1 - West Virginia. U.S. Census Bureau; 2011.

104. Center for Public Health Systems Science. Point-of-Sale Report to the Nation: The Tobacco Retail and Policy Landscape. St. Louis, MO: Cneter for Public Health Systems Science at the Brown School at Washington University in St. Louis and the National Cancer Institute, State and Community Tobacco Control Research Initative;2014. 
105. Luke DA, Ribisl KM, Smith C, Sorg AA. Family Smoking Prevention and Tobacco Control Act: Banning Outdoor Tobacco Advertising Near Scools and Playgrounds. American Journal of Preventive Medicine.40(3):295-302.

106. Robert Wood Johnson Foundation. 2014 Measures and Data Sources. County Health Ranking and Roadmaps: Building a Culture of Health, County by County 2014; http://www.countyhealthrankings.org/sites/default/files/resources/2014Measures_datasou rces_years.pdf. Accessed December 10, 2014.

107. American Lung Association. State of Tobacco Control 2014. State Governments 2014; http://www.stateoftobaccocontrol.org/at-a-glance/state-governments/. Accessed December 10, 2014.

108. McLaughlin I, Tobacco Control Legal Consortium. License to Kill?: Tobacco Retailer Licensing as an Effective Enforcement Tool. 2010.

109. U.S. Food and Drug Administration. Compliance and Enforcement. Tobacco Products 2014; http://www.fda.gov/TobaccoProducts/GuidanceComplianceRegulatoryInformation/ucm2 32109.htm. Accessed December 10, 2014. 